\title{
Analysis of Heat Transfer in Metal Hydride Based Hydrogen Separation
}

by

W. H. Fleming Jr.

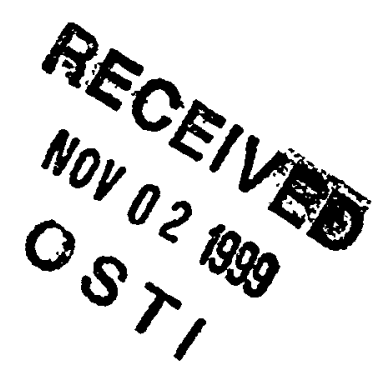

Westinghouse Savannah River Company

Savannah River Site

Aiken, South Carolina 29808

This paper was prepared in connection with work done under the above contract number with the U. S. Department of Energy. By acceptance of this paper, the publisher and/or recipient acknowledges the U. S. Government's right to retain a nonexclusive, royalty-free license in and to any copyright covering this paper, along with the right to reproduce and to authorize others to reproduce all or part of the copyrighted paper. 


\section{DISCLAIMER}

This report was prepared às an account of work sponsored by an agency of the United States Government. Neither the United States Government nor any agency thereof, nor any of their employees, makes any warranty, express or implied, or assumes any legal liability or responsibility for the accuracy, completeness, or usefulness of any information, apparatus, product, or process disclosed, or represents that its use would not infringe privately owned rights. Reference herein to any specific commercial product, process, or service by trade name, trademark, manufacturer, or otherwise does not necessarily constitute or imply its endorsement, recommendation, or favoring by the United States Government or any agency thereof. The views and opinions of authors expressed herein do not necessarily state or reflect those of the United States Government or any agency thereof.

This report has been reproduced directly from the best available copy.

Available to DOE and DOE contractors from the Office of Scientific and Technical Information, P. O. Box 62, Oak Ridge, TN 37831; prices available from (423) 576-8401.

Available to the public from the National Technical Information Service, U. S. Department of Commerce, 5285 Port Royal Road, Springfield, VA 22161. 


\section{DISCLAIMER}

Portions of this document may be illegible in electronic image products. Images are produced from the best available original document. 


\title{
ANALYSIS OF HEAT TRANSFER \\ IN A METAL HYDRIDE BASED HYDROGEN SEPARATION PROCESS
}

by

\author{
William H. Fleming, Jr. \\ Bachelor of Science \\ University of Florida, 1992 \\ Submitted in Partial Fulfillment of the \\ Requirements for the Degree of Master of Science in the \\ Department of Mechanical Engineering \\ University of South Carolina
}

1999

Department of Mechanical Engineering Director of Thesis
Department of Mechanical Engineering 2nd Reader

Dean of the Graduate School 


\section{ACKNOWLEDGEMENT}

I would like to take this opportunity to express my appreciation to the faculty of the Department of Mechanical Engineering for their investment in my graduate education. I thank my advisor, Dr. Jamil A. Khan for his tireless support, guidance and supervision during the course of this work. I would also like to thank the second reader of this thesis, Dr. Curtis A. Rhodes for his valuable input and encouragement.

I would like to thank Dr. L. Kit Heung, Nagarajan Shanmuganathan, and Donna Hasty of the Savannah River Site for their assistance and encouragement during this work.

Finally, I would like to express my appreciation to my wife Tanya for her continued patience, understanding, and support not only for this endeavor, but throughout my graduate studies. 
WSRC-TR-99-00348, Rev. 2

\section{ABSTRACT}

The Thermal Cycling Absorption Process (TCAP) is a metal hydride based hydrogen separation system configured as a helical shell-and-tube heat exchanger. The column (tube side) is packed with Palladium deposited on kieselguhr $(\mathrm{Pd} / \mathrm{k})$. This packed column is thermally cycled by a hot and cold nitrogen system on its exterior surface (shell side), while a stream of hydrogen and other inert gases are passed through the packed column. Hydrogen gas is absorbed and desorbed from the Palladium, causing a separation from the gas stream. The rate at which the hydrogen is separated is dependent only upon how quickly the $\mathrm{Pd} / \mathrm{k}$ can be thermally cycled.

This thesis presents a transient heat transfer analysis to model the heat transfer in the $\mathrm{Pd} / \mathrm{k}$ packed column, and the impact of adding metallic foam. Thermal cycling times for varying packed column diameters, materials, and compositions are also determined. A parametric based argument is presented to optimize the material selection and geometric design basis of a TCAP heat exchanger. 


\section{Contents}

Acknowledgement................................ ii

Abstract............................................ iii

Contents..................................... iv

List of Figures...$\ldots \ldots \ldots \ldots \ldots \ldots \ldots \ldots \ldots \ldots \ldots \ldots \ldots$ vi

Nomenclature.................................. ix

Chapter 1 Introduction........................... 1

1.1 General..................................

1.2 Literature Review ............................. 6

Chapter 2 Problem Statement ....................... 12

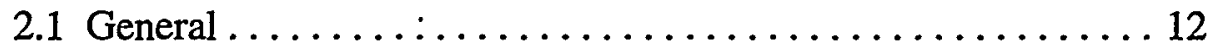

2.2 Specific .................................. 13

Chapter 3 Analytical Model ........................ 15

3.1 Introduction ................................ 15

3.2 Critical Parameters ............................. 19

3.3 Input and Related Data. ..........................20

3.4 Shell Side - Nitrogen Heat Transfer Coefficients. . . . . . . . . 27

3.5 Tube Side - Pd/k Packed Column Heat Transfer Coefficients... 32

3.6 Overall Heat Transfer Coefficient at Pd/k Column Wall. .......37

3.7 Heats of Reaction ............................. 38

3.8 Transient Temperature Calculation ......................39 
3.9 Pressure Drop in the Nitrogen Side. . . . . . . . . . 53

Chapter 4 Experimental Apparatus and Procedure ......... 55

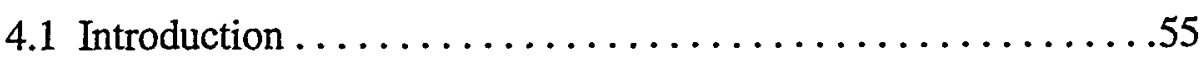

4.2 Experimental Work ................... 55

4.3 Results of Transient Tests $\ldots \ldots \ldots \ldots \ldots \ldots \ldots \ldots \ldots \ldots \ldots \ldots$

4.4 Experimental Conclusions . . . . . . . . . . . . 71

Chapter 5 Results and Discussion $\ldots \ldots \ldots \ldots \ldots \ldots \ldots \ldots$

5.1 Review of Analytical Model.$\ldots \ldots \ldots \ldots \ldots \ldots \ldots 77$

5.2 Definition of Cases $\ldots \ldots \ldots \ldots \ldots \ldots \ldots \ldots \ldots \ldots$

5.3 Effect of Varying Nitrogen Flow . . . . . . . . . . . 79

5.4 Effect of Increasing Column Diameter $\ldots \ldots \ldots \ldots \ldots 2$

5.5 Effect of Different Column Wall Materials $\ldots \ldots \ldots \ldots 3$

5.6 Effect of Adding Different Metal Foams ............ 84

5.7 Cycle Times with Varied Parameters $\ldots \ldots \ldots \ldots \ldots . \ldots 87$

5.8 Effect of Varying Time Interval $\ldots \ldots \ldots \ldots \ldots \ldots \ldots$

5.9 Comparison of Results $\ldots \ldots \ldots \ldots \ldots \ldots \ldots \ldots$

Chapter 6 Conclusions and Recommendations .............. 103

6.1 Conclusions. ........................ 103

6.2 Recommendations...................... 105

Bibliography $\ldots \ldots \ldots \ldots \ldots \ldots \ldots \ldots \ldots \ldots \ldots \ldots \ldots \ldots \ldots \ldots . \ldots \ldots$ 


\section{List of Figures}

Figure 3.1 Axial Cross Section of TCAP Heat Exchanger Showing Flow Paths. 16

Figure 3.2 Detailed Fabrication Drawing of TCAP Heat Exchanger

Figure 3.3 Detailed Fabrication Drawing of Column in Annulus

Figure 3.4 Bill of Materials for TCAP Heat Exchanger

24

Figure 3.5 Axial Cross Section of TCAP Heat Exchanger Showing Sections Used in Transient Temperature Calculations

42

Figure 4.1 Lab Equipment Schematic

Figure 4.2 Surface Temperature Response of Long Cylinder After Sudden Exposure to Uniform Convective Environment

Figure 4.3 Centerline Temperature Response of Long Cylinder After Sudden Exposure To Uniform Convective Environment

Figure 4.4 Measured Temperature Transients for Centerlines of Aluminum Bar 66

Figure 4.5 Measured and Theoretical Temperature Transients for Centerlines of Spheres

Figure 4.6 Transient Coil 1 and 1 Atm 
Figure 4.7 Transient for Coil 2 and $1 \mathrm{Atm}$

Figure 4.8 Transient for Coil 3 and 1 Atm 74

Figure 4.9 Temperature Distribution at Various in a Cylinder of Radius $\mathrm{R}$ with Zero Initial Temperature and Surface Temperature V.

Figure 4.10 Transient Average Temperature in Cylinder with Conduction 75

Figure 4.11 Temperature Transients at Centerline of Sphere 76

Figure 4.12 Temperature Transients at Centerline of Sphere Times for K Divided by 1.4

Figure 5.1 Cooling Times vs. Cold Nitrogen Flow Rate

Figure 5.2 Heating Times vs. Hot Nitrogen Flow Rate

Figure 5.3 Reynolds Number in Sections vs. Cooling Time

Figure 5.4 Reynolds Number in Sections vs. Heating Time

Figure 5.5 Effective Cold Heat Transfer Coefficient for Pd/k-foam Packed Column

Figure 5.6 Effective Hot Heat Transfer Coefficient for Pd/k-foam Packed Column

Figure 5.7 Overall Heat Transfer Coefficient at Packed Column for $7000 \mathrm{lbs} / \mathrm{hr}$ Cold Nitrogen Flow 
WSRC-TR-99-00348, Rev. 2

Figure 5.8 Overall Heat Transfer Coefficient at Packed Column for $7000 \mathrm{lbs} / \mathrm{hr}$ Hot Nitrogen Flow

100

Figure 5.9 Cooling Cycle Times at $7000 \mathrm{lbs} / \mathrm{hr}$ Nitrogen for All Cases 101

Figure 5.10 Heating Cycle Times at $7000 \mathrm{lbs} / \mathrm{hr}$ Nitrogen for All Cases 102

viii 
WSRC-TR-99-00348, Rev. 2

\section{Nomenclature}

A Area, cross sectional or surface, $\mathrm{ft}^{2}$

$\mathrm{A}_{\text {annulus }}$ - Free cross sectional area in the annulus, $\mathrm{ft}^{2}$

Alfoam Aluminum foam

atm Atmospheres

Btu British Thermal Units

C Constant for Zukauskas tube bank correlations

$\mathrm{C}_{2} \quad$ Correction factor for Zukauskas tube bank correlations

Cgen Heat Capacitance of Absorption/Desorption, Btu/ ${ }^{\circ} \mathrm{F}$

Cp Specific Heat, Btu/lb $\cdot^{\circ} \mathrm{F}$

$\mathrm{Cp} 1, \mathrm{Cp} 2 \ldots \quad$ Specific heat of Section 1, Section $2 \ldots$ typical, Btu/lb ${ }^{\circ} \mathrm{F}$

$\mathrm{CpN} \quad$ Specific Heat of Nitrogen; Btu/lb $\cdot{ }^{\circ} \mathrm{F}$

$\mathrm{Cu} \cdot \quad$ Copper

Cufoam Copper foam

D Diameter, inside or outside, $\mathrm{ft}$

$\mathrm{D}_{\mathrm{p}} \quad$ Particle diameter, $\mathrm{ft}$

dp Pressure drop, psi

$\mathrm{E}_{\mathrm{g}} \quad$ Energy generation, Btu 


\begin{tabular}{|c|c|}
\hline$E_{\text {in }}$ & Energy transfer into a control volume, Btu \\
\hline $\mathrm{E}_{\text {out }}$ & Energy transfer out of a control volume, Btu \\
\hline$E_{\text {st }}$ & Energy stored within a control volume, Btu \\
\hline f & Friction factor \\
\hline Fo & Fourier Number \\
\hline G & Mass velocity, $\mathrm{ft} / \mathrm{sec} \cdot \mathrm{ft}^{2}$ \\
\hline$g_{c}$ & Gravitational constant, $32.17 \mathrm{ft} \cdot \mathrm{lb} / \mathrm{lbf} \cdot \mathrm{s}^{2}$ \\
\hline h & Heat transfer coefficient, Btu/hr $\cdot \mathrm{ft}^{2} \cdot{ }^{\circ} \mathrm{F}$ \\
\hline$h_{c}$ & Convective heat transfer coefficient, Btu/hr$\cdot \mathrm{ft}^{2} \cdot{ }^{\circ} \mathrm{F}$ \\
\hline $\mathrm{h}_{\text {contact }}$ & Thermal contact conductance, $\mathrm{Btu} / \mathrm{hr} \cdot \mathrm{ft}^{2} \cdot{ }^{\circ} \mathrm{F}$ \\
\hline$h_{N}$ & Nitrogen side heat transfer coefficients, Btu/hr $\cdot \mathrm{ft}^{2} \cdot{ }^{\circ} \mathrm{F}$ \\
\hline$h_{\mathrm{pdk}}$ & $\mathrm{Pd} / \mathrm{k} \cdot$ packed column side heat transfer coefficient, $\mathrm{Btu} / \mathrm{hr} \cdot \mathrm{ft}^{2} \cdot{ }^{\circ} \mathrm{F}$ \\
\hline$h_{\text {pdkfoam }}$ & $\begin{array}{l}\mathrm{Pd} / \mathrm{k} \text { with foam packed column side heat transfer coefficient, } \\
\mathrm{Btu} / \mathrm{hr}^{2} \cdot \mathrm{ft}^{2} \cdot{ }^{\circ} \mathrm{F}\end{array}$ \\
\hline$h_{w}$ & $\begin{array}{l}\text { Apparent heat transfer coefficient at packed column wall, Btu/hr. } \\
\mathrm{ft}^{2} \cdot \circ \mathrm{F} \text {. }\end{array}$ \\
\hline $\mathrm{H} 2$ & Hydrogen \\
\hline k & Thermal conductivity, Btu/hr $\cdot \mathrm{ft} \cdot{ }^{\circ} \mathrm{F}$ \\
\hline $\mathrm{k}_{\text {colwall }}$ & Thermal conductivity in column wall, Btu/hr. $\mathrm{ft} \cdot{ }^{\circ} \mathrm{F}$ \\
\hline $\mathrm{k}_{\mathrm{e}}$ & Effective thermal conductivity in packed column, Btu/hr$\cdot \mathrm{ft} \cdot{ }^{\circ} \mathrm{F}$ \\
\hline $\begin{array}{c}\mathrm{k}_{\text {effwfoam }} \\
\text {, }\end{array}$ & $\begin{array}{l}\text { Effective thermal conductivity in packed column with foam, } \\
\mathrm{Btu} / \mathrm{hr} \cdot \mathrm{ft} \cdot{ }^{\circ} \mathrm{F}\end{array}$ \\
\hline $\mathrm{k}_{\mathrm{f}}$ & Thermal conductivity of fluid in packed column, Btu/hr. $\mathrm{ft} \cdot{ }^{\circ} \mathrm{F}$ \\
\hline
\end{tabular}




\begin{tabular}{|c|c|}
\hline $\mathrm{k}_{\text {foam }}$ & Thermal conductivity of foam in packed column, Btu/hr. $\mathrm{ft} \cdot{ }^{\circ} \mathrm{F}$ \\
\hline $\mathrm{k}_{\mathrm{ow}}$ & Apparent thermal conductivity of fluid in packed column at w \\
\hline & $\mathrm{Btu} / \mathrm{hr} \cdot \mathrm{ft} \cdot{ }^{\circ} \mathrm{F}$ \\
\hline $\mathrm{k}_{\mathrm{s}}$ & Thermal conductivity of solid in packed column, Btu/hr $\cdot \mathrm{ft} \cdot{ }^{\circ} \mathrm{F}$ \\
\hline $\mathrm{L}$ & Length, $\mathrm{ft}$ \\
\hline $\mathrm{m} 1, \mathrm{~m} 2 \ldots$ & Mass of Section 1 , Section $2, \ldots$. typical, lbs \\
\hline $\mathrm{N}_{\mathrm{L}}$ & Number of tubes in longitudinal direction \\
\hline nofoam & No foam \\
\hline $\mathrm{Nu}_{\mathrm{D}}$ & Nusselt Number based upon diameter \\
\hline OD & Outside Diameter, $\mathrm{ft}$ \\
\hline $\mathrm{p}$ & Porosity \\
\hline $\operatorname{Pr}$ & Prandtl Number \\
\hline psi & pounds-force per square inch \\
\hline psia & pounds-force per square inch absolute \\
\hline $\mathbf{R}$ & Outer Radius, $\mathrm{ft}$ \\
\hline $\operatorname{Re}$ & Reynolds Number \\
\hline $\operatorname{Re}_{\mathrm{D}}$ & Reynolds Number based upon diameter \\
\hline $\mathrm{Re}_{\mathrm{m}}$ & Modified Reynolds Number for use in packed column \\
\hline $\mathrm{rpm}$ & Rotations per minute \\
\hline slpm & Standard liters per minute \\
\hline SS & Stainless Steel (Type 316) \\
\hline STP & Standard Temperature and Pressure, $32^{\circ} \mathrm{F}$ at $1 \mathrm{~atm}$ \\
\hline TN & Supply Temperature of Nitrogen, ${ }^{\circ} \mathrm{F}$ \\
\hline
\end{tabular}


TN1, TN2... Nitrogen temperature at Section 1 , Section $2{ }^{\circ} \mathrm{F}$, typical

$\begin{array}{ll}\mathrm{T}_{\mathrm{s}} & \text { Surface temperature, }{ }^{\circ} \mathrm{F} \\ \mathrm{T}_{\infty} & \text { Free stream temperature, }{ }^{\circ} \mathrm{F} \\ \mathrm{U}_{\mathrm{o}} & \text { Overall heat transfer coefficient, Btu/hr} \cdot \mathrm{ft}^{2} \cdot{ }^{\circ} \mathrm{F} \\ \mathrm{V} & \text { Velocity, } \mathrm{ft} / \mathrm{sec} \\ \mathrm{V}_{\mathrm{s}} & \text { Superficial velocity in packed column, } \mathrm{ft} / \mathrm{sec} \\ \text { vol } & \text { Volume, } \mathrm{ft}^{3} \\ \mathrm{w} & \text { Mass flow rate, } \mathrm{lbs} / \mathrm{hr} \\ \mathrm{wN} & \text { Nitrogen mass flow rate, } \mathrm{lbs} / \mathrm{hr}\end{array}$

\section{Greek Letters}

$\alpha \quad$ Thermal diffusivity, $\mathrm{ft}^{2} / \mathrm{sec}$

$\chi \quad$ Correction factor for in-line tube arrangement from Zukauskas correlation

$\Delta \quad$ Characteristic length

$\Delta \mathrm{p} \quad$ Pressure drop, psi

$\Delta \mathrm{Q} 1, \Delta \mathrm{Q} 2 \ldots$ Heat transferred in section 1 , section $2 \ldots$ typical, Btu

$\Delta$ Qgen Heat generated by heat of absorption/desorption in packed column, Btu

$\Delta \mathrm{t} \quad$ Time interval, sec

$\varepsilon$

Average void fraction in packed column

$\varepsilon_{\mathrm{w}}$

Average void fraction in packed column in vicinity of wall

$\phi \quad$ Effective thickness of fluid film 

$\phi_{\mathrm{w}}$ Effective thickness of fluid film in packed column in vicinity of wall. Absolute Viscosity, lb/ft-sec
Mass density, $\mathrm{lb} / \mathrm{ft}^{3}$

\section{Subscripts}

f

i

$\max$

$\mathrm{n}$

o

$\mathbf{s}$

$\mathrm{X}$

1.25

2

\section{Superscripts}

' (prime) Intermittent value

$\mathrm{m}$
Final conditions

Initial conditions, control volume inlet, Inner

Maximum fluid velocity

nth time step

Outer

Swirl-flow

Cross-flow

Parameters for 1.25 inch diameter packed column

Parameters for 2 inch diameter packed column 
WSRC-TR-99-00348, Rev. 2

\section{Chapter 1}

\section{INTRODUCTION}

\subsection{General}

According to the United States Environmental Protection Agency (EPA) [1993], $66 \%$ of carbon monoxide emissions and $50 \%$ of smog-forming emissions come from gasoline-powered vehicles. Due to the world's dependence upon the use of internal combustion engines for mobility, transportation is responsible for about $33 \%$ of the air pollutants that affect the ozone layer. In fact, over half of the air-toxin problems associated with air pollution are attributable to these vehicles. Influenced by environmental concerns, a larger effort is necessary to provide automobiles with cleaner burning fuels.

Automotive air-pollution problems first became apparent in the 1940s in Los Angeles. Almost 50 years have passed since Prof. A.J. Haagen-Smit [1952] demonstrated that the smog problem in Los Angeles resulted from reactions between nitrogen oxides and hydrocarbons in the presence of sunlight. Since then, it has become increasingly clear that the automobile is a major contributor to hydrocarbon and nitrogen oxide emissions, as well as the prime cause of high carbon monoxide levels in urban areas. Much work is in progress on the use of alternatives to gasoline and diesel. Of the non-petroleum-based fuels, natural gas, methanol and ethanol are receiving the greatest 
attention. Longer term possibilities include synthetic gasoline and diesel made from shale oil or coal, as well as hydrogen [Heywood, 1985].

Hydrogen is clean, abundant and accessible, making it a leading contender as an alternate fuel. Hydrogen combustion produces no pollution and emits water as opposed to petroleum-based fuels, which emit carbon monoxide. Hydrogen is the most abundant element in the universe, making it an ideal component of a renewable and sustainable future energy system. There are three methods for obtaining hydrogen gas: electrolysis of water, steam reforming of natural gas, and gas separation techniques. Electrolysis uses electricity to separate water into its constituents, hydrogen and oxygen. Due to its dependency upon electricity, The United States Department of Energy (DOE) has concluded that electrolysis is unlikely to become the predominant method for large quantities of hydrogen production in the future. The more predominant method for producing hydrogen (as a synthesis gas) is steam reforming of natural gas.

In addition to hydrogen production methods, hydrogen may also be obtained by separation from gas mixtures (air). Hydrogen is commonly mixed with other gases, usually inert gasses - such as nitrogen and oxygen. One method of separation is by thermal cycling of materials which are capable of absorbing and desorbing hydrogen.

Metal hydrides are metallic or intermetallic compounds that have the ability to reversibly absorb relatively large amounts of hydrogen at ambient temperatures and pressures. Cohen and Wernick [1982] found that for applications such as hydrogen storage and transport, this ability offers several advantages over traditional hydrogen containment systems. This technology allows hydrogen to be stored in a solid form. For * example, Snape and Lynch [1980] found that a hydride at room temperature and at 
atmospheric pressure can store hydrogen at densities $20 \%$ to $80 \%$ greater than that of liquid hydrogen at $-433^{\circ} \mathrm{F}$. For gas storage to approach these densities, very high pressures and heavy containment vessels are required.

In addition, Snape and Lynch [1980] state that the relatively high heat of reaction, up to $40 \mathrm{Btu} /\left(\mathrm{mole}_{2}\right)$, also makes metal hydrides attractive for use in heat storage, waste recovery, and heat pumps. Desorption pressures ranging from 0.05 to $60 \mathrm{~atm}$ make them particularly suitable for staged hydrogen compression [Sandrock and Huston, 1981]. A pump or compressor utilizing metal hydrides requires no moving parts other than valves.

Unfortunately, there are several disadvantages associated with metal hydrides. They tend to be very heavy because they are primarily metallic compounds. The cost of some of the more attractive hydrides is high, particularly those of Palladium. And, large amounts of energy are generally required for absorption and desorption, leading to potentially high energy costs. Therefore, optimization of the operation of the metal hydride can reduce excessive energy and material costs.

In general, metal hydrides have relatively fast reaction rates, large heats of reactions, and low thermal conductivities. Consequently, the limiting factor in the rates of absorption and desorption in metal hydrides is the rate at which the heat of reaction can be supplied to, or removed from, the metal hydride. Therefore, accurate modeling of the heat transfer is of prime importance in optimizing the performance of a metal hydride based system.

The Thermal Cycling Absorption Process (TCAP) is a metal hydride based, thermally cycled hydrogen gas separation process invented by Myung W. Lee of the 
Savannah River Site. The main component of this separation process is a shell-and-tube type heat exchanger utilizing a Palladium deposited on kieselguhr $(\mathrm{Pd} / \mathrm{k})$ packed column. Palladium is a metal hydride material which absorbs hydrogen reversibly due to the relatively small size of the hydrogen molecule. The hydrogen gas temperature and pressure controls the direction of the reaction. Kieselguhr, a highly porous diatomite, has a low pressure drop during the gas flow in the packed column and provides a large surface area for deposition of the Palladium metal. Pure Palladium crumbles into a fine powder after repeated absorption of hydrogen but remains on the small kieselguhr particles without breaking up once properly deposited. The hydrogen absorption properties of Palladium are relatively unaffected after deposit on the kieselguhr.

The heat exchanger is constructed of a helically coiled column, which occupies the annular space between an inner and outer shell. Coiled tubes are used to obtain a larger heat transfer area per unit volume. The $\mathrm{Pd} / \mathrm{k}$ is packed into the pores of copper or aluminum foam with a relatively low void fraction inside the column, which increases the potential for heat transfer. The packed column occupies the annular space between an inner and outer shell, with nitrogen gas circulating through the annulus. In operation, the column temperature is cycled between a low and high temperature, creating a cycle of two distinct steps - an absorption step and a desorption step, which separates hydrogen from the inert gasses. For a given column diameter and length, the throughput is determined primarily by the rate at which the column, and thus the $\mathrm{Pd} / \mathrm{k}$, can be cycled between the two temperatures. Therefore, for effective and efficient separation, the heat transfer aspects of this column are crucial. 
WSRC-TR-99-00348, Rev. 2

Few measurements and models have been presented which describe the thermal conductivity of metal hydride materials. Suissa, et al. [1984] measured the thermal conductivities of two metal hydrides between 2 and 5 atmospheres (atm). They found that increasing the hydrogen pressure from 2 to $5 \mathrm{~atm}$ increased the effective thermal conductivity by $5 \%$. Similarly, Lin et. al. [1985] measured the thermal conductivity of iron-titanium alloys, another type of hydride material. They found that packing the powder in the pores of aluminum foam with a void fraction of $92 \%$ increased the thermal conductivity by $40 \%$ over that measured for the powder alone. Palladium is a lowpressure metal hydride material, and operates effectively on the order of $1 \mathrm{~atm}$, therefore, the pressure dependency of effective thermal conductivity at higher pressures developed by Suissa, et al. would not apply to the operation of the $\mathrm{Pd} / \mathrm{k}$ metal hydride. Also, since the $\mathrm{Pd} / \mathrm{k}$ consists of athin metallic layer deposited on a very low conductive material, the experiments based upon metallic alloy powders performed by Lin et. al. [1985] may be suspect due to their higher thermal conductivities.

In this process, accurately modeling the heat transfer depends greatly on the model's ability to correctly determine the thermal conductivity within the packed bed and resultant heat transfer coefficients. In this paper; a model is presented which describes heat transfer in a low pressure, stagnant packed metal hydride based system with and without a heat transfer-enhancing medium. The time dependent temperature profiles calculated by the model are compared with the experimental measurements in different arrangements of hydride material packed beds to determine the ability of the model to accurately reflect the process. 
WSRC-TR-99-00348, Rev. 2

\subsection{Literature Review}

A thorough literature review was made which focused on three key areas: 1) modeling of nitrogen flow and its heat transfer characteristics in the shell side of the TCAP heat exchanger; 2) modeling of low flow and heat transfer characteristics in $\mathrm{Pd} / \mathrm{k}$ packed column; and 3) modeling of metal foam inclusion in $\mathrm{Pd} / \mathrm{k}$ packed column.

The inlet and outlet sections and internal shell of the TCAP heat exchanger are modeled as turbulent flow in circular tubes. Dittus and Boelter [1930] proposed convection correlations to express average Nusselt numbers for fully developed turbulent . flow (Reynolds number $>5000$ ) in smooth circular tubes. Incropera [1990] states that these correlations can also be evaluated by using the hydraulic diameter. These correlations were formulated through experimentation and hold today as extensions of Reynolds' [1901] original fluid flow experiments.

For the shell side annulus of the heat exchanger containing the helical packed column, an empirical correlation for a bank of tubes in crossflow can be used. The heat transfer coefficient between the hot and cold nitrogen and the column wall is dependent upon the mass flow rate. Colburn [1933] recommended a dimensionless equation for gases flowing normal to banks of unbaffled in-line tubes. This correlation was based upon the data for air available in the 1930s and was limited to the use of ten longitudinal rows of coils. It was not until 1952 that Kays and Lo [1952] provided correction factors for Colburn's correlation that compensated for tube banks consisting of less than ten longitudinal rows. Still, some of the earlier work by Grimison [1937, 1938] is in popular use today. Grimison was the first to actively pursue a correlation for the average heat 
transfer coefficient for the entire tube bank based on the configuration differences, and correction for number of rows for Reynolds numbers of up to 40,000 .

Further investigation of flow past a single tube, and its heat transfer facilitated the understanding of the physical phenomenon of heat transfer in banks of tubes in crossflow. Several books pertaining to heat exchanger design were published, including Keys and London [1958]. However, these books dealt only with flows of gases at low Reynolds numbers. More recently accelerated development of science and technology has revealed new challenges in the field of heat transfer of tubes in crossflow. Zukauskas [1972] recognized this need for more reliable formulas and provided them for calculation of heat transfer of tubes in flows of gases at higher Reynolds numbers than previously developed. Using extensive experimental data, Zukauskas [1972] developed correlations for heat transfer for tubes in cross flow in the range of Prandtl number from 0.7 to 500 and that of Reynolds number from 1 to $2 \times 10^{6}$. Because of the more extensive research performed and documented by Zukauskas, his methods will be used in this study.

The heat transfer within the packed column is more difficult to model. The search was first directed towards Nusselt number correlations for packed beds. The presence of the $\mathrm{Pd} / \mathrm{k}$ modifies the column wall heat transfer to the extent that correlations for the flow through an empty tube are not applicable. Whitaker [1972] correlated data for heat transfer from gases to different kinds of packing from several sources. The types of packing included spheres - which models the $\mathrm{Pd} / \mathrm{k}$ packing - but the correlation is valid only for Reynolds numbers from 20 to $10^{4}$, which is inappropriate for this application of very low Reynolds number (0.06). Upadhyay [1975] used the mass transfer analogy to study heat and mass transfer in packed beds at Reynolds numbers from 0.01 to 10 , and 
developed a Nusselt number correlation. The range of void fraction tested by Upadhyay was fairly narrow ( 0.371 to 0.451$)$ and data were for solid cylindrical pellets in water only. Use of this correlation for gases will lead to high uncertainty. Beek [1962] provided a more specialized equation to calculate the heat transfer from the wall of a packed bed to a gas, but the result is only valid for Reynolds numbers of 40 to 2000 .

With the lack of available Nusselt number correlations for heat transfer coefficient in this particular arrangement, the literature review was redirected towards finding the effective thermal conductivity within the packed bed. The axial effective thermal conductivity was first examined, and was found to be negligible due to the low Reynolds number flow and the lack of an axial temperature gradient in the packed column. When the radial conductivity is taken into account, the Legawiec and Ziolkowski [1996] correlation provides an axial effective thermal conductivity only one percent of that of the hydrogen thermal conductivity in the column. Rayleigh [1892] made an early attempt to find the effective thermal conductivity of a two-phase medium for a cubical array of uniform spheres. This model is rigid and artificial and does not allow for the random packing which is encountered in reality. Russell [1935] proposed a less stringent correlation for the effective thermal conductivity of packed cubes, but this correlation does not give good experimental correlation when gas is the continuous medium, as in a packed bed. Laubitz [1959] introduced a correction to Russell's correlation to account for the gas in continuous phase. However, the experiments and their conclusion are based upon cubical shaped powders and would be inappropriate for this application of spherical Pd/k particles. Hadly.[1986] presented the results of an experimental and analytical investigation, which dealt with the effective thermal 
WSRC-TR-99-00348, Rev. 2

conductivity of packed metal powders. The resultant correlation was based on an analytical technique that used very small void fractions and would not apply for the $\mathrm{Pd} / \mathrm{k}$ case.

Ofuchi and Kunii [1964] studied packed beds with larger void fractions (.34 to .6) and stagnant fluids, (Reynolds number $\approx 0$ ). Their studies with fluid flows approaching Reynolds numbers of zero compared closely with the theoretical equation of stagnant conductivities found by Kunii and Smith [1960]. Due to the higher void fractions used and their dependence on Reynolds numbers approaching zero- Kunii and Smith's correlation for effective thermal conductivity in the bed presented by Ofuchi and Kunii [1964] will be used. Yagi and Kunii [1960, 1962] provide a correlation for finding the heat transfer coefficient at the wall for Reynolds number approaching zero. Ofuchi and Kunii [1964] provide this calculated heat transfer coefficient as a correction term when the effective thermal conductivity is assumed to be constant throughout the bed. The correlations provided by Ofuchi and Kunii will be used to calculate the effective thermal conductivity as well as the heat transfer coefficient of the $\mathrm{Pd} / \mathrm{k}$ packed column.

Heat transfer in packed beds result from contributions of conduction, convection, and radiation. Yovonovich [1967] states the contribution to the total heat transfer from conduction, which is most significant, is dependent upon the thermal conductivity of the packing material and the surrounding gas, but also on the interfluid contact areas through which heat flows and the contact resistance occurring at these temperatures. Unlike conduction and convection, radiation is temperature dependent and is most significant at high temperatures. Chen and Churchill [1963] concluded in their study of packed beds that radiation effects are important only for temperatures above $1600^{\circ} \mathrm{F}$. Wakao and 
Vortmeyer [1971] have shown that the convective contribution is dependent upon the fluid pressure and void fraction of the packed bed. According to Perry [1963], from about 1 torr to $10 \mathrm{~atm}$ the effect of pressure is negligible on thermal conductivity of gases. Therefore, the average operating pressure of $1 \mathrm{~atm}$ for this process is assumed to have no effect on effective thermal conductivity.

Jaguaribe [1983] proposed a correlation for the effective thermal diffusivity in a packed bed. This will be used as a comparison between experimental and analytical results.

In the absence of available information for finding the effective thermal conductivity of the metallic foam embedded in the $\mathrm{Pd} / \mathrm{k}$ packed column, the literature review focused on geometrical correlations. Roshenow, et al [1985] provide a method for approximating the effective thermal conductivity for composites arranged into geometric arrays. These geometric arrays are arranged into groups of elemental parallel resistances that are summed in series. The imbedded metal foam will be modeled as spherical inclusions (the $\mathrm{Pd} / \mathrm{k}$ ) in a cubic array (the foam continuous lattice).

Due to the helical arrangement of the packed column inside of the heat exchanger annulus, it becomes necessary to evaluate the percentage of flow that may spiral down the length of the packed column. Perry [1963] provides a correlation to evaluate the fraction of swirl flow.

Watson et. al. [1985] measured the effective thermal conductivity of iron titanium alloy powders. They found packing the powder in the pores of aluminum foam with a void fraction of $92 \%$ increased the thermal conductivity $40 \%$ over that measured for powder alone. No analytical correlation was provided, results were reported for graphical 
comparison. It is worth noting that a metallic alloy powder has higher thermal conductivity than $\mathrm{Pd} / \mathrm{k}$, which is a metallic coating on an insulation material.

Much of the available literature on hydrogen and hydrogen technologies, is published by the DOE on the internet. The internet is also a great source for pollution and smog statistics provided by the EPA. Discussions of pollution and alternative fuels are commonly found in internal combustion textbooks, such as Heywood [1988] and Obert [1973]. Much of the current research with hydrogen fueled engines, such as the Stirling engine are available via the Internet by investigating research projects at Universities both domestic and abroad.

Heung [1997b] provides partial development and synopsis of the TCAP process for separation of hydrogen. Heung also provides overviews of applied hydrogen technologies, including the Savannah River Site hydrogen fueled bus. Information on hydride materials and their properties are also provided.

Many sources provide thermophysical properties of metals and gasses, including Kreith [1993] or Incropera [1990], Lide [1995] and the International Critical Tables [1928] contain kieselguhr properties. 
WSRC-TR-99-00348, Rev. 2

\section{Chapter 2}

\section{Problem Statement}

\subsection{General}

The TCAP heat exchanger's throughput capacity is proportional to the total volume stored in the $\mathrm{Pd} / \mathrm{k}$ metal hydride and is inversely proportional to the cooling and heating cycle time. The obvious goal of the separation process is to maximize throughput and thereby obtain the quickest separation possible. The absorption and desorption of hydrogen by the $\mathrm{Pd} / \mathrm{k}$ is almost instantaneous and is heat transfer limited rather than kinetic limited. Consequently, throughput is dependent almost entirely upon heat transfer between the $\mathrm{Pd} / \mathrm{k}$ and nitrogen. The critical parameters of the heat transfer of the column are: 1) heating and cooling loads; 2) the hot and cold nitrogen gas temperatures and the nitrogen circulation rate; and 3) the heat transfer coefficients controlling the heat transfer between the nitrogen and $\mathrm{Pd} / \mathrm{k}$. The heating and cooling loads are determined by the heat capacity of the heat exchanger, target temperature swing and the target heating/cooling time. The heat capacity includes the sensible heats of the column walls, the $\mathrm{Pd} / \mathrm{k}$, metallic foam, the feed gas, and the heat of hydrogen absorption. The actual heating/cooling time will be determined by the hot and cold nitrogen inlet temperatures, the nitrogen mass flow rate, the nitrogen flow path opening in the annular space, and the effect of the metallic foam in the $\mathrm{Pd} / \mathrm{k}$ packed column. The effective heat transfer coefficients for the shell side and the tube side are quite involved. 
WSRC-TR-99-00348, Rev. 2

The temperature difference between the nitrogen and the $\mathrm{Pd} / \mathrm{k}$ is the driving force for heat transfer. The desired capacity of the exchanger may be achieved by using the proper length of packed column and/or adjusting the diameters. In general, larger diameters will yield slower heating and cooling rates, impacting the cycle time and throughput. This paper calculates the heat load required for a given cycle time, then considers the rate of heating and cooling.

\subsection{Specific}

Due to the need for increased capacity for the new TCAP heat exchanger, the $\mathrm{Pd} / \mathrm{k}$ packed column diameter was increased to 2 inches from the existing 1.25 inches, while maintaining its existing uncoiled length of 39 feet. This increase in diameter yielded a $180 \%$ growth in cross-sectional area/volume, potentially increasing the volume of hydrogen which could be separated. The challenge was to increase the throughput by a factor of 2.8, but maintain the same cooling and heating time of the existing TCAP heat exchanger. Also, the increase in cross-sectional area increased the required heat flux through the packed column wall, due to the fact that the column wall surface area does not increase by the same factor as the cross sectional area. In fact, only a $60 \%$ gain in available surface area was obtained by the diameter increase. Therefore, the heat transfer area per unit volume decreased. The required heat flux of the larger column would have to be a factor of 1.7 greater than that of the smaller diameter packed column. The design challenge would be to achieve this flux increase. The purpose of the testing and analysis was to determine to what extent the presence of a heat transfer-enhancement 
WSRC-TR-99-00348, Rev. 2

medium, such as metallic foam, would compensate for the effect of the larger diameter and volume.

A method was necessary to model the heat transfer in this metal hydride based heat exchanger and to determine the feasibility of the larger diameter packed column. In order to establish the maximum throughput of the heat exchanger, the design was optimized by performing parametric studies. These parametric studies include: 1) comparison of different materials to minimize heat capacitance and increase thermal diffusion; 2) assessment of heat transfer enhancement within the packed column by addition of metallic foam; 3) comparison of different geometries in order to maximize both the packed bed-tube side heat transfer and the nitrogen gas-tube side heat transfer coefficients; 4) optimization of hot and cold nitrogen gas temperatures and flow rates; 5) application of a time dependent analysis with sufficiently small time increments; and 6) knowledge and consideration of practical limitations of fabrication and commercially available equipment. 
WSRC-TR-99-00348, Rev. 2

\section{Chapter 3}

\section{ANALYTICAL MODEL}

\subsection{Introduction}

In this chapter, a model for studying the heat transfer in the TCAP heat exchanger will be developed. This model considers the nitrogen flow in the shell side of the heat exchanger, and its affect on the coiled $\mathrm{Pd} / \mathrm{k}$ packed column (tube side) in the annulus of the inner and outer shells. See Figure 3.1 for an axial cross section showing the heat exchanger flow paths. The analysis accounts for internal heat and mass transfer within the nitrogen side of the heat exchanger, as well as the heat and mass transfer within the $\mathrm{Pd} / \mathrm{k}$ packed column. The heat transfer calculation is complex due to cyclical cooling and heating and heat release of absorption or heat consumption of desorption, as well as constant changes in the temperatures of various components of the heat exchanger and nitrogen. This problem is simplified without significant compromise by making the following assumptions.

1) The hydride phase and the gas in the void space are in thermal equilibrium.

2) There is no pressure gradient within the packed column.

3) The hydrogen in gas phase behaves as an ideal gas. 


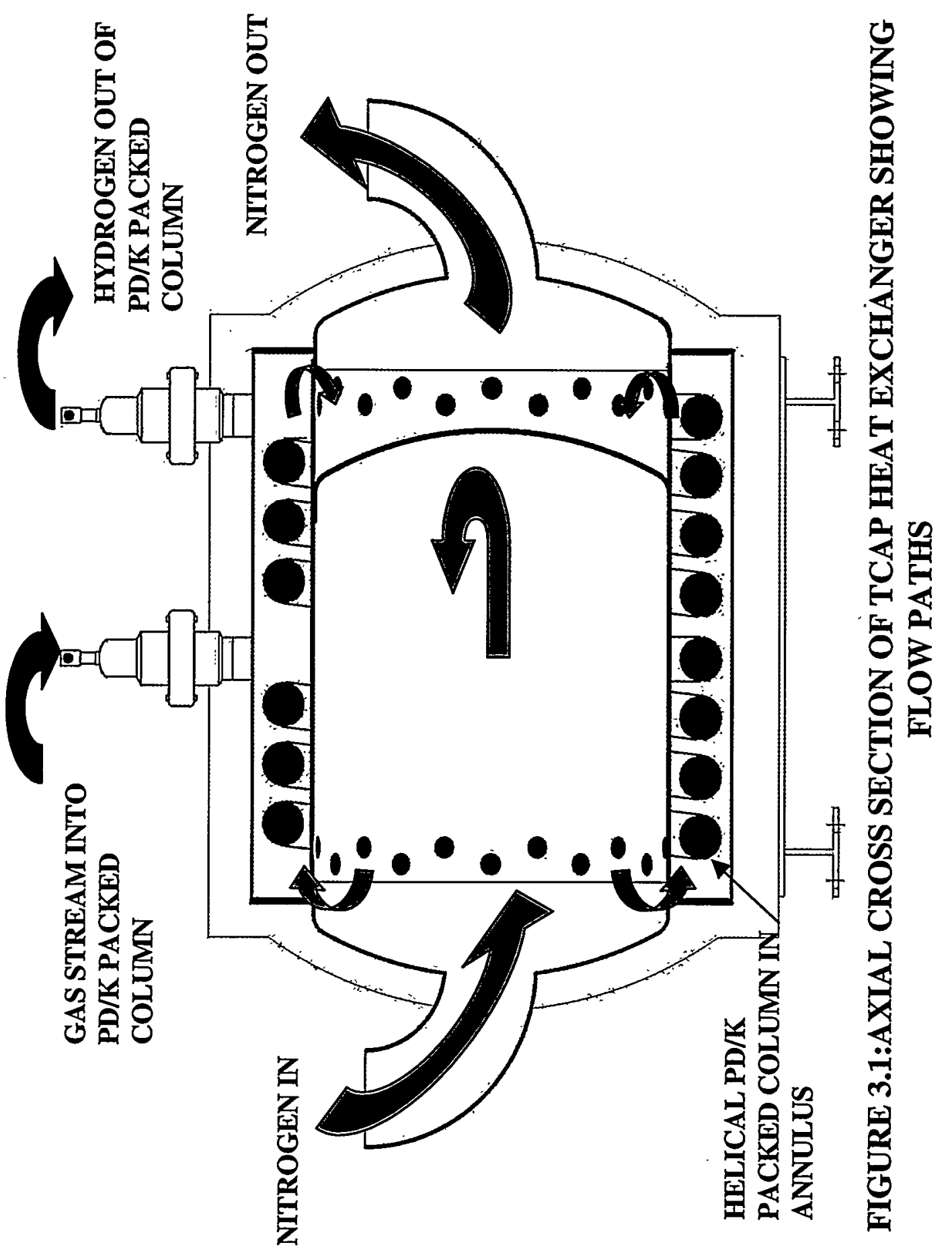


4) The temperature in the packed column is only a function of time and is uniform throughout the system at any instant.

5) The hydrogen pressure inside the packed column is approximately one atmosphere.

6) The hydrogen's heat of absorption/desorption during cooling/heating is uniform and proportional to the $342^{\circ} \mathrm{F}$ temperature change of $\mathrm{Pd} / \mathrm{k}$ hydrogen hydride through heating and cooling cycles. Of the 400 STP liters of gas mixture in the 2 inch packed column, $50 \%$ is hydrogen and $50 \%$ inert gases with hydrogen completely absorbed/desorbed into/from the $\mathrm{Pd} / \mathrm{K}$. The existing 1.25 inch column contains 145 STP liters of gas mixture.

7) The thermophysical properties of nitrogen, with the exception of density, do not vary significantly with pressure and temperature in the operating range.

8) The operating pressure of the nitrogen in hot and cold loops is 150 psia.

9) Heat transfer between the valves and piping and the nitrogen is considered negligible due to vacuum jacketing.

10) Heat transfer between pipe and heat exchanger with environment is neglected due to polished Inconel 625 outer shell that is perfectly insulated.

11) The void fraction is 0.34 in the $\mathrm{Pd} / \mathrm{k}$ packed column, with or without foam (due to high porosity), and is 0.4 at the column wall. 
By assuming that the hydride phase and gas in the void space are in thermal equilibrium, we are able to employ correlations for the effective thermal conductivity of two phase mixtures, as is the case with packed beds. The absence of a pressure gradient within the packed column further strengthens the argument presented in Section 1.2, that axial thermal conduction can be neglected. A large pressure gradient within the column affects the thermal conductivity of the hydrogen gas. Modeling the hydrogen gas phase in the packed column as an ideal gas allows the use of published data for thermophysical properties of hydrogen without any correction for formation of a metal hydride compound. By assuming that the temperature in the packed column is only a function of time, and not position, a lumped-capacitance method can be used for studying the heat transfer within the packed column. After examination of Van't Hoff relations for Palladium-hydrogen systems, it can be concluded that the operation of the packed column will be on the order of $1 \mathrm{~atm}$. Heats of absorption and desorption are changes in total heat or enthalpy for the hydrogen reaction with the Palladium. With the assumption of constant specific heat for the hydrogen, the heats of reaction become only a function of temperature, with the total enthalpy change proportional to the total temperature change of the $\mathrm{Pd} / \mathrm{k}$ material, resulting in an equivalent heat capacitance (discussed below). The quantities of gas mixture in the 2 inch and 1.25 inch packed columns are based on the reversible hydrogen capacity of $\mathrm{Pd} / \mathrm{k}$ from Table 3.1 , and the volume of $\mathrm{Pd} / \mathrm{k}$ is calculated from dimensional information. Even at $150 \mathrm{psia}(10 \mathrm{~atm})$, the thermal conductivity, absolute viscosity, specific heat, and Prandtl number of the hot and cold nitrogen show insignificant dependence upon pressure, but do vary with temperature. Vacuum-jacketed piping and valves are commercially available for use in cryogenic delivery systems and 
are natural choices for this application. The outer shell of the TCAP heat exchanger is made from a polished nickel-chromium alloy and is insulated with 4 inches of zirconiumsilica based fibrous blanket. This in effect renders the heat transfer from the exterior sections of the TCAP heat exchanger negligible. A void fraction of 0.34 within the packed column is a typical value obtained with spherical particles of this diameter (Table 3.1). According to Ofuchi and Kunii [1964], a void fraction of 0.4 is the smallest packing of spherical particles that can be achieved at the flat wall surface. Having made these assumptions to render a practical model, it is still necessary to emphasize the important aspects of the design and the model.

\subsection{Critical Parameters}

The critical parameters affecting the heat transfer in the TCAP column can be better understood by reviewing the geometry of the TCAP heat exchanger in Figure 3.1. The 2 inch OD, 0.065 inch thick wall, 39 foot long column is formed into 2 identical coils. The coil diameter is 20 inches center to center. The new 2 inch packed column is filled with metal (aluminum or copper) foam to improve heat transfer. The $\mathrm{Pd} / \mathrm{k}$ particles occupy the pores of the metallic foam. An inner shell and an outer shell form an annular space to house the column coil. The inner shell is closed at one end, so that the hot/cold nitrogen flows into one end of the inner shell, through a number of holes into the annular space where the packed column is. After passing through the column coil, the nitrogen flows through another group of holes and back into the far end of the inner shell.

The critical parameters for heat transfer aspects of the heat exchanger are: 1) heating and cooling loads; 2) the hot and cold nitrogen temperatures and the nitrogen 
circulation rate; and 3) the heat transfer coefficients controlling the heat transfer between the nitrogen and the $\mathrm{Pd} / \mathrm{k}$ in the packed column. The heating and cooling loads are determined by the heat capacity of the heat exchanger, target temperature swing and the target heating/cooling time. The actual heating/cooling time will be determined by the hot and cold nitrogen inlet temperatures, the nitrogen mass flow rate, the nitrogen flow path opening in the annular space housing the packed column, and the effect of metal foam on the packed column heat transfer coefficient. The temperature difference between the nitrogen and the $\mathrm{Pd} / \mathrm{k}$ is the driving force for heat transfer. It is obvious that the colder and the hotter the nitrogen, the greater the temperature gradient - the more the heat transfer. The effective heat transfer coefficients for the heating or cooling nitrogen and the $\mathrm{Pd} / \mathrm{k}$ packed column are quite involved and will be discussed below.

\subsection{Input and Related Data}

The geometry and dimensions for the new TCAP heat exchanger are shown in Figures 3.2; 3.3, and 3.4. These dimensions are used to calculate masses, volumes, surface areas and cross sectional areas for use in calculating velocities, Reynolds numbers, heat transfer coefficients, pressure drops and ultimately heating and cooling times. The dimensions for the existing 1.25 inch diameter packed column based TCAP heat exchanger are scaled down from the above referenced Figures, keeping the column length constant at 39 feet. Thermophysical properties of the Pd/k are obtained from Heung [1997a] and included in Table 3.1. 
Table 3.1. Thermophysical Properties of Pd/k (Heung, [1997a])

\begin{tabular}{|l|l|}
\hline Kieselguhr (k) & $\begin{array}{l}\text { Chromosorb } \\
\text { mesh }(.001 \mathrm{ft} \text { dia.), by Johns-Manville }\end{array}$ \\
\hline Composition & $\begin{array}{l}50 \% \text { Pd deposited on kieselguhr, done } \\
\text { by Ionex Research Corporation, P.O. } \\
\text { Box 602, Broomfield, CO, 80020 }\end{array}$ \\
\hline Bulk Density & $0.8 \mathrm{~g} / \mathrm{cc}\left(50 \mathrm{lb} / \mathrm{ft}^{3}\right)$ \\
\hline Reversible Hydrogen Capacity & $25 \mathrm{STP}$ liter $/$ liter of $\mathrm{Pd} / \mathrm{k}$ \\
\hline Specific Heat & $0.13 \mathrm{cal} / \mathrm{g} \cdot{ }^{\circ} \mathrm{C}\left(0.13 \mathrm{Btu} / \mathrm{lb} \cdot{ }^{\circ} \mathrm{F}\right)$ \\
\hline Thermal Conductivity & $0.73 \mathrm{Btu} / \mathrm{hr} \cdot \mathrm{ft} \cdot{ }^{\circ} \mathrm{F}$ \\
\hline
\end{tabular}

The heats of absorption and desorption for a Pd/k-Hydrogen metal hydride system are also from Heung [1997a] and are listed in Table 3.2. 


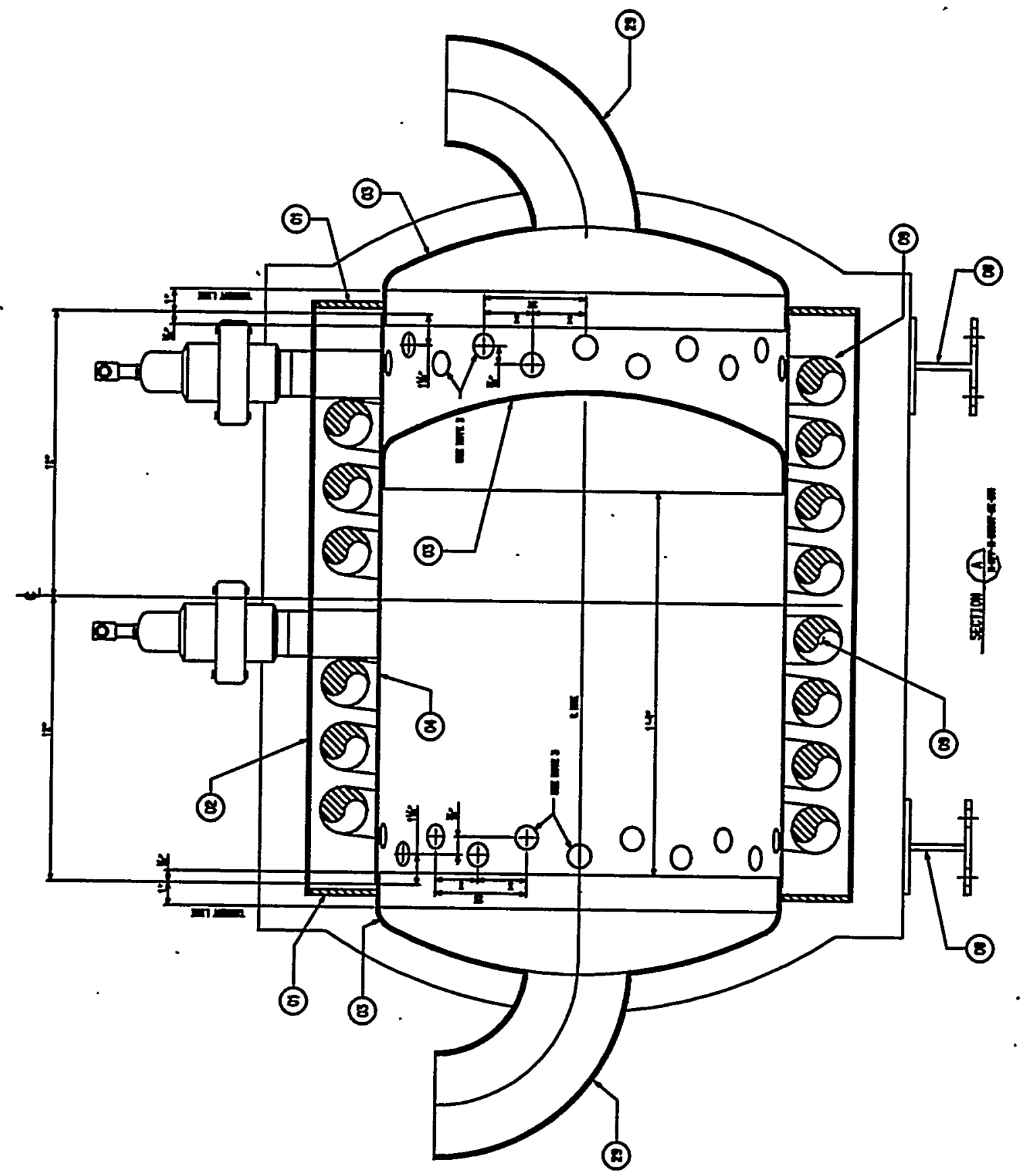

Figure 3.2 Detailed Fabrication Drawing of TCAP Heat Exchanger 


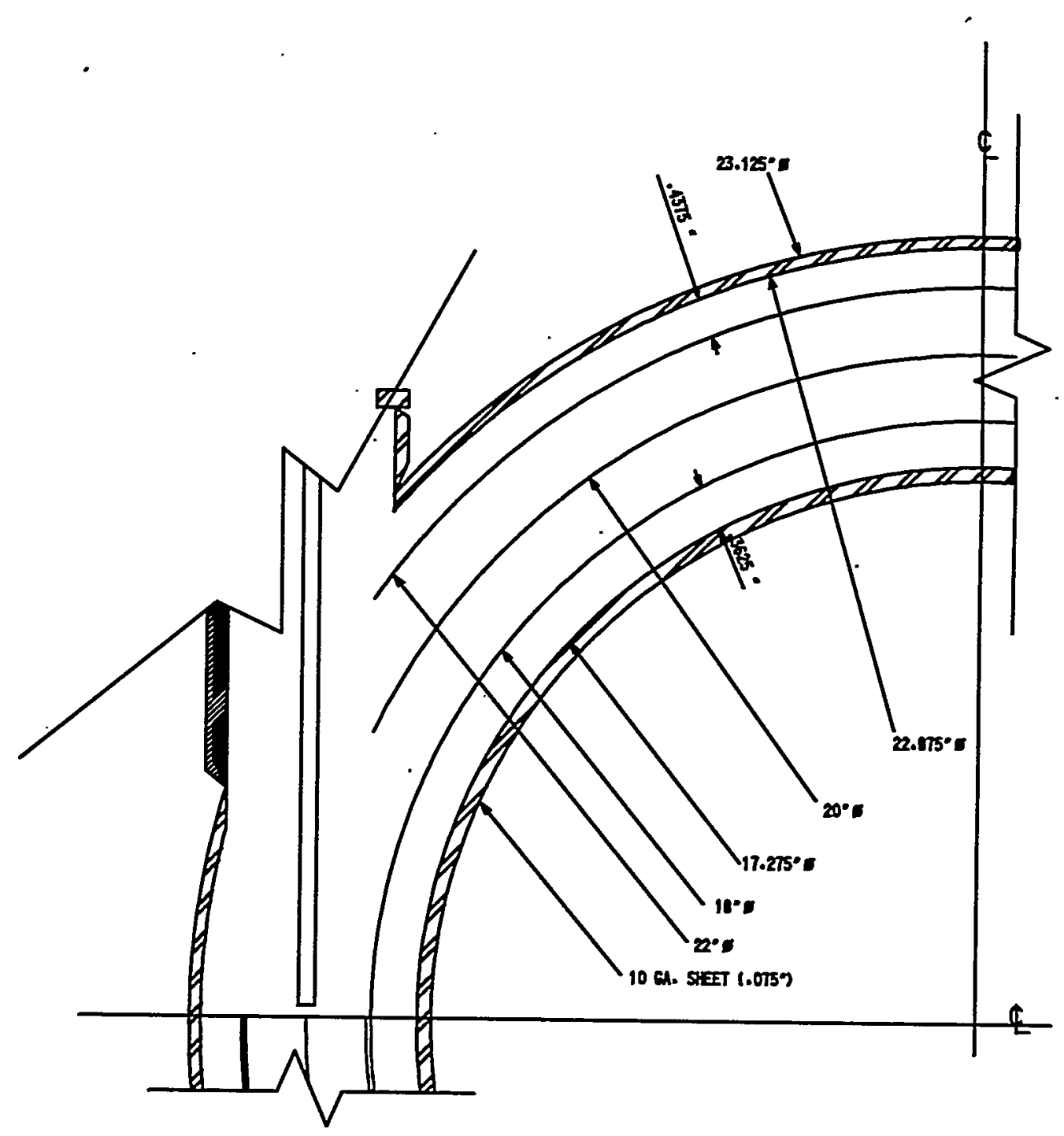

Figure 3.3 Detailed Fabrication Drawing of Column in Annulus 


\begin{tabular}{|c|c|c|c|c|c|}
\hline \multicolumn{6}{|c|}{ BILL of MTERINL } \\
\hline ITEH HO. & OUATITY & DESCRIPTIOH & DINENSIOKS & TEIGH JNCONEL 625 & AREA \\
\hline 01 & 2 & FLAT BEND, 58-443, NLLOY RO6G25 (GRUDE U) & $23 / 1 / 2 \times 171 / 6 \times 1 / 4$ & $15 \mathrm{LB}$. & $1.4 \mathrm{FT}^{2}$ \\
\hline 02 & 2 & 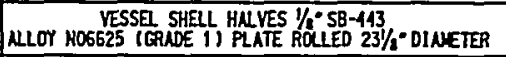 & $23 \% \mathrm{k} \times 75.25 \times .125$ & $68 \mathrm{LB}$. & $12.4 \mathrm{FT}^{2}$ \\
\hline 03 & 3 & 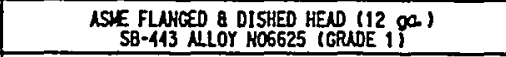 & $171 / y^{\circ} 0.0 . \times .1054^{\circ}$ & 12 LB. & $0.75 \mathrm{FT}^{1.94 \mathrm{FT}^{2}}$ flanos \\
\hline or & 1 & 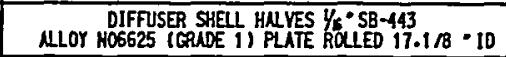 & $22.0 \times 53.8 \times .075$ & $27 \mathrm{LB}$. & $8.2 \mathrm{fT}^{2}$ \\
\hline 05 & 4 & 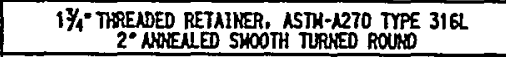 & & & \\
\hline$\infty 6$ & 1 & 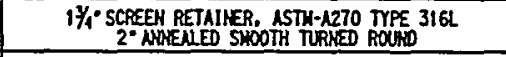 & & & \\
\hline 07 & 1 & $\begin{array}{l}2.00^{\circ} 00.065^{\circ} \text { YMLL HEEICLL COIL, SA-213 } \\
\text { TYPE 316L TUBE, } 20^{\prime} \text { LOAG }\end{array}$ & & & \\
\hline 08 & 2 & $\begin{array}{c}\text { YESSE SLOQE SUPPORT } 1 / 9^{\circ} \\
\text { SA-240 TYPE 3OA1 PLATE }\end{array}$ & & & \\
\hline 09 & 2 & $\begin{array}{l}\text { COPPER FOMN 78 DEHSITY, } 10 \text { PORE PER IHEH } \\
\text { (GRG OR ASTROKET) }\end{array}$ & $1.878 \cdot 0.0 . \times 2 \cdot$ LOHG & & \\
\hline 10 & 3 & $\begin{array}{c}1 \% / 4 \cdot \text { SCH. } 105 \text { SEMLESS SST BY CAP } \\
\text { A03-PP3IGL }\end{array}$ & & & \\
\hline 11 & 4 & 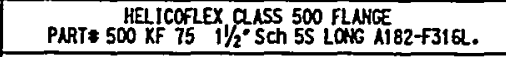 & & & \\
\hline 12 & 4 & $\begin{array}{l}\text { HEIICOFLEX CQASS } 500 \text { OUICX DISCOAACCT FLAHGE } \\
\text { PARTE } 500 \text { B } 75 \text { 304L. }\end{array}$ & & & \\
\hline 13 & 4 & $\begin{array}{l}\text { HEIICOFLEX SELL } \\
\text { PART } * \text { HL } 290 P \text { P }-3.2 \times 75 \text { SILVER. }\end{array}$ & $\cdot$ & • & \\
\hline 14 & 2 & $\begin{array}{l}\text { HELICOFLEX CLASS } 500 \text { FLANCEE } \\
\text { PART } 500 \text { KF } 75 \text { 2. TUBE SHORT A182 F316L. }\end{array}$ & & & \\
\hline 15 & 1 & HOTT FILTER 5 MICROH 316L & & & \\
\hline 16 & AR & 325 IESH 31EL SST SCREEH & - & & \\
\hline 17 & AR & 40 KESH 31EL SST SCREEH & & & \\
\hline 18 & 4 & CANOW YCR PLUG SS-8-YCR-P & & & \\
\hline 19 & 1 & CAJOH YCR GASXET MI-8-VCR-2-CR & & & \\
\hline 20 & 4 & CAJOK YCR FEULEE WUT SS-8-YCR-9 & & & \\
\hline 21 & 4 & 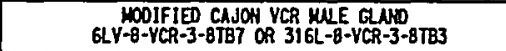 & & & \\
\hline 22 & 4 & $\begin{array}{l}\text { CAJOH TUBE SOCKET YELD FEUME CONACTOR } \\
\text { HO. SS-4-TSY-7-2 OR GLY-A-TSY-7-2 }\end{array}$ & & & \\
\hline 23 & 4 & $\begin{array}{c}11 / 2=\text { SCH.55 SENAESS SST } 15 \text { EBOY } \\
\text { A403-YYPS16L }\end{array}$ & & & \\
\hline 24 & 4 & 21/2" SCH.10S A312-TP3O1L SENLESS PIPE & & & \\
\hline 25 & 4 & $\begin{array}{l}\text { EPD PLATE } \\
1 / 2-5 A-210 \text { TYPE } 301 L \text { RATE }\end{array}$ & & & \\
\hline 26 & 4 & $\begin{array}{c}\text { CAJOH BUTT YED ELEOY } \\
\text { 316L-8TB7-9 }\end{array}$ & & & \\
\hline 27 & 4 & $1 / 2^{*} .065$ YALL SA-213 TPE 316L TUBIHG & & & \\
\hline 28 & 2 & $\begin{array}{l}\text { THER WOYELL TUEE } \\
*^{\circ} .065 \text { YMLL SA-213 TYPE } 316 L \text { TUBIMG }\end{array}$ & & & . \\
\hline 29 & 2 & $1^{\circ}$ LR $90^{\circ}$ SCH.10S SEAKESS ELBOY A403-4P3O1L & & 5 LB. & \\
\hline
\end{tabular}

\section{Figure 3.4 Bill of Materials for TCAP Heat Exchanger}


WSRC-TR-99-00348, Rev. 2

Table 3.2. Van't Hoff Equation Parameters for the Pd/k Hydrogen System (Heung, [1997a])

\begin{tabular}{|l|l|}
\hline H2 Heat of Absorption & $-8880 \mathrm{Cal} / \mathrm{Mole} \mathrm{H} 2$ (-35.3 Btu/Mole H2) \\
\hline H2 Heat of Desorption & $9800 \mathrm{Cal} /$ Mole H2 (38.9 Btu/Mole H2) \\
\hline
\end{tabular}

Thermophysical properties for the gases and metals used are from Appendix A of Incropera [1990]. The thermophysical properties of the nitrogen and hydrogen will be taken at the time cycle average temperatures of $40^{\circ} \mathrm{F}$ for cold and $268^{\circ} \mathrm{F}$ for hot while at a nitrogen pressure of $10 \mathrm{~atm}$ and hydrogen pressure of $1 \mathrm{~atm}$.

Thermophysical properties for the metallic foam such as density and specific heat are equivalent to the pure copper or aluminum material of which the foam is made of and may also be found from Incropera [1990]. However, the information provided by ERG of Oakland, California, the manufacturer of the foam, states that the thermal conductivity of the aluminum foam for a $93.2 \%$ porosity is $4.7 \mathrm{Btu} / \mathrm{hr} \cdot \mathrm{ft} \cdot{ }^{\circ} \mathrm{F}$, and for copper foam of the same porosity (currently in development) is $8.0 \mathrm{Btu} / \mathrm{hr} \cdot \mathrm{ft} \cdot{ }^{\circ} \mathrm{F}$.

The material for the existing 1.25 inch TCAP packed column wall is 316 stainless steel. The new 2 inch column studied will be either copper or 316 stainless steel.

As previously mentioned, one of the critical parameters for efficient heat transfer is the hot and cold nitrogen supply temperatures. From Knight [1997], the target temperature of the $\mathrm{Pd} / \mathrm{k}$.during the cooling cycle is $-13^{\circ} \mathrm{F}\left(-25^{\circ} \mathrm{C}\right)$; and target temperature during heating cycle is $329^{\circ} \mathrm{F}\left(165^{\circ} \mathrm{C}\right)$. Klein et. al. [1997] state that the owner and operator of the existing TCAP heat exchanger has specified that a two-stage refrigerant compressor not be used due to maintenance concerns. The maximum cold 
nitrogen temperature of $-40^{\circ} \mathrm{F}$ is limited by commercially available single stage, halocarbon refrigerant compressors. Likewise, a $20^{\circ} \mathrm{F}$ increase above target heating temperature is expected to provide a comparable heating cycle time for that of cooling cycle. Therefore, the maximum cold nitrogen supply temperature will be set at $-40^{\circ} \mathrm{F}$, while the maximum hot nitrogen supply temperature will be set at $349^{\circ} \mathrm{F}$, and will not be varied. These maximum hot and cold nitrogen temperatures are also consistent with the design of the existing 1.25 inch diameter column heat exchanger.

The second consideration for the hot and cold nitrogen is its flow rate, which will be varied between $500 \mathrm{lbs} / \mathrm{hr}$ and 20,000 lbs/hr. An optimum flow rate will be determined and chosen for calculation of the nitrogen heat transfer coefficients and subsequent heating and cooling times of the $\mathrm{Pd} / \mathrm{k}$ in the new column. The selection of the optimum flow will consider pressure drop, as well as gain in cooling time versus increase in flow rate. The existing 1.25 inch heat exchanger has a design nitrogen flow rate of $3800 \mathrm{lbs} / \mathrm{hr}$, which will not be varied.

In summary, the existing TCAP heat exchanger will be evaluated with: 1) 3800 $\mathrm{lbs} / \mathrm{hr}$ hot and cold nitrogen flow; 2) $-40^{\circ} \mathrm{F}$ cold and $349^{\circ} \mathrm{F}$ hot nitrogen supply temperatures; 3) 1.25 inch outside diameter, 316 stainless steel column wall; 4) dimensions scaled down from new heat exchanger in Figures 3.2 - 3.4; and 4) No metal foam in packed column. The new TCAP heat exchanger will be evaluated with: 1) 500 to $20,000 \mathrm{lbs} / \mathrm{hr}$ hot and cold nitrogen flow; 2) $-40^{\circ} \mathrm{F}$ cold and $349^{\circ} \mathrm{F}$ hot nitrogen supply temperatures; 3) 2 inch outside diameter, (a) 316 stainless steel and (b) copper column wall; 4) dimensions for the new heat exchanger as shown in Figures 3.2 - 3.4; and 4) (a) No metal foam, (b) aluminum foam and (c) copper foam in packed column. 
WSRC-TR-99-00348, Rev. 2

\subsection{Shell Side - Nitrogen Heat Transfer Coefficients}

The shell side of the TCAP heat exchanger includes: 1) the inlet and outlet piping and fittings to and from the housing; 2) the entrance and exit sections of the housing including the inner shell; and 3) the annular space between the inner and outer shells containing the coiled packed column. The nitrogen side heat transfer coefficients are a function of the nitrogen flow velocity in these different sections. This velocity is dependent upon the nitrogen mass flow rate and the cross sectional area normal to the flow. For a given mass flow rate, the velocity and the pressure drop increase as the available flow area decreases. A high velocity yields a high heat transfer coefficient due to turbulence mixing created by shearing of the flow layers, and thus more rapid heating and cooling.

Due to the complicated nature of turbulence and modeling of internal flow in the turbulent regime $(\operatorname{Re}>2300)$, empirical correlations based upon experimentation are necessary to compute the Nusselt number and subsequently the heat transfer coefficient. As mentioned in Section 1.2, the Dittus-Boelter [1930] equation will be used to determine the heat transfer coefficient in unobstructed portions of the shell side of the heat exchanger including the inlet and outlet piping sections, and the entrance and exit sections of the housing including the inner shell.

The Dittus-Boelter equation for fully developed turbulent flow in smooth tubes is the following:

$$
{ }^{N u}{ }_{D}=0.023 \cdot \operatorname{Re}_{D}{ }^{0.8} \cdot \operatorname{Pr}^{0.4}
$$


Where

$$
\begin{aligned}
\mathrm{Nu}_{D} & =\frac{h \cdot \mathrm{D}}{\mathrm{k}} \\
\operatorname{Re}_{D} & =\frac{\rho \cdot \mathrm{V} \cdot \mathrm{D}}{\mu} \\
V & =\frac{\mathrm{w}}{\rho \cdot \mathrm{A}}
\end{aligned}
$$

Equation (3.1) is applicable for $R e_{D} \geq 10,000$. It is expected that this correlation is valid for all flows of hot/cold nitrogen between 500 and 20,000 lbs/hr. The nitrogen flows in the inlet/outlet piping sections and entrance and exit of the housing resemble that of pipe flow, and therefore Equations (3.1) - (3.3) are directly applicable. However, the nitrogen flow inside of the inner shell resembles that of a plenum, with a common inlet and outlet. For the flow inside the inner shell, an equivalent value for the diameter is necessary, therefore the hydraulic diameter will be used in Equations (3.1) - (3.3) per Incropera [1990]. For a concentric annulus, the hydraulic diameter is the difference between the outer and inner diameters. The inner diameter is found as an equivalent diameter for half of the cross sectional area of the inner shell, and the outer diameter is taken as the diameter of the inner shell. The thermophysical properties of nitrogen for the above equations are evaluated at the mean bulk fluid temperature.

As mentioned above, the heat transfer is directly dependent upon the velocity, or Reynolds number, the design of the heat exchanger should minimize the transverse distance or gap between the packed column in the annulus and the inner and outer shells 
until the pressure drop is prohibitively large or until the opening is too small to be fabricated. Irrespective of pressure drop, the gap between the $\mathrm{Pd} / \mathrm{k}$ packed column and the inner and outer shells forming the annulus is limited by the manufacturing tolerances of the packed column's coil diameter, dimensions of the fabricated inner and outer shells, and allowance for the thermal growth of the shells and packed column. Therefore, the gap between the outer shell and column is fixed at 0.4375 inch, the gap between the inner shell and column is fixed at 0.3625 inch (average of $0.4 \mathrm{inch}$ ) and will not be varied. The Nusselt correlations developed by Zukauskas for tube banks are based upon the maximum velocity around the tubes, which occurs in the gap between the packed column wall and the inner/outer shells in this arrangement. This equation was developed for conditions similar to but not exactly the same as the TCAP heat exchanger annulus. However, the validity of this correlation with the coiled arrangement is certain.

Coiled tubes are used in heat exchange equipment to obtain a large heat transfer per unit volume. Likewise, heat transfer to or from a bank of tubes in cross flow is prevalent in engineering applications. The flow within the series of tubes is dominated by boundary layer separation effects and wake interactions, which enhances heat transfer. The column turns at the front of the heat exchanger act as turbulence generators for the following column turns, enhancing heat transfer.

As mentioned in Section 1.2, the Zukauskas [1972] equation will be used to determine the heat transfer coefficient for the nitrogen flow over the coiled packed column in the annulus of the heat exchanger. The Zukauskas equation for flow over tube banks is:

$$
{ }^{N u} \mathrm{D}=\mathrm{C} \cdot \operatorname{Re}_{\mathrm{Dmax}}{ }^{\mathrm{m}} \cdot \mathrm{Pr}^{0.36} \cdot \mathrm{C}_{2}
$$


WSRC-TR-99-00348, Rev. 2

$$
\begin{aligned}
\mathrm{h}_{\mathrm{N}} & =\frac{\dot{\mathrm{Nu}} \mathrm{D} \cdot \mathrm{k}}{\mathrm{D}} \\
\operatorname{Re}_{\mathrm{Dmax}} & =\frac{\rho \cdot \mathrm{V}_{\max } \cdot \mathrm{D}}{\mu} \\
\mathrm{V}_{\max } & =\frac{\mathrm{w}}{\rho \cdot \mathrm{A}_{\text {annulus }}} \\
\mathrm{C}_{2} & =0.95
\end{aligned}
$$

Where $\mathrm{C}=0.27 \& \mathrm{~m}=0.63$ for $\mathrm{Re}_{\mathrm{Dmax}}$ from $10^{3}$ to $2 \times 10^{5}$, (subcritical flow) and $\mathrm{C}=0.021$ \& $m=0.84$ for $\operatorname{Re}_{D \max }$ from $2 \times 10^{5}$ to $2 \times 10^{6}$ (critical flow) for inline tube arrangements. Equation (3.2) is still applicable. For the varying flows of hot/cold nitrogen between 500 and $20,000 \mathrm{lbs} / \mathrm{hr}$, it is expected that the correlation for subcritical flow will be appropriate for all flow rates due to the 0.4 inch gap. Zukauskas' correlation was based upon 10 rows of tubes, but the packed column forms a cross pattern of 7 rows of tubes at any given cross section, therefore, a correction factor $\mathrm{C}_{2}$ must be applied - which is also provided by Zukauskas [1972]. The nitrogen thermophysical properties for the above equations are evaluated at the mean bulk fluid temperature.

It should be noted that Equations (3.5), (3.7) and (3.8) were developed for cross flow through perpendicular rows of tubes. In this case the coiled packed column in the annular space is not exactly perpendicular to the flow and forms a potential swirl path along the length of the heat exchanger. Presumably, some fraction of the nitrogen can flow through the swirl path and reduce the cross-flow portion of the nitrogen. This will reduce the maximum velocity and therefore the heat transfer coefficient found in equation 
(3.5). The percentage of the total flow that will take the swirl path can be found from Equation 5-60 in Perry [1963] and its modification from Heung [1999]. For compressible flow through a conduit, the flow rate is directly proportional to the flow area and inversely proportional to the square root of the flow path:

$$
\frac{G_{X}}{G_{S}}=\frac{\left(\frac{A}{L^{0.5}}\right)_{X}}{\left(\frac{A}{L^{0.5}}\right)_{S}}
$$

For approximation, the cross flow area is the gap between the packed column and the inner/outer shells, and the length is the coiled length of the column. The pitch distance between the sequential coil turns defines the swirl flow area, and the length is the uncoiled length of the column. It is expected that the swirl flow is small in comparison to the cross-flow area and can be neglected.

Due to the increase of the column cross section from the 1.25 inch to a 2 inch diameter column, the heat transfer area per volume decreased, and the heat flux of the column surface increases. The required increase is the same as the increase in volume per surface area of the column:

$$
\frac{\left(\frac{\mathrm{vol}}{\mathrm{A}}\right)_{2}}{\left(\frac{\mathrm{vol}}{\mathrm{A}}\right)_{1.25}}=1.7
$$

In order to achieve the same cycle time, the heat flux of the larger column must be approximately 1.7 times the smaller column. As can be shown by a general heat transfer 
equation, the required increase can be achieved by either increasing the heat transfer coefficient in the annulus over the packed column, increasing the heat transfer coefficient in the packed bed, and/or increasing the temperature difference between the nitrogen and $\mathrm{Pd} / \mathrm{k}$. Due to the restraint on the cold and hot nitrogen temperatures as mentioned above, the heat transfer coefficients must compensate for the inability to adjust the available temperature gradient. To increase the heat transfer coefficients, it is expected that the nitrogen flow rate for the 2 inch column will have to greatly exceed the existing flow rate of $3800 \mathrm{lbs} / \mathrm{hr}$ (at the same hot/cold temperatures), not only to compensate for the increased heat flux, but to compensate for the limitation on gap (maximum velocity) between column and inner and outer shells. The lower of the two heat transfer coefficients will limit the overall heat transfer from the $\mathrm{Pd} / \mathrm{k}$ to the nitrogen. Therefore, it would be erroneous to overlook the dependency of the overall heat transfer upon the heat transfer coefficient within the $\mathrm{Pd} / \mathrm{k}$ packed column.

\subsection{Tube Side - Pd/k Packed Column Heat Transfer Coefficients}

The tube side of the TCAP heat exchanger consists of the $\mathrm{Pd} / \mathrm{k}$ packed column, with and without embedded metal foam. The $\mathrm{Pd} / \mathrm{k}$ packed column is a packed bed with spherical particles of $\mathrm{Pd} / \mathrm{k}$ with a particle diameter of $0.001 \mathrm{ft}$ (Table 3.1), and packing void fraction of 0.34 in the bed and 0.4 at the column wall (assumption 10). As discussed in Section 1.2, extensive literature review was performed to determine the proper correlation to apply to this arrangement. From the U.S. DOE RDD-5 [1999], the nominal flow in the packed column is on the order of $0.5 \mathrm{slpm}$. At this minimal velocity, the Reynolds number based upon $\mathrm{Pd} / \mathrm{k}$ particle diameter approaches zero. The low Reynolds 
number allows the use of the Ofuchi and Kunii [1964] correlations for heat transfer coefficients and effective thermal conductivity within and at the wall of the packed column. However, the Reynolds number within the column must be calculated and is given by Ofuchi and Kunii:

$$
\operatorname{Re}_{\mathrm{m}}=\frac{\rho \cdot \mathrm{V}_{\mathrm{s}} \cdot \mathrm{D}_{\mathrm{p}}}{\mu}
$$

This correlation of Reynolds number is dependent upon the superficial velocity; that is, the velocity in the packed column as if the $\mathrm{Pd} / \mathrm{k}$ was absent. Ofuchi and Kunii reviewed the experimental data of many investigators that had studied thermal conductivity of packed beds with stagnant fluids. Neglecting radiation effects per Chen and Churchill [1963] from Section 1.2, Ofuchi and Kunii provide the following reduced equations for the effective thermal conductivity:

where

$$
k_{e}=k_{f}\left[\varepsilon+\left[\frac{(1-\varepsilon)}{\left(\phi+\frac{2}{3} \cdot \frac{k_{f}}{k_{s}}\right)}\right]\right]
$$

$$
\phi=\phi_{1}+\left(\phi_{1}-\phi_{2}\right) \cdot \frac{\varepsilon-0.260}{0.216}
$$

and $\phi_{1}$ and $\phi_{2}$ are a function of $k_{s} / k_{f}$, found graphically from Figure 3 of Ofuchi and Kunii [1964]. Equations (3.13) and (3.14) account both for the thermal conductivity of . the solid $\mathrm{Pd} / \mathrm{k}$ and the gaseous hydrogen. 
The heat transfer coefficient at the wall is a function of thermal conductivity at the wall. Ofuchi and Kunii provide the following reduced equation for Reynolds number approaching zero:

where

$$
\begin{gathered}
\mathrm{h}_{\mathrm{w}}=0+\left[\frac{\mathrm{D}_{\mathrm{p}}}{\mathrm{k}_{\mathrm{f}}} \cdot\left[\frac{1}{\left(\frac{\mathrm{k}_{\mathrm{ow}}}{\mathrm{k}_{\mathrm{f}}}\right)}-\frac{0.5}{\mathrm{k}_{\mathrm{e}}} \frac{\mathrm{k}_{\mathrm{f}}}{\mathrm{k}^{-1}}\right]^{-1}\right. \\
\mathrm{k}_{\mathrm{ow}}=\mathrm{k}_{\mathrm{f}}\left[\left(\varepsilon_{\mathrm{w}}\right) \cdot(2)+\left[\frac{\left(1-\varepsilon_{\mathrm{w}}\right)}{\left(\phi_{\mathrm{w}}+\frac{1}{3} \cdot \frac{\mathrm{k}_{\mathrm{f}}}{\mathrm{k}_{\mathrm{s}}}\right)}\right]\right]
\end{gathered}
$$

Equations (3.15) and (3.16) are correction factors and are a consequence of assuming the thermal conductivity is constant throughout the packed column. Again, with $\phi_{\mathrm{w}}$ as a function of $k_{s} / k_{f}$, found graphically from Figure 3 of Ofuchi and Kunii [1964]. With the effective thermal conductivity known within the packed column and the heat transfer coefficient found for the wall, the overall.effective heat transfer coefficient can be found for the packed column by considering thermal resistances in series.

$$
\mathrm{h}_{\mathrm{pdk}}=\left(\frac{\frac{\mathrm{D}}{2}}{\mathrm{k}_{\mathrm{e}}}+\frac{1}{\mathrm{~h}_{\mathrm{w}}}\right)^{-1}
$$

As discussed in the above nitrogen section, a higher heat transfer coefficient is needed for the larger diameter column to achieve a higher heat flux. In addition to this, as 
can be seen from equation (3.17), the overall heat transfer coefficient decreases as the diameter of the column increases. Without some means of enhancing the heat transfer in the packed column, comparable cooling/heating times for the 2 inch column cannot be obtained. The heat transfer in the packed column would decrease with the greater diameter and would continue to limit the overall heat transfer from the $P d / k$ to the nitrogen in the annulus. One way to improve the effective thermal conductivity of the packed column is the use of metallic foams. Because of the relatively small size of the $\mathrm{Pd} / \mathrm{k}$ particles, they can easily fill the pores of commercially available metal foams. Copper or aluminum foam is proposed in the design to improve heat transfer in the $\mathrm{Pd} / \mathrm{k}$ packed column.

In order to model the inclusion of metal foam in the column, an analysis must be made of the geometry of the metal foam and how the $\mathrm{Pd} / \mathrm{k}$ material is packed into this foam. The goal is to find an effective thermal conductivity of the packed bed with the $\mathrm{Pd} / \mathrm{k}$ material, the hydrogen gas, and the metal (aluminum or copper) foam. For simplification, the $\mathrm{Pd} / \mathrm{k}$ and hydrogen thermal conductivity will be combined and given the value calculated by Equation (3.13). This value will be used in the correlation for effective thermal conductivity of a cubic array with spherical inclusions provided by Roshenow [1985]. The metal foam is assigned a thermal conductivity provided by ERG, the foam manufacturer. Therefore, the effective thermal conductivity of the packed Pd/k column with metallic foam can be found by the following:

$$
\mathrm{k}_{\text {effwfoam }}{ }^{\mathrm{k}} \text { foam }\left[1-\Delta \cdot\left[1+\frac{\gamma}{\sqrt{-\gamma-1}} \cdot\left(\cot \left(\frac{1}{\sqrt{-\gamma-1}}\right)\right)\right]\right]^{-1}
$$


WSRC-TR-99-00348, Rev. 2

Where

$$
\Delta=\left[\frac{\mathrm{p}}{\left(\frac{\pi}{6}\right)}\right]^{\left(\frac{1}{3}\right)}
$$

and

$$
\gamma=\frac{\left(\frac{4}{\pi \cdot \Delta^{2}}\right) \cdot \frac{\mathrm{k}_{\text {foam }}}{\mathrm{k}_{\mathrm{e}}}}{\left(1-\frac{\mathrm{k}_{\text {foam }}}{\mathrm{k}_{\mathrm{e}}}\right)}
$$

Equation (3.19) provides a characteristic length as a function of the porosity of the foam. Equation (3.20) is an assigned variable for the calculation of the effective thermal conductivity in the cubic array. Once the effective thermal conductivity of the packed column with metal foam has been found with Equation (3.18), a correlation can be made as in Equation (3.17) to find the overall effective heat transfer coefficient for the packed column with foam by considering thermal resistances in series and including a contact resistance between the foam and the column wall. The contact resistance, or contact conductance, varies by material types and has been provided by Cengel [1998]. The overall effective heat transfer coefficient in the packed bed with metal foam can be found by:

$$
\mathrm{h}_{\text {pdkfoam }}=\left(\frac{\mathrm{D}}{\frac{2}{\mathrm{k}_{\text {effwfoam }}}}+\frac{1}{\mathrm{~h}_{\mathrm{w}}}+\frac{1}{\mathrm{~h}_{\text {contact }}}\right)^{-1}
$$




\subsection{Overall Heat Transfer Coefficient at Pd/k Column Wall}

The heat transfer rate between the cold (or hot) nitrogen and the $\mathrm{Pd} / \mathrm{k}$ is determined by three resistances: 1) from Pd/k to column wall, 2) through the column wall, and 3) from column wall to nitrogen. It can be shown that the resistance of the column wall is very small and can be neglected, leaving 1 and 3 as the controlling resistances. For the purposes of comparing the overall heat transfer coefficient from the $\mathrm{Pd} / \mathrm{k}$ to the nitrogen for varying column geometry and composition, thermal resistances in series may be utilized, and will follow the form of:

$$
\mathrm{U}_{\mathrm{O}}=\left[\frac{1}{\mathrm{~h}_{\mathrm{N}}}+\frac{\frac{\mathrm{D}_{\mathrm{o}}}{2} \cdot \ln \left(\frac{\mathrm{D}_{\mathrm{o}}}{\mathrm{D}_{\mathrm{i}}}\right)}{\mathrm{k}_{\text {colwall }}}+\frac{1}{\mathrm{~h}_{\mathrm{pdk}}}\right]^{-1}
$$

for the packed column without embedded metal foam, and:

$$
\mathrm{U}_{\mathrm{O}}=\left[\frac{1}{\mathrm{~h}_{\mathrm{N}}}+\frac{\frac{\mathrm{D}_{\mathrm{o}}}{2} \cdot \ln \left(\frac{\mathrm{D}_{\mathrm{o}}}{\mathrm{D}_{\mathrm{i}}}\right)}{\mathrm{k}_{\text {colwall }}}+\frac{1}{\mathrm{~h}_{\text {pdkfoam }}}\right]^{-1}
$$

for the packed column with embedded metal foam. For thin walled piping or vessels it is customary to neglect the conductive resistance through the wall due to its relatively 
insignificant impact upon the overall heat transfer. However, in this study, the conductive resistance through the column wall will be included.

\subsection{Heats of Reaction}

Absorption and desorption of hydrogen into or from the $\mathrm{Pd} / \mathrm{k}$ is a surface phenomenon and the mass transfer is uniform as long as the sites for absorption and desorption are available. As the hydrogen gas in the $\mathrm{Pd} / \mathrm{k}$ column is cooled and absorbed by the palladium to form a metal-hydride, a heat of reaction is released, causing the $\mathrm{Pd} / \mathrm{k}$ temperature to increase. This exothermic chemical heat of absorption is linearly proportional to the temperature change of the $\mathrm{Pd} / \mathrm{k}$ and hydrogen compound. Due to its linear dependence upon temperature, the total amount of energy can be determined based upon the number of moles of hydrogen in the column and divided by the total temperature swing of the $\mathrm{Pd} / \mathrm{k}$-hydrogen compound. This ratio of energy to temperature change provides a quantity commonly called heat capacitance - the product of the mass and specific heat of the material. Similarly, as the hydrogen gas in the $\mathrm{Pd} / \mathrm{k}$ column is heated and desorbed by the palladium, a heat of reaction is released, decreasing the temperature of the $\mathrm{Pd} / \mathrm{k}$. This endothermic chemical heat of desorption is also linear to the temperature swing of the $\mathrm{Pd} / \mathrm{k}$ and hydrogen compound and can be calculated as a heat capacitance. These equivalent heat capacitances for absorption and desorption of hydrogen will be used in a manner similar to the heat capacitances (product of mass and specific heat) calculated for the other sections within the heat exchanger. 
WSRC-TR-99-00348, Rev. 2

\subsection{Transient Temperature Calculation}

Equipped with: 1) the thermophysical properties of metals and gases; 2) masses, volumes, and areas of the heat exchanger; and 3) heat transfer coefficients of the shell side and column side of the heat exchanger, the temperature response of the $\mathrm{Pd} / \mathrm{k}$ column to a step change of the nitrogen temperature can now be calculated. Due to the $\mathrm{Pd} / \mathrm{k}$ temperature variation from $329^{\circ} \mathrm{F}$ during hot cycle to $-13^{\circ} \mathrm{F}$ during the cold cycle, this calculation will be based on transient analysis of the heat transfer across the heat exchanger as a function of time.

In order to develop a method for calculating the transient temperature change within the heat exchanger over an increment of time, the first law of thermodynamics, or conservation of energy must be applied. In this approach, a fixed control volume analysis will be used to analyze the mass and heat transfers across its boundaries over a specified time interval. Over the given time interval, there must be a balance between all energy changes within the control volume. Here, the conservation of energy equation can be introduced as:

$$
\frac{d}{d t} E_{\text {in }}+\frac{d}{d t} E_{g} \cdot-\frac{d}{d t} E_{\text {out }}=\frac{d}{d t} E_{s t}
$$

The second ferm, the thermal energy generation rate, is associated with the rate of conversion of chemical energy to thermal energy - as in the case of heat of absorption . and desorption. As discussed in Section 3.7, this heat generation will be combined with the heat capacitance stored in the $\mathrm{Pd} / \mathrm{k}$ column. Therefore equation (3.24) may be reduced to a more familiar form:

$$
\frac{\mathrm{d}}{\mathrm{dt}} \mathrm{E}_{\text {in }}-\frac{\mathrm{d}}{\mathrm{dt}} \mathrm{E}_{\text {out }}=\frac{\mathrm{d}}{\mathrm{dt}} \mathrm{E}_{\mathrm{st}}
$$


WSRC-TR-99-00348, Rev. 2

or in terms of convection and capacitance:

$$
{ }^{w} \cdot c_{p} \cdot\left(T_{\text {in }}-T_{\text {out }}\right)=h_{c} \cdot A \cdot\left(T_{s}-T_{\infty}\right)=m \cdot c \cdot \frac{T_{i}-T_{f}}{\Delta t}
$$

Equation (3.26) can be used on a time interval basis to find an energy balance between the energy change in the flowing heat transfer medium, the convective heat transfer within the shell side or column side of the heat exchanger, and change in energy storage due to temperature change in the mass being cooled or heated. Equation (3.26) allows the calculation of heat transfer between the nitrogen and an exposed section within the heat exchanger, with the section's temperature change equivalent to the energy transferred during the specified time interval divided by its capacitance. This same explanation lends itself to the calculation of temperature change for the hot and cold nitrogen as it flows through the heat exchanger. Equation (3.26) is also applicable to heat transfer within the packed column.

The transient analysis for this heat transfer calculation has been performed by dividing the heat exchanger into several sections (control volumes) and considering the temperature profiles for each section. The heat exchanger is first broken into two halves of equivalent geometry and capacity. The inlet to center point contains one coiled column, and the center point to outlet contains the second coiled column. This not only provides for a more concise model, but also allows the study of the two packed columns as separate entities. Within each of the two halves, five sections were designated, for a total of ten sections in the analysis. All results are based upon achieving the cooling or 
heating target temperatures for the entire $\mathrm{Pd} / \mathrm{k}$ packed column. The ten sections of the heat exchanger are shown in Figure 3.5 and are designated as follows:

1. Inlet Tee - the piping and pipe fittings from the nitrogen isolation valve to the heat exchanger inlet.

2. Entrance - the inlet dished head, one end plate, $80 \%$ of the inner shell and the baffle at the end of the inner shell (plenum)

3. Outer shell 1 - from inlet to center point of the heat exchanger (50\% of the outer shell).

4. Column wall 1 - from inlet to center point of the heat exchanger ( $50 \%$ of the column wall).

5. $\mathrm{Pd} / \mathrm{k} 1-50 \%$ of the $\mathrm{Pd} / \mathrm{k}$ inside of the column, including foam if appropriate, and the equivalent capacitance of the heat of absorption/desorption, from inlet to center point of the heat exchanger.

6. Outer shell $2-50 \%$ of the outer shell, from center point to outlet of the heat exchanger.

7. Column wall $2-50 \%$ of the column wall, from center point to outlet of the heat exchanger.

8. $\mathrm{Pd} / \mathrm{k} 2-50 \%$ of the $\mathrm{Pd} / \mathrm{k}$ inside of the column, including foam if appropriate, and the equivalent capacitance of the heat of absorption/desorption, from center point to outlet of the heat exchanger.

9. Exit - the end plate, $20 \%$ of the inner shell and one dished head.

10. Outlet Tee - the piping and pipe fittings from the heat exchanger outlet to the nitrogen isolation valve. 


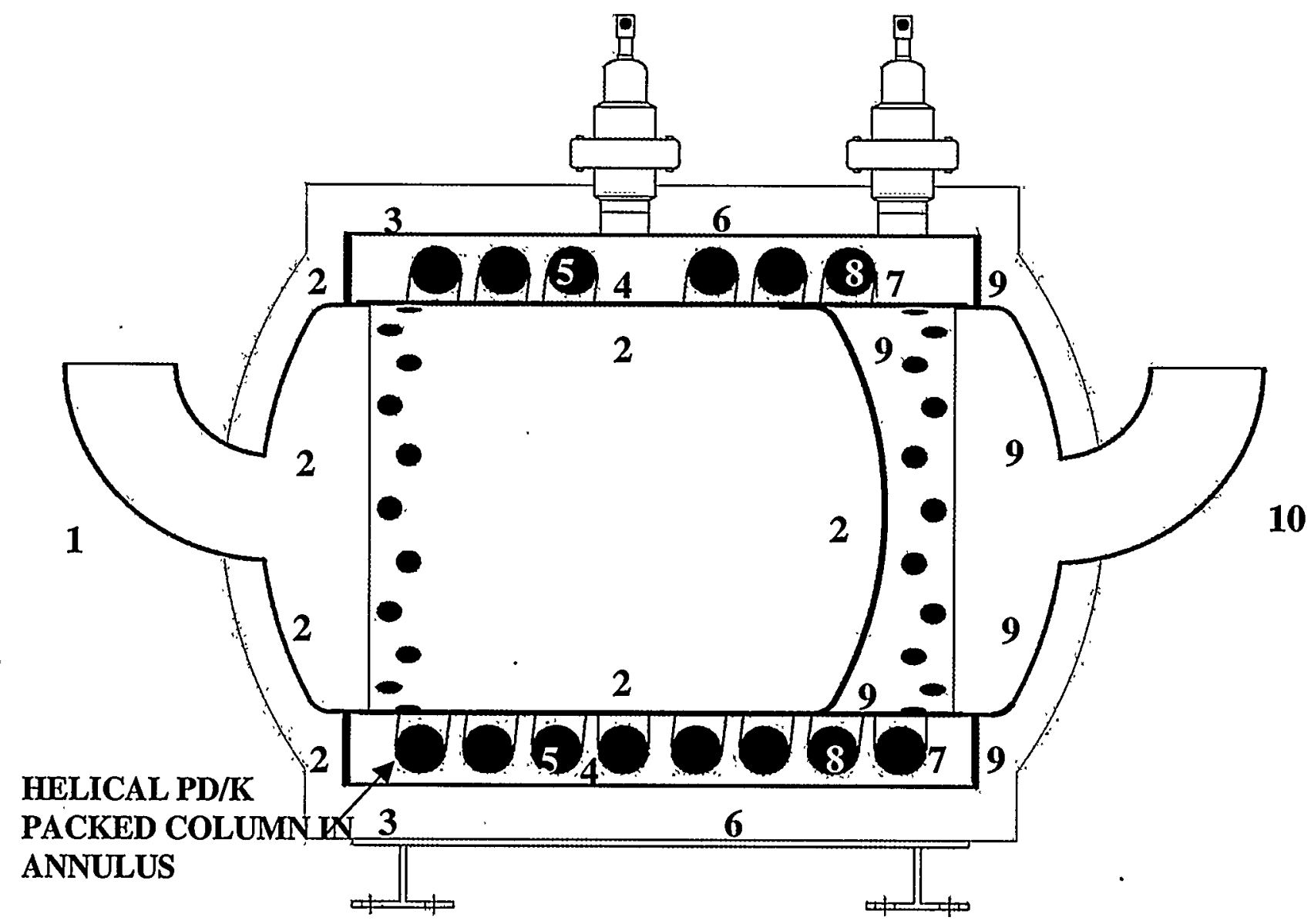

FIGURE 3.5:AXIAL CROSS SECTION OF TCAP HEAT EXCHANGER SHOWING SECTIONS AS USED IN TRANSIENT TEMPERATURE CALCULATIONS 
Applying equation (3.26) to the ten sections, with the initial section and inlet nitrogen temperatures known, the heat transfer is calculated during a specified time increment based upon the corresponding convective heat transfer coefficient. This heat transfer is equated to the heat capacitance (product of mass and specific heat) of the section to estimate its new temperature for the same time interval. This amount of energy is also equated to the nitrogen mass flow rate in the same time increment to estimate the exit temperature of the nitrogen which becomes the inlet nitrogen temperature to the succeeding section.

Consistent with Equations (3.25) and (3.26) the following method is used to conduct the calculation:

- At the beginning of the hot or cold cycle, all sections are initially at their target temperature. $\mathrm{TXi}_{\mathrm{n}}=-13^{\circ} \mathrm{F}$ or $329^{\circ} \mathrm{F}$

- The nitrogen entering the inlet tee to the heat exchanger remains constant at the supply temperature, $\mathrm{TN}=-40^{\circ} \mathrm{F}$ or $329^{\circ} \mathrm{F}$, at a chosen flow rate, $w$.

- The following equations are based upon the cooling cycle and can be applied to the heating cycle in a similar manner, with strict attention to the sign convention used in the equations. In the case of cooling, the heat gained by the nitrogen in each section must equal the heat lost by the mass in that section.

- In a finite time interval $(\Delta t)$, the heat transfer equations are:

For time zero, in initial state, with $\mathbf{n}=\mathbf{0}$ 
a) Section 1 (Inlet Tee):

$\Delta \mathrm{Q} 1_{\mathrm{n}}=\mathrm{h} 1 \cdot \mathrm{A} 1 \cdot\left(\mathrm{T} 1_{\mathrm{i}_{\mathrm{n}}}-\mathrm{TN}\right) \cdot \Delta \mathrm{t} \quad$ Heat loss from Inlet tee area to nitrogen

$\mathrm{T} 1_{\mathrm{f}}=\mathrm{T} 1_{\mathrm{i}_{\mathrm{n}}}-\left(\frac{\Delta \mathrm{Q} 1_{\mathrm{n}}}{\mathrm{m} 1 \cdot \mathrm{Cp} 1}\right)$

Final temperature of Inlet Tee due to heat removed

$\mathrm{TN1} \mathrm{f}_{\mathrm{n}}=\left(\frac{\Delta \mathrm{Q} 1_{\mathrm{n}}}{\mathrm{wN} \cdot \mathrm{CpN} \cdot \Delta \mathrm{t}}\right)+\mathrm{TN}$

Temperature of nitrogen leaving Inlet Tee due to heat gain, entering Entrance

b) Section 2 (Entrance):

$\Delta \mathrm{Q} 2_{\mathrm{n}}=\mathrm{h} 2 \cdot \mathrm{A} 2 \cdot\left(\mathrm{T} 2_{\mathrm{i}_{\mathrm{n}}}-\mathrm{TN} \mathrm{f}_{\mathrm{n}}\right) \cdot \Delta t \cdot$ Heat loss from Entrance area to nitrogen $\mathrm{T} 2_{\mathrm{f}}=\mathrm{T} 2_{\mathrm{n}}-\left(\frac{\Delta \mathrm{Q} 2_{\mathrm{n}}}{\mathrm{m} 2 \cdot \mathrm{Cp} 2}\right) \quad \begin{aligned} & \text { Final temperature of Entrance due to heat } \\ & \text { removed }\end{aligned}$ $\mathrm{TN} 2_{\mathrm{n}}=\left(\frac{\Delta \mathrm{Q} 2_{\mathrm{n}}}{\mathrm{wN} \cdot \mathrm{CpN} \cdot \Delta \mathrm{t}}\right)+\mathrm{TN} 1_{\mathrm{n}} \quad \begin{aligned} & \text { Temperature of nitrogen leaving Entrance } \\ & \text { due to heat gain, entering Outer Shell } 1\end{aligned}$

c) Section 3 (Outer Shell 1):

$\Delta Q 3_{n}=h 3 \cdot A 3 \cdot\left(T 3_{i_{n}}-T N 2 f_{n}\right) \cdot \Delta t \quad$ Heat loss from Outer Shell 1 area to nitrogen $\mathrm{T} 3_{\mathrm{f}_{\mathrm{n}}}=\mathrm{T} 3_{\mathrm{i}_{\mathrm{n}}}-\left(\frac{\Delta \mathrm{Q} 3_{\mathrm{n}}}{\mathrm{m} 3 \cdot \mathrm{Cp} 3}\right) \quad \begin{aligned} & \text { Final temperature of Outer Shell } 1 \text { due to } \\ & \text { heat removed }\end{aligned}$ ${ }^{\mathrm{TN}} 3_{\mathrm{f}_{\mathrm{n}}}=\left(\frac{\Delta \mathrm{Q} 3_{\mathrm{n}}}{\mathrm{wN} \cdot \mathrm{CpN} \cdot \Delta \mathrm{t}}\right)+\mathrm{TN} 2_{\mathrm{f}_{\mathrm{n}}} \quad \begin{aligned} & \text { Temperature of nitrogen leaving Outer Shell } \\ & 1 \text { due to heat gain, entering Column Wall } 1\end{aligned}$ 
d) Section 4 (Column Wall 1):

$\Delta 4_{n}=h 4 \cdot A 4 \cdot\left(T 4_{i_{n}}-T N 3_{f}\right) \cdot \Delta t \quad \begin{aligned} & \text { Heat loss from Column Wall } 1 \text { area to } \\ & \text { nitrogen }\end{aligned}$ $\mathrm{T}^{\prime} \mathrm{f}_{\mathrm{n}}=\mathrm{T} 4_{\mathrm{i}_{\mathrm{n}}}-\left(\frac{\Delta \mathrm{Q}_{\mathrm{n}}}{\mathrm{m} 4 \cdot \mathrm{Cp} 4}\right)$

Intermittent final temperature of Column Wall 1 due to heat removed

$\mathrm{TN}^{\prime} \mathrm{f}_{\mathrm{n}}=\left(\frac{\Delta \mathrm{Q}_{\mathrm{n}}}{w \mathrm{~N} \cdot \mathrm{CpN} \cdot \Delta \mathrm{t}}\right)+\mathrm{TN} 3_{\mathrm{f}_{\mathrm{n}}}$

Intermittent temperature of nitrogen leaving Column Wall 1 due to heat gain, entering Outer Shell 2.

e) Section $5(\mathrm{Pd} / \mathrm{k} /($ foam $) 1)$ :

$$
\begin{aligned}
& \Delta \mathrm{Q}_{\mathrm{n}}=\mathrm{h} 5 \cdot \mathrm{A5} \cdot\left(\mathrm{T}_{\mathrm{i}_{\mathrm{n}}}-\mathrm{T} 4^{\prime} \mathrm{f}_{\mathrm{n}}\right) \cdot \Delta \mathrm{t} \\
& \mathrm{T} 5^{\prime} \mathrm{f}_{\mathrm{n}}=\mathrm{T} 5_{\mathrm{i}}-\left(\frac{\Delta \mathrm{Q} 5_{\mathrm{n}}}{\mathrm{m} 5 \cdot \mathrm{Cp} 5}\right)
\end{aligned}
$$

Heat loss from $\mathrm{Pd} / \mathrm{k} /$ (foam) 1 to Column Wall 1 at intermittent temperature

Intermittent final temperature of $\mathrm{Pd} / \mathrm{k} /$ (foam) 1 due to heat removed

$\mathrm{T} 4_{\mathrm{f}}=\mathrm{T} 4_{\mathrm{i}_{\mathrm{n}}}-\left(\frac{\Delta \mathrm{Q} 4_{\mathrm{n}}-\Delta \mathrm{Q} 5_{\mathrm{n}}}{\mathrm{m} 4 \cdot \mathrm{Cp} 4}\right)$

Corrected final temperature of Column Wall 1 due to heat supplied from $\mathrm{Pd} / \mathrm{k} /$ (foam)

$\mathrm{TN} 4_{\mathrm{f}}=\left(\frac{\Delta \mathrm{Q} 4_{n}-\Delta \mathrm{Q} 5_{\mathrm{n}}}{\mathrm{wN} \cdot \mathrm{CpN} \cdot \Delta \mathrm{t}}\right)+\mathrm{TN} 3_{\mathrm{f}_{\mathrm{n}}}$

Corrected temperature of nitrogen leaving Column Wall 1 due to heat gain, entering Outer Shell 2.

$\Delta$ Qgen $_{n}=\operatorname{Cgen} 5 \cdot\left(\mathrm{T}_{\mathrm{i}_{n}}-\mathrm{T}^{\prime} \mathrm{f}_{\mathrm{n}}\right) \cdot \Delta t \quad \begin{aligned} & \text { Heat generation from absorption of } \\ & \text { hydrogen in } \mathrm{Pd} / \mathrm{k} 1\end{aligned}$ $\mathrm{T} 5_{\mathrm{f}_{\mathrm{n}}}=\mathrm{T} 5^{\prime} \mathrm{f}_{\mathrm{n}}+\left(\frac{\Delta \text { Qgens }_{\mathrm{n}}}{\mathrm{m} 5 \cdot \mathrm{Cp} 5}\right)$

Corrected final temperature of $\mathrm{Pd} / \mathrm{k} /$ (foam) 1 due to heat of absorption 
WSRC-TR-99-00348, Rev. 2

f) Section 6 (Outer Shell 2):

$\Delta \mathrm{Q}_{\mathrm{n}}=\mathrm{h} 6 \cdot \mathrm{A} 6 \cdot\left(\mathrm{T}_{\mathrm{i}_{\mathrm{n}}}-\mathrm{TN} 4_{\mathrm{f}}\right) \cdot \Delta \mathrm{t} \quad$ Heat loss from Outer Shell 2 area to nitrogen $\mathrm{T}_{\mathrm{f}_{\mathrm{n}}}=\mathrm{T} 6_{\mathrm{i}_{\mathrm{n}}}-\left(\frac{\Delta \mathrm{Q} 6_{\mathrm{n}}}{\mathrm{m} 6 \cdot \mathrm{Cp} 6}\right) \quad \cdot \quad \begin{gathered}\text { Final temperature of Outer Shell } 2 \text { due to } \\ \text { heat removed }\end{gathered}$ ${ }^{\mathrm{TN}} 6_{\mathrm{f}}=\left(\frac{\Delta \mathrm{Q}_{\mathrm{n}}}{\mathrm{wN} \cdot \mathrm{CpN} \cdot \Delta \mathrm{t}}\right)+\mathrm{TN} 4_{\mathrm{f}} \quad \begin{gathered}\text { Temperature of nitrogen leaving Outer Shell } \\ 2 \text { due to heat gain, entering Column Wall } 2\end{gathered}$

g) Section 7 (Column Wall 2):
$\Delta Q 77_{n}=h 7 \cdot A 7 \cdot\left({ }^{T} 7_{n}-T N 6_{f_{n}}\right) \cdot \Delta t \quad \begin{aligned} & \text { Heat loss from Column Wall } 2 \text { area to } \\ & \text { nitrogen }\end{aligned}$
$\mathrm{T} 7^{\prime} \mathrm{f}_{\mathrm{n}}=\mathrm{T} 7 \mathrm{i}_{\mathrm{n}}-\left(\frac{\Delta \mathrm{Q} 7_{\mathrm{n}}}{\mathrm{m} 7 \cdot \mathrm{Cp} 7}\right)$
Intermittent final temperature of Column Wall 2 due to heat removed
$\mathrm{TN}^{\prime} \mathrm{f}_{\mathrm{n}}=\left(\frac{\Delta \mathrm{Q} 7_{\mathrm{n}}}{\mathrm{wN} \cdot \mathrm{CpN} \cdot \Delta \mathrm{t}}\right)+\mathrm{TN}_{\mathrm{f}}$
Intermittent temperature of nitrogen leaving Column Wall 2 due to heat gain, entering Exit. 
WSRC-TR-99-00348, Rev. 2

h) Section $8(\mathrm{Pd} / \mathrm{k} /($ foam $) 2)$ :

$\Delta \mathrm{Q}_{\mathrm{n}}=\mathrm{h} 8 \cdot \mathrm{A8} \cdot\left(\mathrm{T} 8_{\mathrm{i}_{\mathrm{n}}}-\mathrm{T}^{\prime} \mathrm{f}_{\mathrm{n}}\right) \cdot \Delta \mathrm{t} \quad \begin{aligned} & \text { Heat loss from } \mathrm{Pd} / \mathrm{k} /(\text { foam }) 2 \text { to Column } \\ & \text { Wall } 2 \text { at intermittent temperature. }\end{aligned}$

$\mathrm{T}^{\prime}{ }_{\mathrm{f}_{\mathrm{n}}}=\mathrm{T} 8_{\mathrm{i}_{\mathrm{n}}}-\left(\frac{\Delta \mathrm{Q} 8_{\mathrm{n}}}{\mathrm{m} 8 \cdot \mathrm{Cp} 8}\right) \quad \begin{aligned} & \text { Intermittent final temperature of } \mathrm{Pd} / \mathrm{k} /(\text { foam }) \\ & 2 \text { due to heat removed }\end{aligned}$

$\mathrm{T} 7_{\mathrm{f}_{\mathrm{n}}}=\mathrm{T} 7_{\mathrm{i}_{\mathrm{n}}}-\left(\frac{\Delta \mathrm{Q} 7_{\mathrm{n}}-\Delta \mathrm{Q} 8 \mathrm{n}}{\mathrm{m} 7 \cdot \mathrm{Cp} 7}\right) \quad \begin{aligned} & \text { Corrected final temperature of Column Wall } \\ & 2 \text { due to heat supplied from } \mathrm{Pd} / \mathrm{k} /(\text { foam })\end{aligned}$

TN7 $f_{n}=\left(\frac{\Delta Q 7_{n}-\Delta Q 8_{n}}{w N \cdot C p N \cdot \Delta t}\right)+\mathrm{TN} f_{n} \quad \begin{aligned} & \text { Corrected temperature of nitrogen leaving } \\ & \text { Column Wall } 2 \text { due to heat gain, entering }\end{aligned}$ Exit.

$\Delta$ Qgen $_{n}=\operatorname{Cgen} 8 \cdot\left(T 8_{i_{n}}-T 8^{\prime} f_{n}\right) \cdot \Delta t \quad \begin{aligned} & \text { Heat generation from absorption of } \\ & \text { hydrogen in } P d / k 2\end{aligned}$ $\mathrm{T}_{\mathrm{n}}=\mathrm{T}^{\prime}{ }_{\mathrm{f}_{\mathrm{n}}}+\left(\frac{\Delta \text { Qgen }_{\mathrm{n}}}{\mathrm{m} 8 \cdot \mathrm{Cp} 8}\right) \quad \begin{aligned} & \text { Corrected final temperature of } \mathrm{Pd} / \mathrm{k}(\text { foam }) 2 \\ & \text { due to heat of absorption }\end{aligned}$

i) Section 9 (Exit):

$\Delta \mathrm{Q} 9_{\mathrm{n}}=\mathrm{h} 9 \cdot \mathrm{A} 9 \cdot\left(\mathrm{T}_{\mathrm{i}_{\mathrm{n}}}-\mathrm{TN7} \mathrm{f}_{\mathrm{n}}\right) \cdot \Delta \mathrm{t} \quad$ Heat loss from Exit area to nitrogen T9 $f_{n}=T 9_{i_{n}}-\left(\frac{\Delta Q 9_{n}}{m 9 \cdot C p 9}\right) \quad \begin{aligned} & \text { Final temperature of Exit due to heat } \\ & \text { removed }\end{aligned}$ TN9 $f_{n}=\left(\frac{\Delta Q 9_{n}}{w N \cdot C p N \cdot \Delta t}\right)+T N 7 f_{n} \quad \begin{aligned} & \text { Temperature of nitrogen leaving Exit due to } \\ & \text { heat gain, entering Outlet Tee }\end{aligned}$ 
j) Section 10 (Outlet Tee):

$\Delta Q 10_{n}=h 10 \cdot A 10 \cdot\left(\right.$ T10 $\left._{i_{n}}-{ }^{T N 9} f_{n}\right) \cdot \Delta t \quad$ Heat loss from Outlet Tee area to nitrogen $\mathrm{T} 10_{\mathrm{n}}=\mathrm{T} 10_{\mathrm{i}}-\left(\frac{\Delta \mathrm{Q} 10_{\mathrm{n}}}{\mathrm{m} 10 \cdot \mathrm{Cp} 10}\right) \quad \begin{aligned} & \text { Final temperature of Exit due to heat } \\ & \text { removed }\end{aligned}$ $\mathrm{TN}^{10} \mathrm{f}_{\mathrm{n}}=\left(\frac{\Delta \mathrm{Q} 10_{\mathrm{n}}}{\mathrm{wN} \cdot \mathrm{CpN} \cdot \Delta \mathrm{t}}\right)+\mathrm{TN} \mathrm{f}_{\mathrm{n}} \begin{aligned} & \text { Temperature of nitrogen leaving Outlet Tee } \\ & \text { and heat exchanger assembly }\end{aligned}$

- In the next and each subsequent time interval $(\Delta t)$ from $n=1,2,3 \ldots \infty$, the temperature of each component in each section is changed by the amount of heat it gained or lost in the previous interval. With these new temperatures, the heat transfer calculations are repeated. The new temperatures of the components in each section can be calculated by the following:

a) Section 1 (Inlet Tee):

$\Delta \mathrm{Q} 1_{\mathrm{n}}=\mathrm{h} 1 \cdot \mathrm{A} 1 \cdot\left(\mathrm{T} 1_{\mathrm{f}_{\mathrm{n}-1}}-\mathrm{TN}\right) \cdot \Delta \mathrm{t} \quad$ Heat loss from Inlet tee area to nitrogen $\mathrm{T} 1_{\mathrm{f}}=\mathrm{T} 1_{\mathrm{f}_{\mathrm{n}-1}}-\left(\frac{\Delta \mathrm{Q} 1_{\mathrm{n}}}{\mathrm{m} 1 \cdot \mathrm{Cp} 1}\right) \quad \begin{aligned} & \text { Final temperature of Inlet Tee due to heat } \\ & \text { removed }\end{aligned}$ $\mathrm{TN}_{\mathrm{f}_{\mathrm{n}}}=\left(\frac{\Delta \mathrm{Q} 1_{\mathrm{n}}}{\mathrm{wN} \cdot \mathrm{CpN} \cdot \Delta \mathrm{t}}\right)+\mathrm{TN} \quad \begin{aligned} & \text { Temperature of nitrogen leaving Inlet Tee } \\ & \text { due to heat gain, entering Entrance }\end{aligned}$ 
b) Section 2 (Entrance):

$\Delta \mathrm{Q}_{\mathrm{n}}=\mathrm{h} 2 \cdot \mathrm{A} 2 \cdot\left(\mathrm{T} 2_{\mathrm{f}_{\mathrm{n}-1}}-\mathrm{TN1} \mathrm{f}_{\mathrm{n}}\right) \cdot \Delta \mathrm{t}$ Heat loss from Entrance area to nitrogen $\mathrm{T} 2_{f_{n}}=T 2_{f_{n-1}}-\left(\frac{\Delta Q 2 n}{m 2 \cdot C p 2}\right) \quad \begin{aligned} & \text { Final temperature of Entrance due to heat } \\ & \text { removed }\end{aligned}$ $\mathrm{TN} 2_{\mathrm{n}}=\left(\frac{\Delta \mathrm{Q} 2_{\mathrm{n}}}{\mathrm{wN} \cdot \mathrm{CpN} \cdot \Delta \mathrm{t}}\right)+\mathrm{TN} 1_{\mathrm{f}_{\mathrm{n}}} \quad \begin{aligned} & \text { Temperature of nitrogen leaving Entrance } \\ & \text { due to heat gain, entering Outer Shell } 1\end{aligned}$

c) Section 3 (Outer Shell 1):

$\Delta \mathrm{Q}_{\mathrm{n}}=\mathrm{h} 3 \cdot \mathrm{A} 3 \cdot\left(\mathrm{T} 3 \mathrm{f}_{\mathrm{n}-1}-\mathrm{TN2} \mathrm{f}_{\mathrm{n}}\right) \cdot \Delta \mathrm{t}$ Heat loss from Outer Shell 1 area to nitrogen $\mathrm{T} 3_{\mathrm{f}}=\mathrm{T} 3 \mathrm{f}_{\mathrm{n}-1}-\left(\frac{\Delta \mathrm{Q} 3 \mathrm{n}}{\mathrm{m} 3 \cdot \mathrm{Cp} 3}\right) \quad \begin{aligned} & \text { Final temperature of Outer Shell } 1 \text { due to } \\ & \text { heat removed }\end{aligned}$ ${ }^{\mathrm{TN}} 3_{\mathrm{f}}=\left(\frac{\Delta \mathrm{Q} 3_{\mathrm{n}}}{\mathrm{wN} \cdot \mathrm{CpN} \cdot \Delta \mathrm{t}}\right)+\mathrm{TN2} \mathrm{f}_{\mathrm{n}} \begin{aligned} & \text { Temperature of nitrogen leaving Outer Shell } \\ & 1 \text { due to heat gain, entering Column Wall } 1\end{aligned}$

d) Section 4 (Column Wall 1):

$$
\begin{aligned}
& \Delta 4_{n}=h 4 \cdot A 4 \cdot\left(T 4_{f_{n-1}}-{ }^{T N 3} f_{n}\right) \cdot \Delta t \quad \begin{array}{l}
\text { Heat loss from Column Wall } 1 \text { area to } \\
\text { nitrogen }
\end{array} \\
& { }^{T} 4^{\prime}{ }_{\mathrm{n}}=\mathrm{T} 4_{\mathrm{f}_{\mathrm{n}-1}}-\left(\frac{\Delta \mathrm{Q} 4_{\mathrm{n}}}{\mathrm{m} 4 \cdot \mathrm{Cp} 4}\right) \quad \begin{array}{l}
\text { Intermittent final temperature of Column } \\
\text { Wall } 1 \text { due to heat removed }
\end{array} \\
& \mathrm{TN}^{\prime} \mathrm{f}_{\mathrm{n}}=\left(\frac{\Delta \mathrm{Q} 4_{\mathrm{n}}}{\mathrm{wN} \cdot \mathrm{CpN} \cdot \Delta \mathrm{t}}\right)+\mathrm{TN3} \mathrm{f}_{\mathrm{n}} \begin{array}{l}
\text { Intermittent temperature of nitrogen leaving } \\
\begin{array}{l}
\text { Column Wall 1 due to heat gain, entering } \\
\text { Outer Shell 2. }
\end{array}
\end{array}
\end{aligned}
$$


e) Section $5(\mathrm{Pd} / \mathrm{k} /($ foam $) 1)$ :

$$
\begin{aligned}
& \Delta \mathrm{Q}_{\mathrm{n}}=\mathrm{h} 5 \cdot \mathrm{A} 5 \cdot\left(\mathrm{T}^{5} \mathrm{f}_{\mathrm{n}-1}-\mathrm{T}^{\prime} \mathrm{f}_{\mathrm{n}}\right) \cdot \Delta \mathrm{t} \begin{array}{l}
\text { Heat loss from } \mathrm{Pd} / \mathrm{k} /(\text { foam }) \\
\text { Wall } 1 \text { at intermittent temperature }
\end{array} \\
& { }^{\mathrm{T} 5}{ }_{\mathrm{f}}=\mathrm{T} 5_{\mathrm{f}_{\mathrm{n}-1}}-\left(\frac{\Delta \mathrm{Q} 5_{\mathrm{n}}}{\mathrm{m} 5 \cdot \mathrm{Cp} 5}\right) \quad \begin{array}{l}
\text { Intermittent final temperature of } \mathrm{Pd} / \mathrm{k} /(\text { foam }) \\
1 \text { due to heat removed }
\end{array} \\
& \mathrm{T} 4_{\mathrm{f}}=\mathrm{T} 4_{\mathrm{f}_{\mathrm{n}-1}}-\left(\frac{\Delta \mathrm{Q} 4_{\mathrm{n}}-\Delta \mathrm{Q} 5 \mathrm{n}}{\mathrm{m} 4 \cdot \mathrm{Cp} 4}\right) \begin{array}{l}
\text { Corrected final temperature of Column Wall } \\
1 \text { due to heat supplied from } \mathrm{Pd} / \mathrm{k} /(\text { foam })
\end{array} \\
& \mathrm{TN}_{\mathrm{f}} \mathrm{f}_{\mathrm{n}}=\left(\frac{\Delta \mathrm{Q} 4_{\mathrm{n}}-\Delta \mathrm{Q} 5_{\mathrm{n}}}{\mathrm{wN} \cdot \mathrm{CpN} \cdot \Delta \mathrm{t}}\right)+\mathrm{TN} 3_{\mathrm{f}_{\mathrm{n}}} \quad \begin{array}{l}
\text { Corrected temperature of nitrogen leaving. } \\
\text { Column Wall 1 due to heat gain, entering }
\end{array} \\
& \text { Outer Shell } 2 . \\
& \Delta \text { Qgen }_{n}=\operatorname{Cgen} 5 \cdot\left(\mathrm{T}_{\mathrm{f}_{\mathrm{n}-1}}-\mathrm{T}^{\prime} \mathrm{f}_{\mathrm{n}}\right) \cdot \Delta \mathrm{t} \quad \begin{array}{l}
\text { Heat generation from absorption of } \\
\text { hydrogen in } \mathrm{Pd} / \mathrm{k} 1
\end{array} \\
& \mathrm{~T}_{\mathrm{f}_{\mathrm{n}}}=\mathrm{T}^{\prime} \mathrm{f}_{\mathrm{n}}+\left(\frac{\Delta \mathrm{Qgen}_{\mathrm{n}}}{\mathrm{m} 5 \cdot \mathrm{Cp} 5}\right) \quad \begin{array}{l}
\text { Corrected final temperature of } \mathrm{Pd} / \mathrm{k} /(\text { foam }) \\
1 \text { due to heat of absorption }
\end{array}
\end{aligned}
$$

f) Section 6 (Outer Shell 2):

- $\Delta \mathrm{Q} 6_{\mathrm{n}}=\mathrm{h6} \cdot \mathrm{A6} \cdot\left(\mathrm{T6}_{\mathrm{f}-1}-\mathrm{TN}_{\mathrm{f}} \mathrm{f}_{\mathrm{n}}\right) \cdot \Delta \mathrm{t}$ Heat loss from Outer Shell 2 area to nitrogen

$$
\begin{array}{ll}
{ }^{\mathrm{T} 6_{\mathrm{f}}}=\mathrm{T} 6_{\mathrm{f}_{\mathrm{n}-1}}-\left(\frac{\Delta \mathrm{Q} 6_{\mathrm{n}}}{\mathrm{m} 6 \cdot \mathrm{Cp} 6}\right) & \begin{array}{l}
\text { Final temperature of Outer Shell } 2 \text { due to } \\
\text { heat removed }
\end{array} \\
\mathrm{TN}_{\mathrm{f}}=\left(\frac{\Delta \mathrm{Q} 6_{\mathrm{n}}}{\mathrm{wN} \cdot \mathrm{CpN} \cdot \Delta \mathrm{t}}\right)+\mathrm{TN} 4_{\mathrm{f}} & \begin{array}{l}
\text { Temperature of nitrogen leaving Outer Shell } \\
2 \text { due to heat gain, entering Column Wall } 2
\end{array}
\end{array}
$$


g) Section 7 (Column Wall 2):

$$
\begin{aligned}
& \Delta \mathrm{Q}_{\mathrm{n}}=\mathrm{h} 7 \cdot \mathrm{A} 7 \cdot\left(\mathrm{T7_{f }} \mathrm{f}_{\mathrm{n}-1}-\mathrm{TN} \mathrm{f}_{\mathrm{n}}\right) \cdot \Delta \mathrm{t} \quad \begin{array}{l}
\text { Heat loss from Column Wall } 2 \text { area to } \\
\text { nitrogen }
\end{array} \\
& \mathrm{T}^{7} \mathrm{f}_{\mathrm{n}}=\mathrm{T} 7_{\mathrm{f}_{\mathrm{n}-1}}-\left(\frac{\Delta \mathrm{Q} 7 \mathrm{n}}{\mathrm{m} 7 \cdot \mathrm{Cp} 7}\right) \quad \begin{array}{l}
\text { Intermittent final temperature of Column } \\
\text { Wall } 2 \text { due to heat removed }
\end{array} \\
& \mathrm{TN}^{\prime} \mathrm{f}_{\mathrm{n}}=\left(\frac{\Delta \mathrm{Q} 7_{\mathrm{n}}}{\mathrm{wN} \cdot \mathrm{CpN} \cdot \Delta \mathrm{t}}\right)+\mathrm{TN6}_{\mathrm{f}_{\mathrm{n}}} \begin{array}{l}
\text { Intermittent temperature of nitrogen leaving } \\
\begin{array}{l}
\text { Column Wall } 2 \text { due to heat gain, entering } \\
\text { Exit. }
\end{array}
\end{array}
\end{aligned}
$$

h) Section $8(\mathrm{Pd} / \mathrm{k} /($ foam $) 2)$ :

$$
\begin{aligned}
& \Delta \mathrm{Q}_{\mathrm{n}}=\mathrm{h} 8 \cdot \mathrm{A} 8 \cdot\left(\mathrm{T}_{\mathrm{f}_{\mathrm{n}-1}}-\mathrm{T}^{\mathrm{r}} \mathrm{f}_{\mathrm{n}}\right) \cdot \Delta \mathrm{t} \quad \begin{array}{l}
\text { Heat loss from } \mathrm{Pd} / \mathrm{k} /(\text { foam }) 2 \text { to Column } \\
\text { Wall } 2 \text { at intermittent temperature }
\end{array} \\
& \mathrm{T}^{\prime} \mathrm{f}_{\mathrm{n}}=\mathrm{T} 8_{\mathrm{f}_{\mathrm{n}-1}}-\left(\frac{\Delta \mathrm{Q} 8 \mathrm{n}}{\mathrm{m} 8 \cdot \mathrm{Cp} 8}\right) \quad \cdot \begin{array}{l}
\text { Intermittent final temperature of } \mathrm{Pd} / \mathrm{k} /(\mathrm{foam}) \\
2 \text { due to heat removed }
\end{array}
\end{aligned}
$$

$\mathrm{T} 7_{f_{n}}=T 7_{f_{n-1}}-\left(\frac{\Delta 7_{n}-\Delta Q 8 n}{m 7 \cdot C p 7}\right) \begin{aligned} & \text { Corrected final temperature of Column Wall } \\ & 2 \text { due to heat supplied from } \mathrm{Pd} / \mathrm{k} /(\text { foam })\end{aligned}$

$$
{ }^{T N} 7_{\mathrm{f}}=\left(\frac{\Delta \mathrm{Q} 7_{\mathrm{n}}-\Delta \mathrm{Q} 8_{\mathrm{n}}}{\mathrm{wN} \cdot \mathrm{CpN} \cdot \Delta \mathrm{t}}\right)+\mathrm{TN} 6_{\mathrm{f}_{\mathrm{n}}} \quad \begin{aligned}
& \text { Corrected temperature of nitrogen leaving } \\
& \text { Column Wall } 2 \text { due to heat gain, entering } \\
& \text { Exit. }
\end{aligned}
$$

$$
\begin{aligned}
& \left.\Delta{\text { Qgen } 8:=\operatorname{Cgen} 8 \cdot\left(T 8_{f_{n-1}}-T 8^{\prime} f_{n}\right.}\right) \cdot \Delta t \quad \begin{array}{l}
\text { Heat generation from absorption of } \\
\text { hydrogen in } P d / k 2
\end{array} \\
& \mathrm{~T} 8 \mathrm{f}_{\mathrm{n}}=\mathrm{T}^{\prime} \mathrm{f}_{\mathrm{n}}+\left(\frac{\Delta \mathrm{Qgen} 8_{\mathrm{n}}}{\mathrm{m} 8 \cdot \mathrm{Cp} 8}\right) \quad \begin{array}{l}
\text { Corrected final temperature of } \mathrm{Pd} / \mathrm{k}(\text { foam }) 2 \\
\text { due to heat of absorption }
\end{array}
\end{aligned}
$$


i) Section 9 (Exit):

$$
\begin{array}{ll}
\Delta \mathrm{Q} 9_{\mathrm{n}}=\mathrm{h} 9 \cdot \mathrm{A} 9 \cdot\left({ }^{\mathrm{T} 9} \mathrm{f}_{\mathrm{n}-1}-\mathrm{TN} 7_{\mathrm{f}}\right) \cdot \Delta \mathrm{t} & \text { Heat loss from Exit area to nitrogen } \\
{ }^{\mathrm{T} 9_{\mathrm{f}}}=\mathrm{T} 9_{\mathrm{i}_{\mathrm{n}}}-\left(\frac{\Delta \mathrm{Q} 9_{\mathrm{n}}}{\mathrm{m} 9 \cdot \mathrm{Cp} 9}\right) & \begin{array}{l}
\text { Final temperature of Exit due to heat } \\
\text { removed }
\end{array} \\
{ }^{\mathrm{TN} 9} \mathrm{f}_{\mathrm{n}}=\left(\frac{\Delta \mathrm{Q} 9_{\mathrm{n}}}{\mathrm{wN} \cdot \mathrm{CpN} \cdot \Delta \mathrm{t}}\right)+\mathrm{TN} 7_{\mathrm{f}_{\mathrm{n}}} & \begin{array}{l}
\text { Temperature of nitrogen leaving Exit due to } \\
\text { heat gain, entering Outlet Tee }
\end{array}
\end{array}
$$

j) Section 10 (Outlet Tee):

$$
\begin{gathered}
\Delta Q 10_{n}=h 10 \cdot A 10 \cdot\left(T 10_{f_{n-1}}-T N 9_{f_{n}}\right) \cdot \Delta t \quad \text { Heat loss from Outlet Tee area to nitrogen } \\
\mathrm{T} 10_{f_{n}}=T 10_{f_{n-1}}-\left(\frac{\Delta Q 10_{n}}{m 10 \cdot C p 10}\right) \quad \begin{array}{l}
\text { Final temperature of Exit due to heat } \\
\text { removed }
\end{array} \\
T N 10_{f_{n}}=\left(\frac{\Delta Q 10_{n}}{w N \cdot C p N \cdot \Delta t}\right)+T N 9_{f_{n}} \cdot \begin{array}{l}
\text { Temperature of nitrogen leaving Outlet Tee } \\
\text { and heat exchanger assembly }
\end{array}
\end{gathered}
$$

The above equations, where total time can be calculated by $\mathrm{n} \times \Delta \mathrm{t}$, are used to calculate the temperatures for all components in each section, and ultimately determine when the hot or cold $\mathrm{Pd} / \mathrm{k}$ target temperature is reached to ensure proper absorption or desorption of the hydrogen. 
WSRC-TR-99-00348, Rev. 2

\subsection{Pressure Drop in the Nitrogen Side}

To assist in the selection of an optimum flow rate through the heat exchanger assembly, the pressure drop is calculated within each section, summed, and used for comparison at each flow rate.

The shell side of the TCAP heat exchanger includes: 1) the inlet and outlet piping and fittings to and from the housing; 2) the entrance and exit sections of the housing including the inner shell; and 3) the annular space between the inner and outer shells containing the coiled packed column. Incropera [1990] provides Equation (3.27) for determining the pressure drop for internal pipe flow:

$$
\Delta p=f \cdot \frac{\rho \cdot V^{2}}{2 \cdot D \cdot g_{c}} \cdot L
$$

where

$$
f=0.184 \cdot \operatorname{Re}_{D}^{-0.2}
$$

for smooth surface tubes from Incropera [1990], and where Equation (3.3) is used for $\operatorname{Re}_{D}$ in Equation (3.28). As explained in Section 3.4, the nitrogen flows in the inlet and outlet piping sections and entrance and exit of the housing resemble that of pipe flow, and therefore Equations (3.27) and (3.28) are directly applicable. However, the nitrogen flow inside of the inner shell resembles that of a plenum, with a common inlet and outlet. For the flow inside of the inner shell, the hydraulic diameter is used in the above equations. The thermophysical properties of nitrogen for the above equations are evaluated at the mean bulk fluid temperature. 
The pressure drop in the annulus over the packed column can be found by the following correlation provided by Zukauskas [1972].

$$
\Delta \mathrm{p}=\mathrm{N}_{\mathrm{L}} \cdot \chi \cdot\left(\frac{\rho \cdot \mathrm{V}_{\text {max }}^{2}}{2}\right) \cdot \mathrm{f}
$$

Where $\mathrm{f}$ and $\chi$ are graphically determined from Figure 63 of Zukauskas [1972] for an inline arrangement with specified geometry. Equation (3.8) is used in the above, and the thermophysical properties of nitrogen for the above equations are evaluated at the mean bulk fluid temperature. 
WSRC-TR-99-00348, Rev. 2

\section{Chapter 4}

\section{EXPERIMENTAL APPARATUS AND PROCEDURE}

\subsection{Introduction}

The effective thermal conductivities for stainless steel coils containing $\mathrm{Pd} / \mathrm{k}$ for the purpose of the TCAP heat exchanger were measured at the Thermal Fluids Laboratory at the Savannah River Site Technology Center. This chapter consists of excerpts from Steimke and Fowley.[1999] prepared for the U.S. Department of Energy under Contract DE-AC09-96SR18500.

\subsection{Experimental Work}

\subsubsection{Description of Coils and Sphere}

Three coils were made from stainless steel tubing with a wall thickness of 0.065 inch. Coil \#1, the base case, was made from 2 inch OD tubing bent into a coil having 2.4 turns and an outer diameter of 16 inch. A 2 inch diameter stainless steel disk was welded to each end of the coil and a pipe nipple was welded to one of the disks. Kieselguhr was poured into the coil through the nipple. A tee and two valves were attached to the nipple so that the coil could be independently connected to a pressure gage and to either a vacuum pump or a cylinder of helium gas. Coil \#2 was similar to Coil \#1 except that it also contained copper foam, it had 1.1 turns and the outer diameter was 21.5 inch. The foam copper has $93.2 \%$ void and has an average pore diameter of $0.050 \mathrm{inch}$. Coil \#3 
contained only kieselguhr, had a tubing OD of 1.25 inch, 1.75 turns and an outer diameter of 11 inch. Table 4.1 lists material properties. $\mathrm{Pd} / \mathrm{k}$ is $50 \%$ by weight Palladium on kieselguhr.

\section{Table 4.1 Properties of Materials used in Experiment}

$\underline{\text { material }}$

Density, $\mathrm{lb} / \mathrm{ft}^{3}$

Thermal conductivity, $\mathrm{Btu} / \mathrm{hr} \cdot \mathrm{ft} \cdot{ }^{\circ} \mathrm{F}$

Specific heat, Btu/lb $\cdot{ }^{\circ} \mathrm{F}$

Thermal diffusivity, $\mathrm{ft}^{2} / \mathrm{hr}$

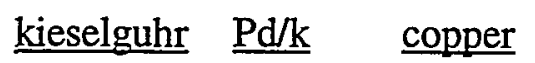

$50 \quad 558$

0.73

218

9.4

119

steel

488

169

0.036

0.21

0.13

0.091

0.11

0.208

0.0061

0.15

3.33

The properties of metals used are from Kreith [1993]. Thermal conductivities for kieselguhr were found in Kreith, Lide [1995], and International Critical Tables [1928] with specific heat data also found in Kreith. The specific heat for Pd/k is the mass weighted average of the specific heats for kieselguhr and Palladium and is also in Table 3.1. The densities of kieselguhr and $\mathrm{Pd} / \mathrm{k}$ were measured by weighing a volume of powder measured in a volumetric cylinder.

The actual TCAP process will use palladium deposited on kieselguhr, $\mathrm{Pd} / \mathrm{k}$. The tests reported here were conducted with kieselguhr only because sufficient $\mathrm{Pd} / \mathrm{k}$ was not available to fill a coil. A smaller scale test was conducted to allow a comparison of the thermal response of kieselguhr and $\mathrm{Pd} / \mathrm{k}$. Three holes were drilled into a hollow stainless steel sphere with an outer diameter of 2.25 inches and a wall thickness of 0.016 inches. A 0.032 inch diameter thermocouple was silver soldered in one hole so that its tip was at 
the center of the sphere. A 3/16 inch outside diameter tube was silver soldered to the second hole of the sphere. The sphere was filled with $\mathrm{Pd} / \mathrm{k}$ using the third hole and the hole was sealed with a disk of stainless steel and epoxy. The sphere was weighed before and after filling so that the mass of $\mathrm{Pd} / \mathrm{k}$ could be calculated. A Tygon tube was used to connect the $3 / 16$ inch stainless steel tube to a vacuum pump and a vacuum was pulled on the sphere overnight. Then the sphere was backfilled with helium at $1 \mathrm{~atm}$. Pinching on the Tygon tube sealed the sphere. Two thermal transient tests were conducted with this configuration. Later, the disk was removed, the $\mathrm{Pd} / \mathrm{k}$ was replaced with kieselguhr and the process was repeated.

The tests were conducted with helium gas instead of hydrogen for safety reasons. The thermal conductivities of helium and hydrogen at $120^{\circ} \mathrm{F}$ are 0.091 and 0.114 Btu/ft'hr ${ }^{\circ} \mathrm{F}$, respectively from Kreith [1993].

\subsubsection{Description of Test Facility and Instrumentation}

The test facility is shown in Figure 4.1 and consisted of an insulated stainless steel tank, an agitator, an electric hoist, two 1000 watt electric heaters, instrumentation and a data acquisition system. The tank had a diameter of 30 inch and a height of 31 inches. The agitator had a three bladed impeller with a diameter of 11 inches, which was rotated at $1800 \mathrm{rpm}$ by a motor mounted on the tank cover. The coil to be tested was suspended 18 inches below the tank cover and 4 inches above the impeller.

The coil was connected to one of two pressure gages using $1 / 4$ inch tubing. Pressure transducer TR-3553 was used to measure pressures for the runs that began at pressure of $1 \mathrm{~atm}$. Four temperatures inside the tank were measured with Type J 
WSRC-TR-99-00348, Rev. 2

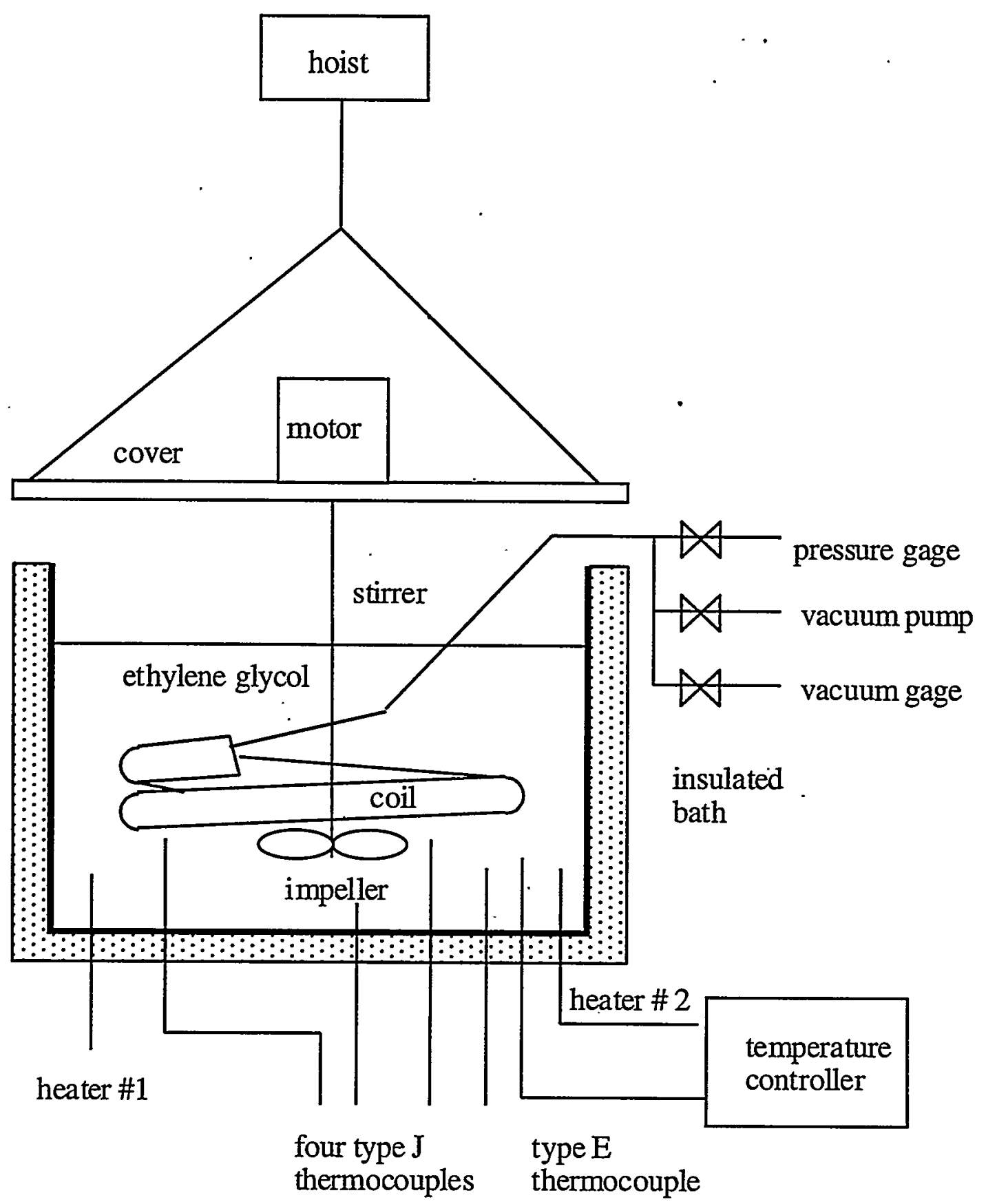

\section{Figure 4.1 Lab Equipment Schematic}


WSRC-TR-99-00348, Rev. 2

thermocouples; TR-3123, TR-1322, TR-1335, TR-1233, TR-1055. The thermocouples were accurate to within $\pm 2^{\circ} \mathrm{C}$. Ambient temperature was measured using thermocouple TR-1055 or thermometer TR-2896. The data acquisition software was Labview V5.0. Tank temperature was controlled using an E type thermocouple connected to an Omega CN9000A controller.

Two 12 inch long aluminum bars with diameters of 2.00 inches and 1.50 inches were prepared to allow the measurement of heat transfer coefficient in the stirred tank. Both bars had a hole drilled down the axis to the center. A type J thermocouple was inserted into each hole to the center and sealed with Scotchcast resin.

\subsubsection{Abbreviated Test Procedure}

Testing was conducted using a written procedure. The coil to be tested was connected to a vacuum pump and a pressure gage and placed in an oven maintained at $100^{\circ} \mathrm{C}$. Coils $\# 1$ and $\# 3$ were kept in the oven for about three days to bake moisture out of the kieselguhr. It should be noted that the coils were still outgassing water vapor at the end of several days. For example, the pressure inside Coil \#1 was 2 torr after three days in the oven while being evacuated with a vacuum pump. When the valve between the coil and the vacuum pump was closed the pressure decreased to 0.5 torr. A leak check was performed to eliminate a leak as the reason that the pressure was higher when the coil was connected to the pressure gage and vacuum pump. Coil \#2 was not placed in the oven because it was too large. However, it was maintained at a vacuum for a longer period than the other coils. After being disconnected from the vacuum pump it maintained a pressure of 1 torr. 
Heaters \#1 and \#2 were used to heat the ethylene glycol to the operating temperature of approximately $100^{\circ} \mathrm{C}$. To perform a test run, heater \#2 and its controller were used to maintain the temperature. The tank cover / agitator assembly was raised using the hoist and a lightweight insulating cover was placed over the tank to reduce heat loss. The coil to be tested was mounted below the tank cover and a $1 / 4$ inch stainless steel tube was used to connect it to a pressure gage. The coil was again connected to a vacuum pump. After evacuation the coil was backfilled with helium at the desired pressure of 1 atm. Note that helium was used instead of hydrogen for safety reasons, because of the residual water vapor the contents of the coils were a mixture of helium and water vapor. Water vapor formed a negligible fraction of the total gas at $1 \mathrm{~atm}$. Data logging was begun on the DAS, the lightweight cover was removed, the tank cover / agitator assembly was lowered into the ethylene glycol and the agitator was energized. Data logging continued until the rate of pressure increase was small. For some runs the rate of data logging was high at the start of the run and was decreased when the rate of pressure changes became smaller. No tank agitation was used for the very last run to allow an estimate of the effect of tank agitation. A total of thirty transients were run with the three coils, although two of the transients were not usable. Laboratory Notebook SRT-ETF980032 was used for this task. Data logs were identified in the notebook by date and time, and in Table 4.2 .

Table 4.2 Listing of Log Names for Experimental Runs

Coil \#1

$1 \mathrm{~atm}$ kieselguhr only, 2" diameter tubing

TCAP 0901 1321,1325

TCAP 09031555

TCAP 09081424 
WSRC-TR-99-00348, Rev. 2

Coil \#2

$1 \mathrm{~atm}$

TCAP 09111543

TCAP 09141237

TCAP 0914 1642, 1649

TCAP 0915 1128,1135,1159

Coil \#3

$1 \mathrm{~atm}$

TCAP 0922 1612, 1617

TCAP 0923 1045, 1102

TCAP 0923 1220, 1226

Coil \#3

$1 \mathrm{~atm}$

TCAP 1005 1608, 1614 kieselguhr and copper foam, 2" diameter tubing

kieselguhr only, 1.25" diameter tubing

\section{Aluminum Bar Test TCAP 10131310}

\section{kieselguhr only, 1.25" diameter, no agitation}

Note: A listing such as TCAP 09011321,1325 in the table is shorthand for two logs; log TCAP 09011321 was made at a high sampling rate for the initial part of the transient, followed by log TCAP 09011325 made at a lower sampling rate for the remainder of the transient.

Heat transfer coefficient was measured in the following way. The coil was removed from the tank cover / agitator assembly and replaced with both aluminum bars. The thermocouples were connected to data acquisition system and a $\log$ was started. The assembly was quickly lowered into the agitated bath and the agitator was energized. Temperature transients were measured for both thermocouples. The log was stopped when the rate of temperature change became very slow. The aluminum bars were exposed to the same tank location and conditions of agitation as the coils were. 
Therefore, the heat transfer coefficients measured using the bars was the same as the coils were exposed to.

The spheres were tested in the following way. Three thermocouples were connected to a data acquisition system. One thermocouple was in the sphere, another was placed in a bath of boiling water and the third was held outside the bath. A log was started and the sphere and the third thermocouple were simultaneously submerged in the bath. The third thermocouple served to time stamp the moment of immersion in the log. The sphere and thermocouple were kept in the bath until rate of temperature change in the sphere was very small. Then the sphere was removed for the bath and allowed to cool to room temperature. Two transients were conducted for both $\mathrm{Pd} / \mathrm{k}$ and kieselguhr.

\subsection{Results of Transient Tests}

\subsubsection{Transient Aluminum Bar Tests}

The purpose of this test was to measure the heat transfer coefficient in the agitated tank. Figures 4.2 and 4.3 from Roshenow [1985] show that the calculated surface and centerline temperatures for transient heat conduction in a long cylinder are functions of Fourier number, $\alpha \cdot t / R^{2}$, with Biot number, $h \cdot R / k$, as a parameter. The Fourier number is a normalized time. The Biot number is a ratio internal to external resistance. Thermal diffusivity is defined as:

$$
\alpha=k /\left(\rho \cdot C_{p}\right)
$$

Figure 4.4 shows the measured temperature transients for the centerline temperatures of the two aluminum cylinders, as well as the average bath temperature. 
The same data were replotted in Figure 4.5 in dimensionless form. Thermal conductivity, $k$, thermal diffusivity, $\alpha$, and radius, $R$, are known for the aluminum cylinders, see Table 4.1. Four of the parametric curves from Figure 4.3 were also plotted in Figure 4.5. The aluminum bar transient data fall between the parametric curves for Biot numbers of 0.1 and 0.4. The Biot numbers for the aluminum bar transients for diameters of 1.5 inch and 2 inch are estimated from Figure 4.5 to be $0.15 \pm 0.04$ and $0.2 \pm 0.05$, respectively. Using the definition of Biot number and a thermal conductivity for aluminum of 119 Btu/fthr $\cdot{ }^{\circ} \mathrm{F}$ gives an external heat transfer coefficient of $300 \pm 75 \mathrm{Btu} / \mathrm{hr} \cdot \mathrm{ft}^{2} \cdot{ }^{\circ} \mathrm{F} \mathrm{hr}$ for both cylinders.

\subsubsection{Transient Coil Tests}

The pressure inside a coil reflects the average temperature of the contents. If the gas inside the coil can be considered to be an ideal gas, then there is exact proportionality between gas pressure and average temperature inside the coil. Any water vapor being outgassed from the kieselguhr is a complication because the partial pressure of water vapor does not obey the Ideal Gas Law: The effect of evolved water vapor was négligible for the $1 \mathrm{~atm}$ transients. Figures 4.6 through 4.8 show that plots of pressure versus time were approximately exponential decays. Transient pressure data were fitted to exponential form in the least squares sense. Time constant is the time required to make $63 \%$ of the total pressure change. Measured time constants for the runs follow. 


\section{Table 4.3 Time Constants for TCAP Transient Tests}

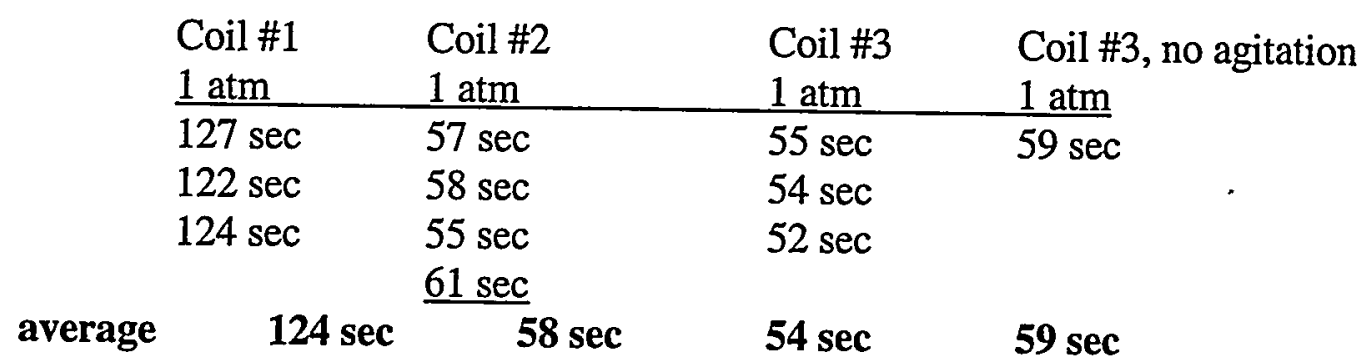




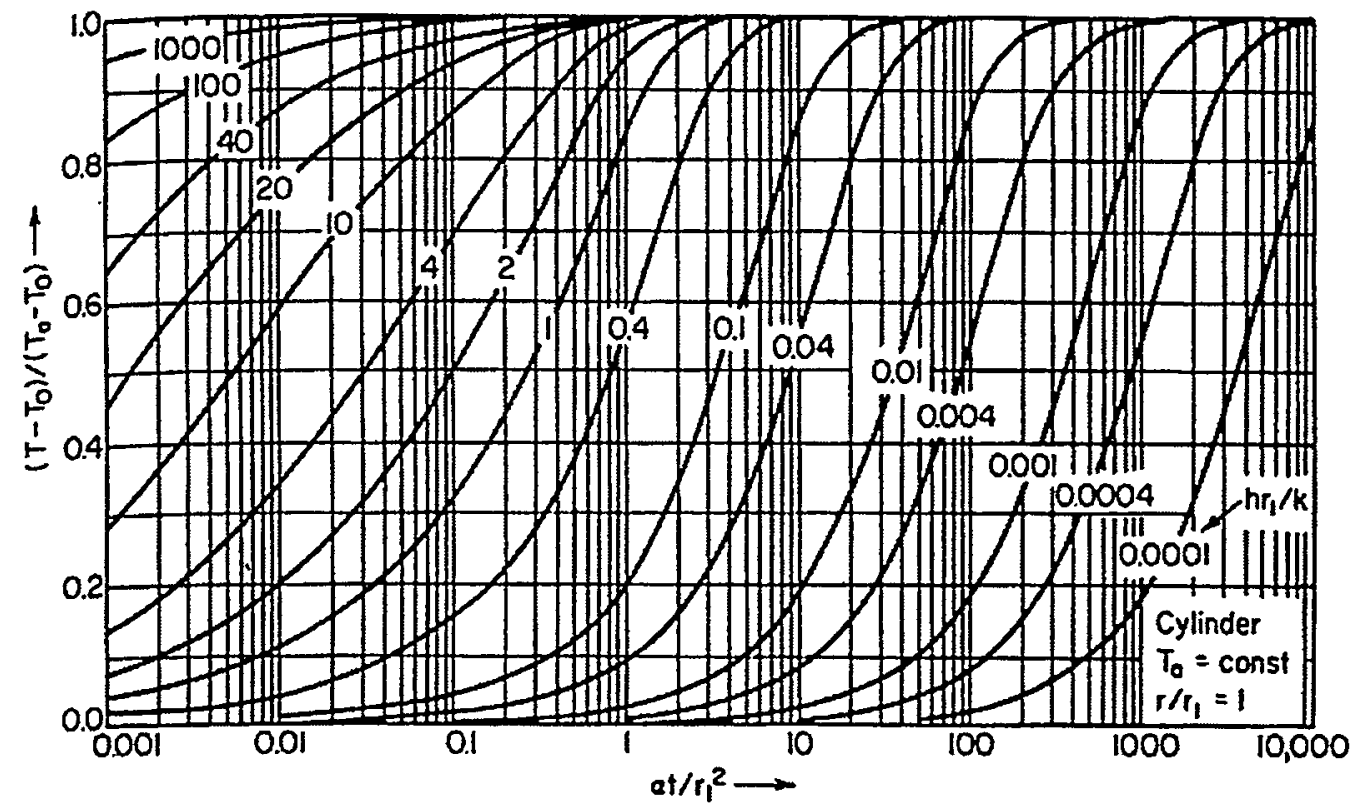

Figure 4.2 Surface Temperature Response of Long Cylinder After Sudden Exposure to Uniform Convective Environment, from Roshenow [1985].

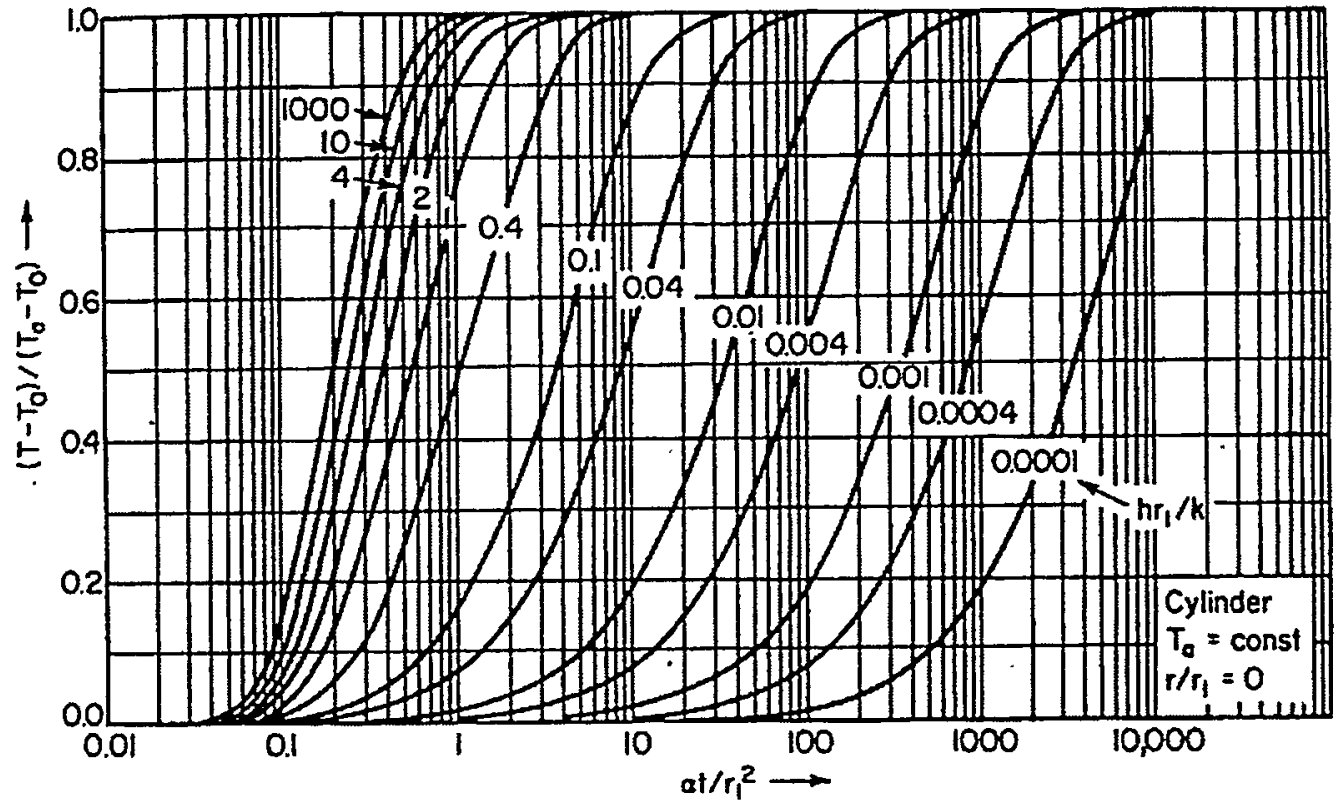

Figure 4.3 Centerline Temperature Response of Long Cylinder After Sudden Exposure to Uniform Convective Environment, from Roshenow [1985]. 


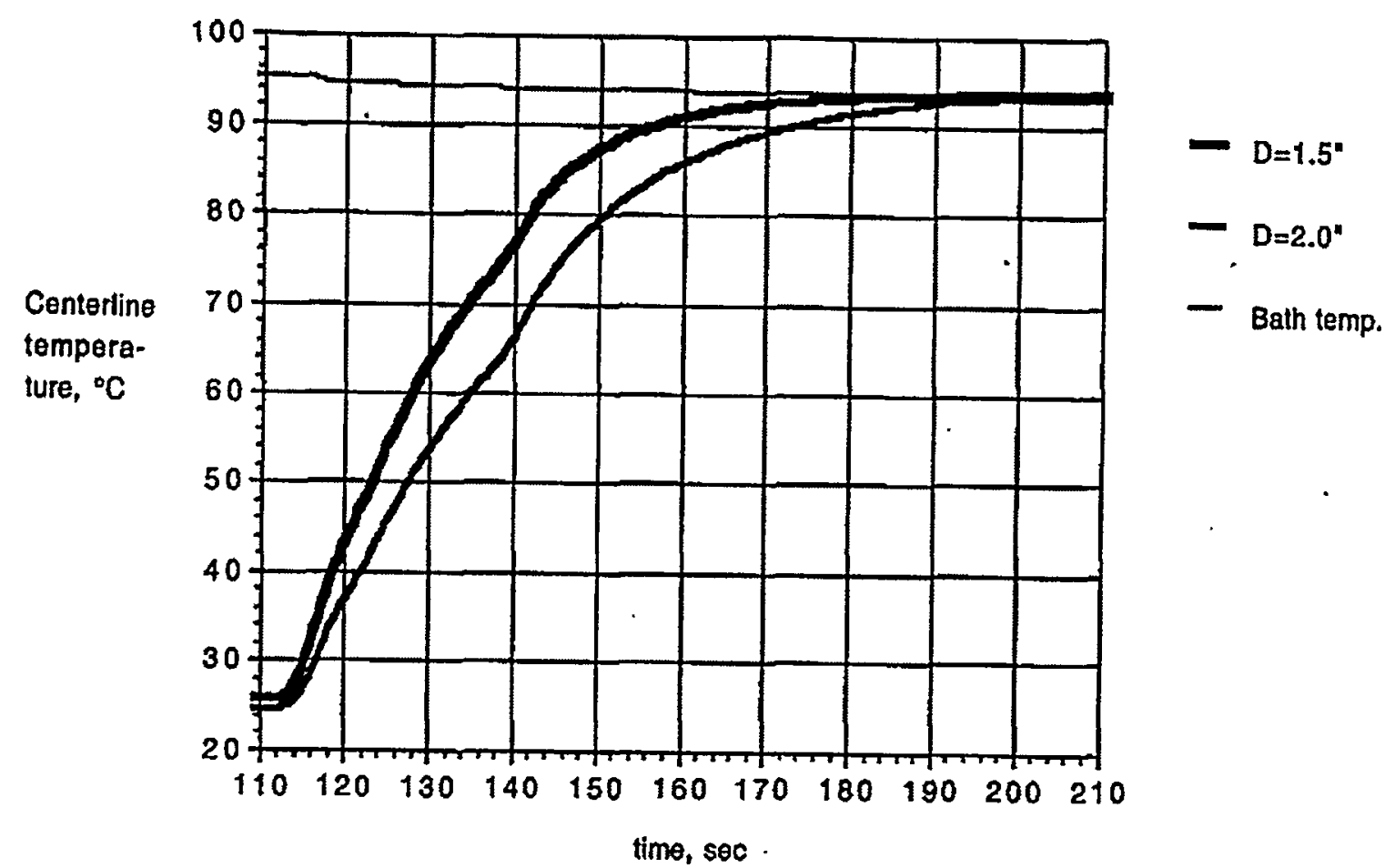

Figure 4.4 Measured Temperature Transients for Centerlines. of Aluminum Bar

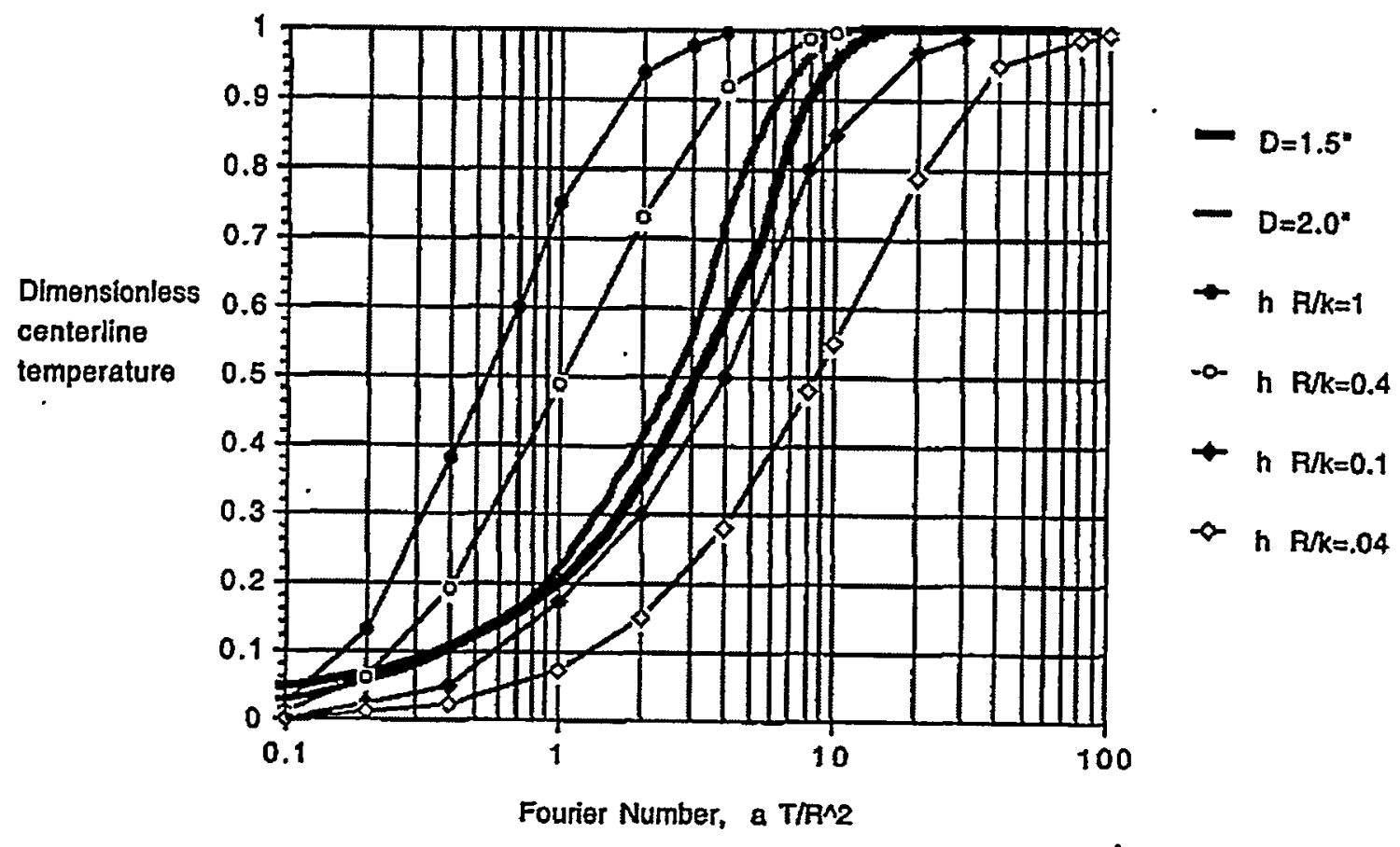

Figure 4.5 Measured and Theoretical Temperature Transients for Centerlines of Cylinders 


\subsubsection{Analysis of Transient Coil Test Data}

The results of the transient tests allow analysis of three effects; the effect of changing tube diameter, the effect of changing helium pressure in the tubes and the effect of replacing some of the kieselguhr with copper foam. The effect of changing diameter was analyzed in the following way. Figure 4.3 was used in Section 4.3 .1 to determine the heat transfer coefficient outside the coils. Note that the curves for Biot numbers of 10 and 1000 are nearly the same. The conclusion is that transient conduction becomes nearly insensitive to Biot number for Biot numbers greater than 10. An estimate of thermal conductivity is needed to calculate the Biot number. The International Critical Tables [1928] state that the thermal conductivity of kieselguhr in air is $0.021 \mathrm{Btu} / \mathrm{hr} \cdot \mathrm{ft} \cdot{ }^{\circ} \mathrm{F}$. For an external heat transfer coefficient of $300 \mathrm{Btu} / \mathrm{hr} \cdot \mathrm{ft}^{2} \cdot{ }^{\circ} \mathrm{F}$ and a radius of $1.0 \mathrm{inch}$ the Biot number is 1200 . Therefore, transient heat conduction in the tubes is insensitive to changes in Biot number. By inspection of Figure 4.2 the temperature of the outer surface of the cylinder reaches the temperature of the bath in a negligible period of time. Figure 4.9, taken from Carslaw [1958], shows transient radial temperature profiles for transient heat conduction in a solid cylinder when the surface of the cylinder instantaneously changes to a new temperature, which is a good approximation here. Normalized temperature is a function of radial position with Fourier number as a parameter. The data were numerically integrated over the radius of the cylinder using the following equation:

$$
\mathrm{T}=\frac{1}{\pi \cdot \mathrm{R}^{2}} \cdot \int_{0}^{\mathrm{R}} 2 \cdot \pi \cdot \mathrm{r} \cdot \mathrm{T}(\mathrm{r}) \mathrm{dr}
$$


The resulting volume weighted average temperature is plotted in Figure 4.10 as function of Fourier number only. One time constant is equivalent to a $63 \%$ change in average temperature. Figure 4.10 shows that a $63 \%$ change in average temperature requires a Fourier number of 0.111 . Knowing this relationship allows determination of the effect of reducing diameter.

$$
\mathrm{Fo}=\alpha \cdot \mathrm{t} / \mathrm{R}^{2}=0.111
$$

Rearranging equation (4.3) gives

$$
\mathrm{t}=0.111 \cdot \mathrm{R}^{2} / \alpha
$$

Therefore, holding thermal diffusivity constant and reducing the radius from 1.00 inch to 0.625 inch reduces time by a factor of $(0.625 / 1.00)^{2}$ or 0.39 . This prediction was compared with the experimental results listed in Table 4.3. For pressure of $1 \mathrm{~atm}$ the time constant for Coil \#3 (1.25 inch diameter tubing) was $44 \%$ as large as the time constant for Coil \#1 (2.00 inch diameter tubing). This percentage is in reasonable agreement with the theoretical prediction of $39 \%$.

The thermal diffusivities of the three coils were calculated using equation (4.3), the diameters and measured time constants with the following results. 
WSRC-TR-99-00348, Rev. 2

\section{Table 4.4 Coil Thermal Diffusivity in $\mathrm{ft}^{2} / \mathrm{hr}$ for Transient Tests}

\begin{tabular}{lll} 
Coil \#1 & Coi1 \#2 & Coil \#3 \\
$1 \mathrm{~atm}$ & $1 \mathrm{~atm}$ & $1 \mathrm{~atm}$ \\
\hline 0.022 & 0.048 & 0.020
\end{tabular}

Effective thermal conductivities were calculated by multiplying the thermal diffusivities in Table 4.4 by density and specific heat. For Coil \#2 a weighted average was used for the product of density and the specific heat for copper and kieselguhr. It should be noted that the thermal conductivities in Table 4.5 are more uncertain than the thermal diffusivities in Table 4.4 because they are products of three measured quantities, each having an uncertainty.

Table 4.5 Coil Effective Thermal Conductivity in Btu/hr.ft ${ }^{\circ} \mathrm{F}$ for Transient

\begin{tabular}{|c|c|c|}
\hline \multirow[b]{2}{*}{ Coil \#1 } & \multicolumn{2}{|c|}{ Tests } \\
\hline & Coil \#2 & Coil \# \\
\hline $1 \mathrm{~atm}$ & $1 \mathrm{~atm}$ & $1 \mathrm{~atm}$ \\
\hline 0.13 & 0.43 & 0.12 \\
\hline
\end{tabular}

Coils \#1 and \#3 contain only kieselguhr and helium and have nearly the same thermal diffusivities. For comparison, the International Critical Tables [1928] gives the thermal conductivity of diatomite (kieselguhr) in air at 700 torr $(0.92 \mathrm{~atm})$ to be 35.6 hectoerg $/ \mathrm{cm} \cdot \mathrm{sec} \cdot{ }^{\circ} \mathrm{C}$ or $0.021 \mathrm{Btu} / \mathrm{hr} \cdot \mathrm{ft} \cdot{ }^{\circ} \mathrm{F}$. The density and specific heat of kieselguhr are $28 \mathrm{lb} / \mathrm{ft}^{3}$ and $0.21 \mathrm{Btu} / \mathrm{lb} \cdot{ }^{\circ} \mathrm{F}$ giving a thermal diffusivity of kieselguhr in air of 0.0036 $\mathrm{ft}^{2} / \mathrm{hr}$, a factor of 6.1 less than the measured thermal diffusivity for kieselguhr in helium at 1 atm for Coil \#1. However, this difference is reasonable because helium has thermal conductivity 5.6 times as large as air. 
The second effect was replacing some of the kieselguhr with copper foam in Coil \#2. A simple analysis was tried, but was found to be unsuccessful. Roshenow [1985] suggested that the thermal conductivity of a composite could be approximated as the volume weighted average of the thermal conductivities of the components. Since thermal diffusivity rather than thermal conductivity was measured, a composite thermal diffusivity was calculated. Copper occupies $6.8 \%$ of the volume and has a thermal diffusivity of $4.4 \mathrm{ft}^{2} / \mathrm{hr}$. The thermal diffusivity of kieselguhr is negligible in comparison and can be ignored. The calculated composite thermal diffusivity is 0.068 times 4.4 or $0.30 \mathrm{ft}^{2} / \mathrm{hr}$. This is much larger than the measured thermal diffusivity of $0.048 \mathrm{ft}^{2} / \mathrm{hr}$ for Coil \#2 at 1 atm. Therefore, this suggested method does not work well. A reason may be resistance to heat flow across the interface between copper and kieselguhr.

\subsubsection{Analysis of Transient Sphere Test Data}

The purpose of this test was to allow a comparison of thermal response for Pd/k and kieselguhr. Figure 4.11 is a plot of normalized temperature at the center of the sphere versus time for the four transients. Normalized temperature is defined as the following. :

$$
\mathrm{T}_{\mathrm{norm}}=\left(\mathrm{T}-\mathrm{T}_{0}\right) /\left(\mathrm{T}_{\mathrm{bath}}-\mathrm{T}_{0}\right)
$$

where $T_{0}$ is the initial temperature of the sphere. Note that the temperature response is slower with kieselguhr than with $\mathrm{Pd} / \mathrm{k}$. Figure 4.12 shows the result of dividing the times for the kieselguhr transient by a factor of 1.4 . This causes the temperature curves to approximately coincide. The primary factor influencing transient heat conduction is thermal diffusivity. 
WSRC-TR-99-00348, Rev. 2

Therefore, as an approximation, the thermal diffusivity for $\mathrm{Pd} / \mathrm{k}$ is a factor of 1.4 larger than the thermal diffusivity listed for kieselguhr in Table 4.4. For Example, the thermal diffusivity of $\mathrm{Pd} / \mathrm{k}$ in Coil \#1 with helium at $1 \mathrm{~atm}$ is estimated to be $0.031 \mathrm{ft}^{2} / \mathrm{hr}$. By extension, if the transient coil tests had been run with $\mathrm{Pd} / \mathrm{k}$ instead of kieselguhr, the transients would be expected to be $40 \%$ faster.

The thermal conductivity of $\mathrm{Pd} / \mathrm{k}$ in helium at $1 \mathrm{~atm}$ can be estimated using the estimated thermal diffusivity, the density and specific heat listed in Table 4.1 and the definition of thermal diffusivity from equation (4.1). The estimated thermal conductivity is $0.17 \mathrm{Btu} / \mathrm{hr} \cdot \mathrm{ft} \cdot{ }^{\circ} \mathrm{F}$

\subsection{Experimental Conclusions}

1. The three coils used in the transient tests were filled with kieselguhr instead of $\mathrm{Pd} / \mathrm{k}$. Coils \#2 and \#3 responded almost equally fast and more than twice as fast as Coil \#1. Therefore, the use of copper foam is an effective method to compensate for effect of increasing the diameter of the tubing used in the coils.

2. Thermal diffusivity was nearly the same for Coils \#1 and \#3, the two coils that contained only kieselguhr and helium.

3. Coil \#3 responded only $10 \%$ more slowly when the bath was not agitated. This effect was expected to be small because the coils were intentionally operated in a condition where internal heat conduction was nearly insensitive to the external Biot number and therefore to external heat transfer coefficient. 
WSRC-TR-99-00348, Rev. 2

4. Based on the transient tests that compared the response of kieselguhr and $\mathrm{Pd} / \mathrm{k}$ it is estimated that the coils would have responded approximately $40 \%$ faster if they had been filled with $\mathrm{Pd} / \mathrm{k}$ rather than kieselguhr. 


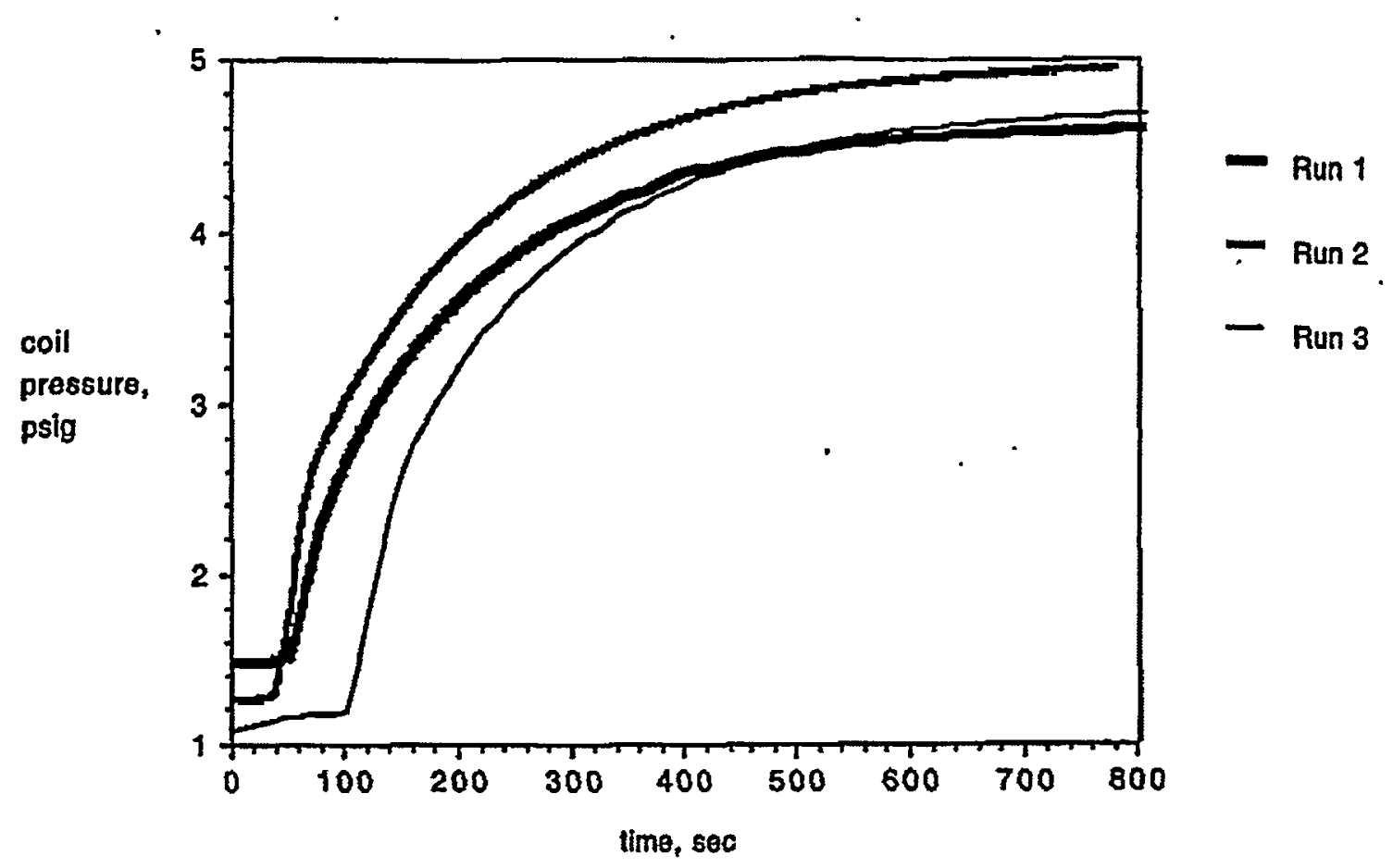

Figure 4.6 Transient for Coil \#1 and 1 atm

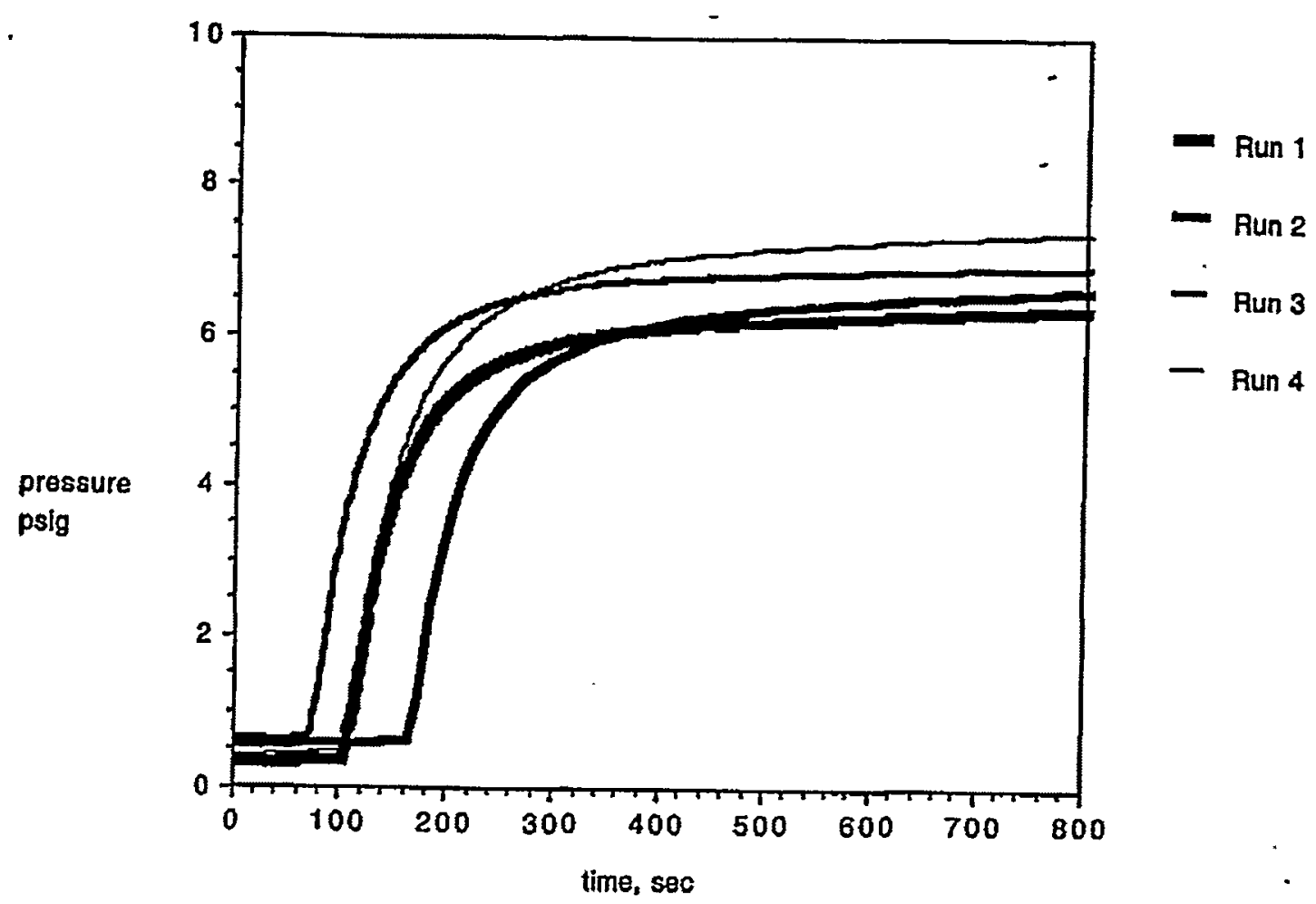

Figure 4.7 Transient for Coil \#2 and 1 atm 


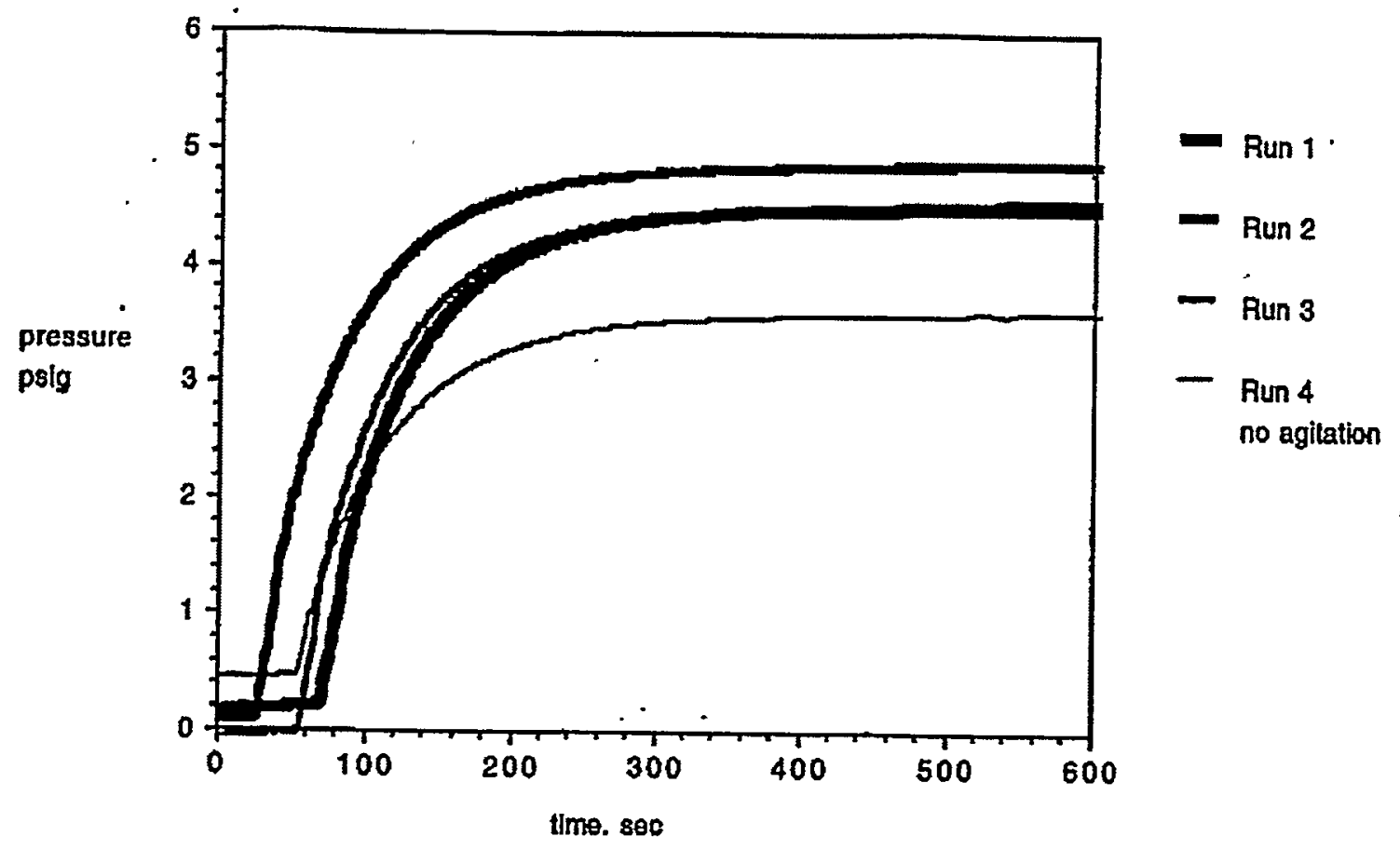

Figure 4.8 Transient for Coil \#3 and 1 atm

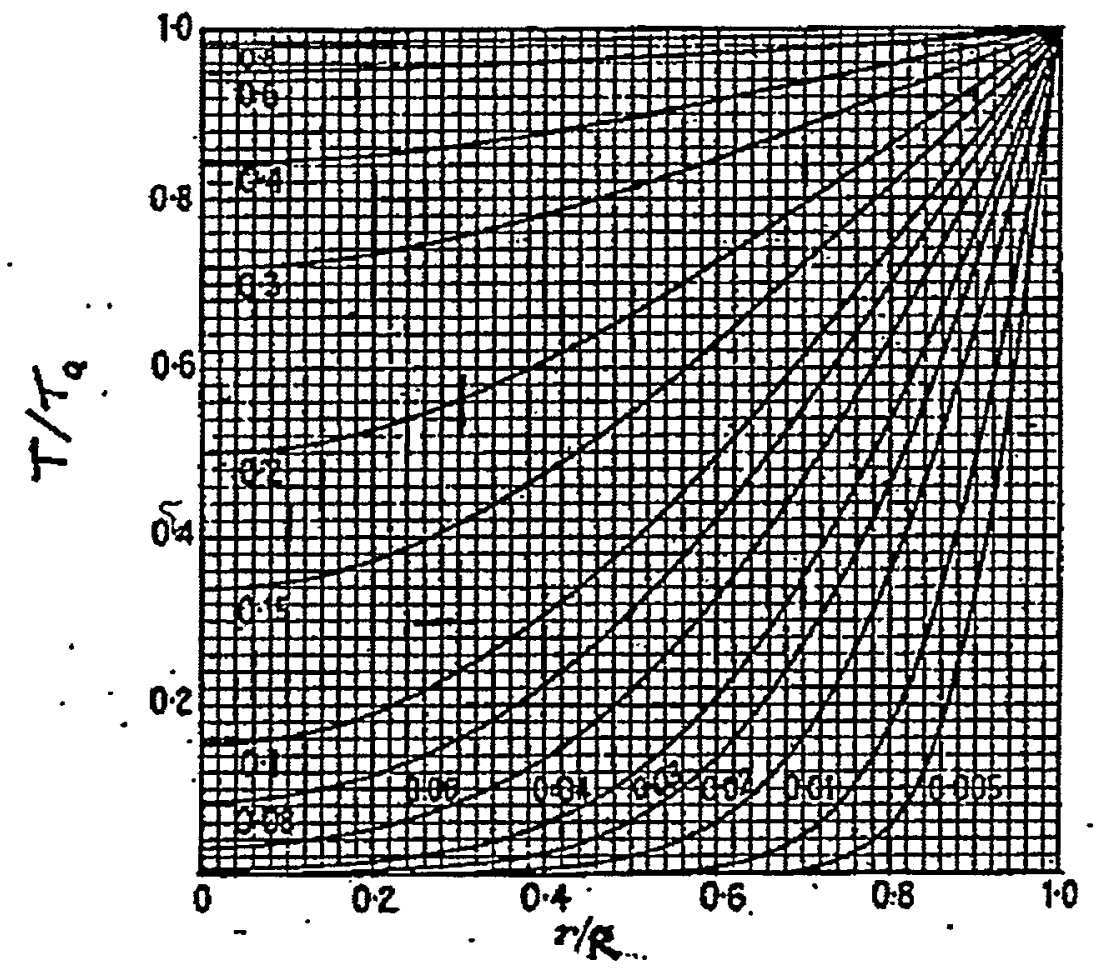

Figure 4.9 Temperature Distribution at Various Times in a Cylinder of Radius $\mathbf{R}$ with Zero Initial Temperature and Surface Temperature V. The Numbers on the Curves are Values of $\alpha \cdot t / R^{2}$, from Carslaw [1959]. 
WSRC-TR-99-00348, Rev. 2

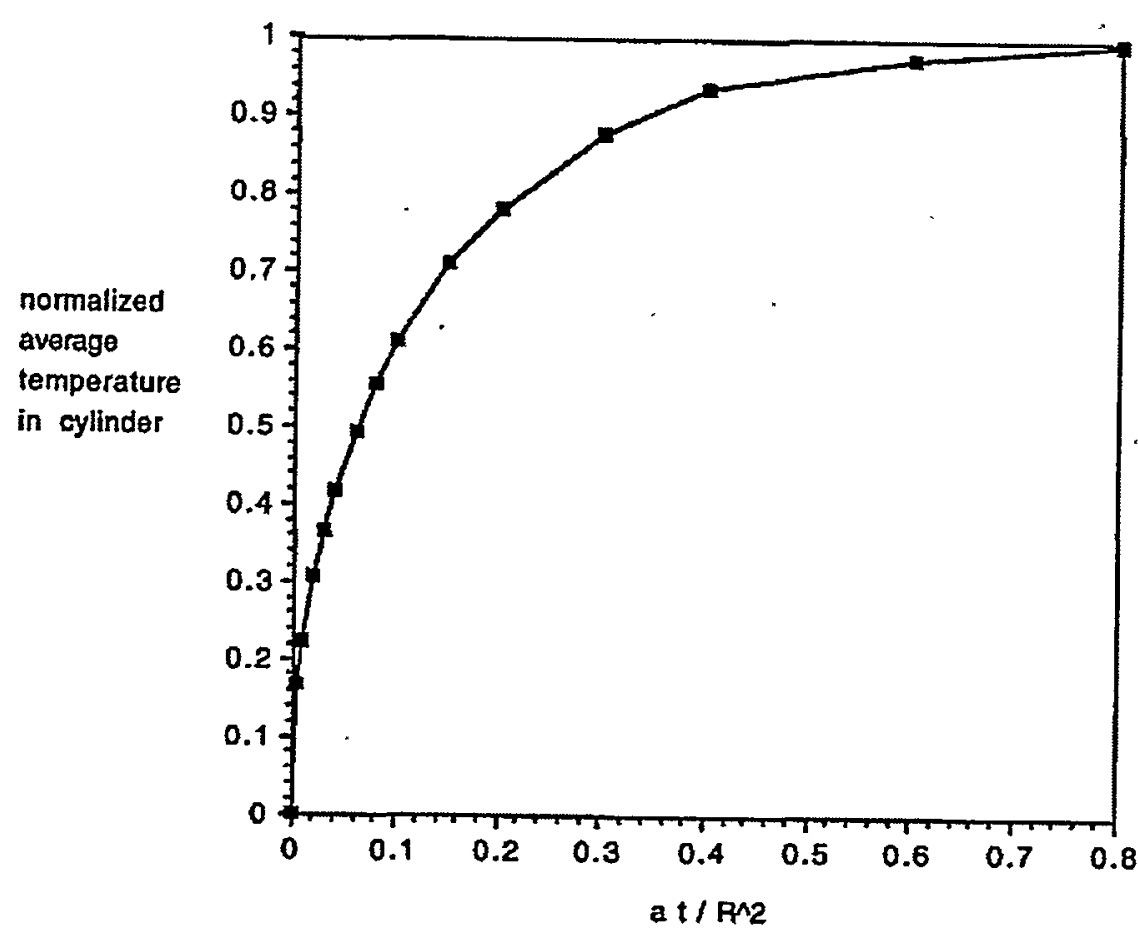

Figure 4.10 Transient Average Temperature in Cylinder with Conduction 

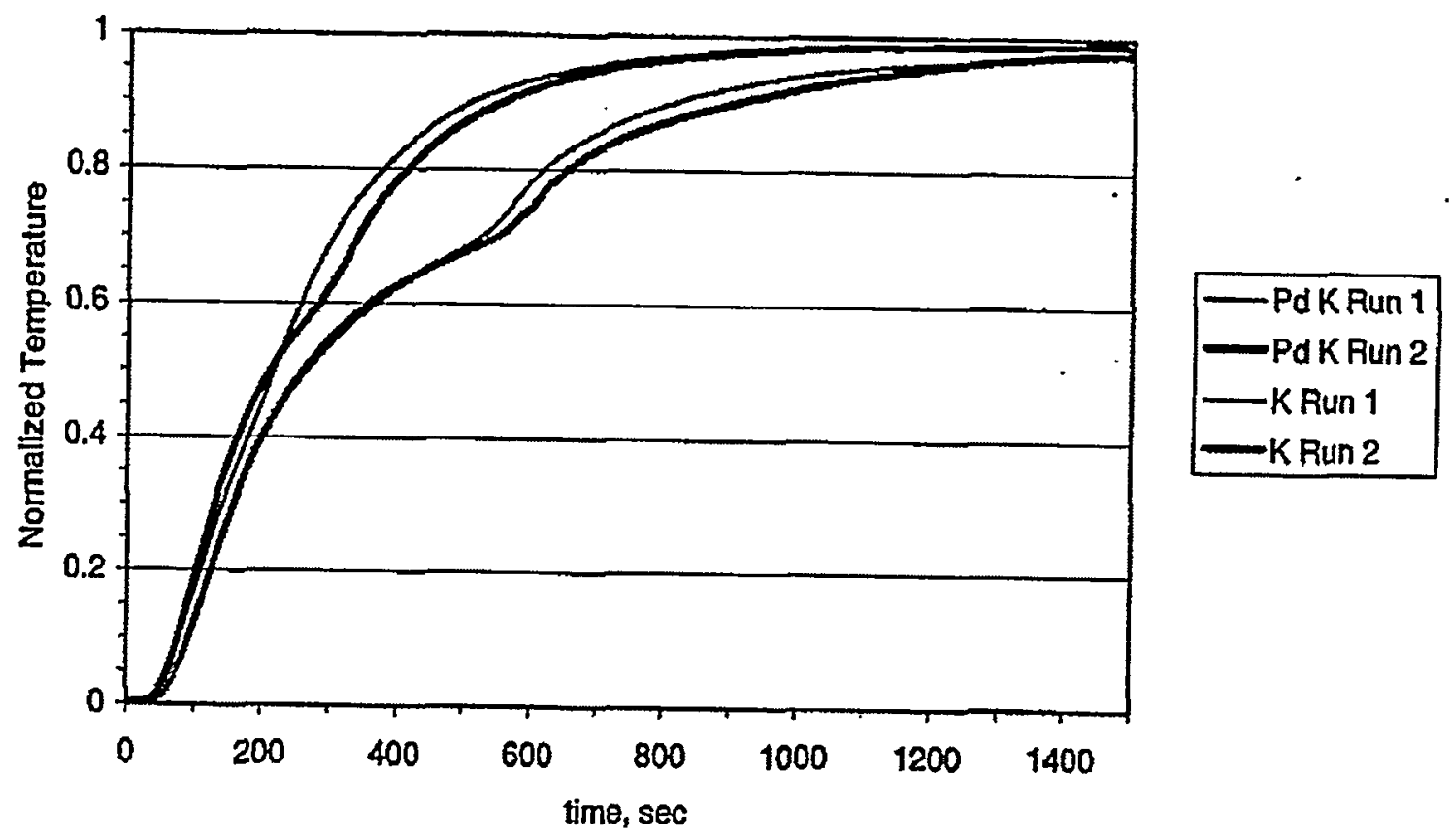

Figure 4.11 Temperature Transients at Centerline of Sphere.
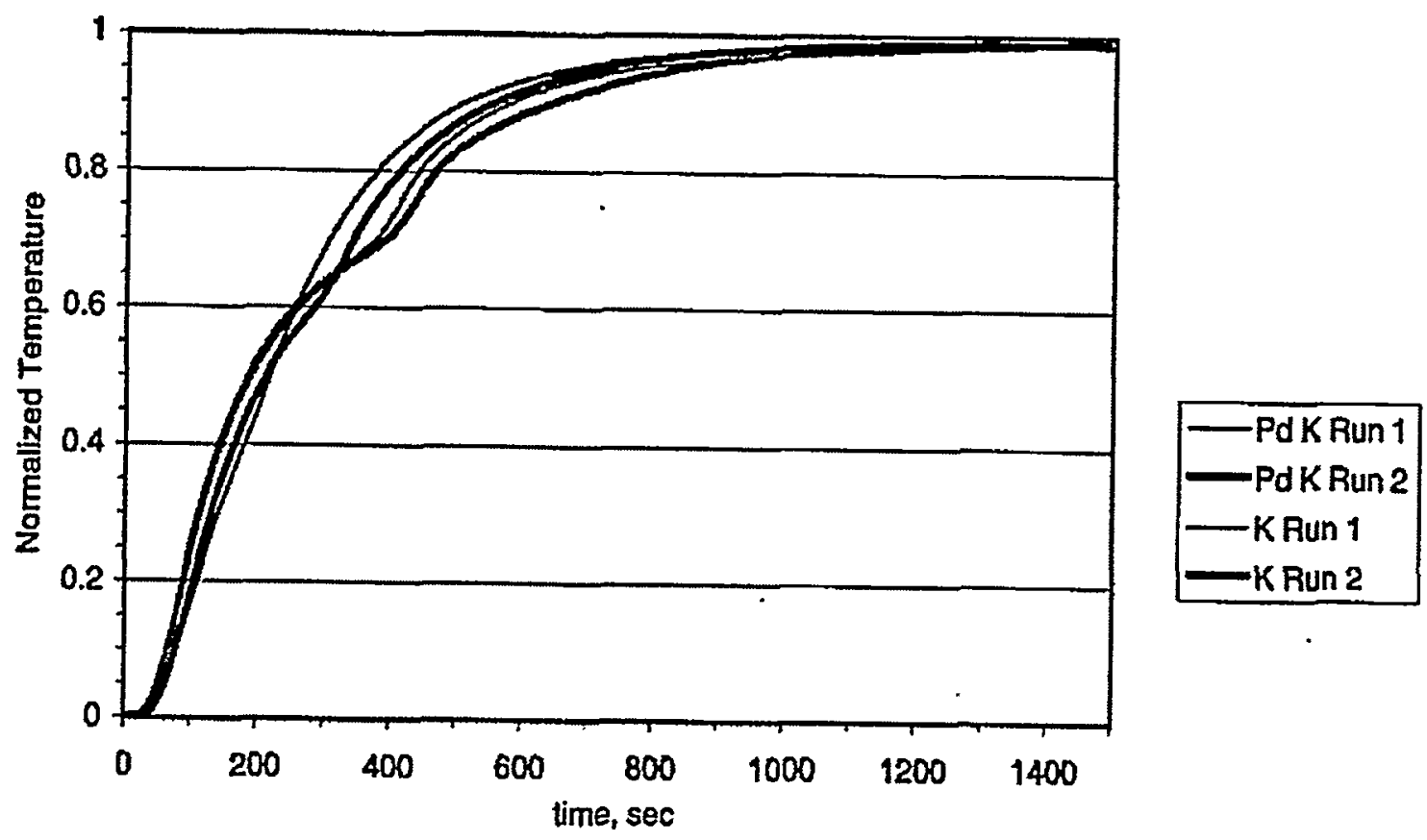

Figure 4.12 Temperature Transients at Centerline of Sphere Times for K Divided by 1.4. 


\section{Chapter 5}

\section{RESULTS AND DISCUSSION}

\subsection{Review of Analytical Model}

As mentioned in Chapter 3, the critical parameters of the new TCAP heat exchanger are the 1) heating and cooling loads; 2) the hot and cold nitrogen temperatures and nitrogen circulation rate; and 3) the heat transfer coefficients controlling the heat transfer between the nitrogen and the $\mathrm{Pd} / \mathrm{k}$ in the packed column.

The heating and cooling loads of the heat exchanger assembly were minimized by the use of the inner shell as a flow plenum prior to distribution of the cooling medium into the annulus and over the coiled packed column containing the $\mathrm{Pd} / \mathrm{k}$. The surface area for heat transfer is restrained by the coil diameter of the packed column, its length, and the minimum fabrication tolerances of the inner and outer shells. Because of the Pd/k packing (with or without foam), the minimum diameter the 2 inch tube could be rolled to is 20 inches center to center. The new column length is restrained to 39 feet in order to match the existing 1.25 inch column. In addition, fabrication restraints on the inner and outer shells can provide no smaller gap than 0.4 inches on either side of the column inside of the annulus. With the dimensions of the heat exchanger fixed, the parametric study was based on the circulated nitrogen in the shell side of the heat exchanger.

The heat transfer in the TCAP heat exchanger could be increased by increasing the temperature gradient between the $\mathrm{Pd} / \mathrm{k}$ in the packed column and the circulating 
nitrogen in the annulus of the heat exchanger. Unfortunately, due to maintenance requirements, the nitrogen supply temperatures are fixed at $-40^{\circ} \mathrm{F}$ and $349^{\circ} \mathrm{F}$ for cold and hot, respectively. Though not as beneficial as increasing the temperature, the nitrogen flow rate can also be varied in order to achieve an optimum cooling and heating time. With a higher nitrogen flow rate, a higher heat transfer coefficient may be achieved, resulting in faster cooling and heating times. This study in nitrogen flow is conducted, but must be considered in parallel with the heat transfer coefficient in the $\mathrm{Pd} / \mathrm{k}$ column.

Since flow is the only available nitrogen variable, the parametric studies are focused on the optimization of the packed column composition. In order to meet the cooling times of the existing 1.25 inch packed column with the 2 inch column (providing $180 \%$ additional throughput), accurate modeling of the packed column with variance of its wall material and heat transfer enhancement medium (metal foam) is imperative.

\subsection{Definition of Cases}

A total of seven different cases for the $\mathrm{Pd} / \mathrm{k}$ packed column are modeled, one for the existing and six for the new. These seven cases are defined below in Table 5.1. 
WSRC-TR-99-00348, Rev. 2

Table 5.1. Definition of Cases for Model.

\begin{tabular}{|c|c|c|c|c|c|}
\hline Case No. & $\begin{array}{c}\text { Column } \\
\text { Outside } \\
\text { Diameter } \\
\text { (inch) }\end{array}$ & $\begin{array}{c}\text { Column } \\
\text { Wall } \\
\text { Thickness } \\
\text { (inch) }\end{array}$ & $\begin{array}{c}\text { Column Wall } \\
\text { Material }\end{array}$ & $\begin{array}{c}\text { Foam } \\
\text { Material }\end{array}$ & $\begin{array}{c}\text { Nitrogen } \\
\text { Flow Rate* } \\
\text { (lbs/hr) }\end{array}$ \\
\hline 1 & 1.25 & 0.065 & 316 S.S. & None & 3800 \\
\hline 2 & 2 & 0.065 & Copper & None & 7000 \\
\hline 3 & 2 & 0.065 & 316 S.S. & None & 7000 \\
\hline 4 & 2 & 0.065 & Copper & Aluminum & 7000 \\
\hline 5 & 2 & 0.065 & 316 S.S. & Aluminum & 7000 \\
\hline 6 & 2 & 0.065 & Copper & Copper & 7000 \\
\hline 7 & 2 & 0.065 & 316 S.S. & Copper & 7000 \\
\hline
\end{tabular}

*See Section 5.3 for selection of nitrogen flow rate.

Note that copper has the highest thermal diffusivity and thus has the quickest response to changes in its thermal environment.

\subsection{Effect of Varying Nitrogen Flow}

The existing 1.25 inch heat exchanger has a fixed design nitrogen flow rate of $3800 \mathrm{lbs} / \mathrm{hr}$. However, before proceeding with other comparisons for heating and cooling times and their dependence upon other parameters such as column diameter, and material composition, an optimum flow for the new 2 inch heat exchanger is determined and selected. Based upon the above initial assessment of the copper wall with copper foam having the highest heat transfer rate, Case 6 is used to determine the cooling and heating times versus supplied nitrogen flow rate.

After calculating the masses and areas for each of the 10 sections designated in Section 3.8, the heat transfer coefficients for the nitrogen side of the heat exchanger are calculated using equations (3.1) - (3.9) for nitrogen flows between 500 and 20,000 lbs/hr. 
WSRC-TR-99-00348, Rev. 2

Based on the Reynolds number, the Dittus-Boelter equation is valid for all nitrogen flows in the range considered. Likewise, Zukauskas' correlation for subcritical flow (Reynolds number) in the annulus is applicable for the complete range of nitrogen flows. For the $\mathrm{Pd} / \mathrm{k}$ packed column, the modified Reynolds number is calculated per equation (3.12), and found to be 0.06 , on the order of zero, allowing the use of the stagnant correlations provided by Ofuchi and Kunii [1964] and equations (3.13) - (3.21) for calculating the effective heat transfer coefficient in the $\mathrm{Pd} / \mathrm{k}$ column with copper foam.

With all input data known, the transient heat transfer calculations are performed using the time dependent equations provided in Section 3.8 using a time interval of 0.1 minutes ( 6 seconds). The results of the transient heat transfer calculations for Case 6 are shown in Figure 5.1 for cooling and Figure 5.2 for heating.

To assist in the selection of the optimum nitrogen flow, pressire drop is also considered through the shell side of the heat exchanger for the nitrogen flows between 500 and $20,000 \mathrm{lbs} / \mathrm{hr}$ using equations (3.25) - (3.27). The results of the total pressure drop calculations for the copper column wall with copper foam are shown in Figure 5.1 for cooling and Figure 5.2 for heating.

From Figures 5.1 and 5.2, it is evident that the gain in cooling and heating time quickly diminishes beyond approximately $5000 \mathrm{lbs} / \mathrm{hr}$, and the curve quickly becomes asymptotic. This curve profile is expected due to the limitation of heat transfer from the $\mathrm{Pd} / \mathrm{k}$ packed column to the nitrogen in the annulus. Also as expected, the pressure drop through the heat exchanger increases proportional to the square of the mass flow rate (velocity). Consequently, the total pressure drop is not very high, considering the supply pressure of $150 \mathrm{psia}$ for the nitrogen system, however, 10,000 $\mathrm{lbs} / \mathrm{hr}$ would seem a logical 
maximum. Based upon the profiles shown in Figures 5.1 and 5.2, the optimum flow rate for the nitrogen system is chosen as $7000 \mathrm{lbs} / \mathrm{hr}$. Very little gain in cycle time is realized beyond this established design point; the life cycle cost for heat transfer equipment and compressors beyond this optimum would be impractical. For the cooling cycle, the time to reach $-13^{\circ} \mathrm{F}$ is about 7.9 minutes and for heating to reach $329^{\circ} \mathrm{F}$ is about 8.3 minutes.

The Reynolds number in the three main sections (shown in Figures 5.3 and 5.4) may be examined to gain a better understanding of the controlling factors for heat transfer. The Reynolds number is a dimensionless ratio of inertial forces to viscous forces and appears in correlations for both turbulent heat transfer and turbulent pressure drop. From the Figures, at cooling and heating times of approximately 8 minutes, it can be noted that the Reynolds number in the annulus over the coiled packed column is considerably smaller than that in the other sections of the heat exchanger. Although the Reynolds number for external flow over the column is not expected to equal those for internal flow in the other sections, it does offer the observation that the limiting parameter in this case is the 0.4 inch gap on either side of the column in the annulus. This fixed geometry in the annulus limits the maximum velocity that can be achieved, affecting the Reynolds number and heat transfer coefficient. With the geometry fixed and the optimum nitrogen flow rate set at $7000 \mathrm{lbs} / \mathrm{hr}$, the remainder of the parametric studies are performed. 
WSRC-TR-99-00348, Rev. 2

\subsection{Effect of Increasing Column Diameter}

In Section 3.4, the argument is presented that the effect of increasing the diameter of the packed column from 1.25 inches to 2 inches requires an increase in heat transfer coefficient by a factor of 1.7 . Using equations (3.13) - (3.17), the effective thermal conductivity in the packed column (less foam) are calculated for Cases 1,2 and 3 and found to be $0.25 \mathrm{Btu} / \mathrm{hr} \cdot \mathrm{ft} \cdot{ }^{\circ} \mathrm{F}$ for the cold cycle and $0.30 \mathrm{Btu} / \mathrm{hr} \cdot \mathrm{ft} \cdot{ }^{\circ} \mathrm{F}$ for the hot. The fact that the effective thermal conductivities are nearly equal is no surprise. The effective thermal conductivity in the packed column is a function of both the thermal conductivity of the $\mathrm{Pd} / \mathrm{k}$ and of the hydrogen and is independent of the path length for heat transfer. However, the effective heat transfer coefficient for the $\mathrm{Pd} / \mathrm{k}$ packed column is dependent upon the thermal resistance path.

The effective heat transfer coefficients within the $\mathrm{Pd} / \mathrm{k}$ packed columns without foam are shown in Figures 5.5 and 5.6, and summarized in Table 5.2.

Table 5.2. Effective Heat Transfer Coefficients for Different Diameters.

\begin{tabular}{|c|c|c|c|c|}
\hline Case No. & $\begin{array}{c}\text { Column Outside } \\
\text { Diameter (inch) }\end{array}$ & $\begin{array}{c}\text { Column Wall } \\
\text { Material }\end{array}$ & $\begin{array}{c}\text { Cold Cycle } \\
\left(\mathrm{Btu} / \mathrm{hr} \cdot \mathrm{ft}^{2} \cdot{ }^{\circ} \mathrm{F}\right)\end{array}$ & $\begin{array}{c}\text { Hot Cycle } \\
\left(\mathrm{Btu} / \mathrm{hr} \cdot \mathrm{ft}^{2} \cdot{ }^{\circ} \mathrm{F}\right)\end{array}$ \\
\hline 1 & 1.25 & 316 S.S. & 4.7 & 5.7 \\
\hline 2 & 2 & Copper & 3.0 & 3.6 \\
\hline 3 & 2 & 316 S.S. & 3.0 & 3.6 \\
\hline
\end{tabular}

For Cases 2 and 3, the effective heat transfer coefficient is independent of the column wall material. The decrease in effective heat transfer coefficient by a factor of 1.6 with increase in diameter is consistent with the earlier argument. Note that the factor of 1.6 is simply the increase in diameter, i.e. heat flow path. The increase in effective heat transfer coefficient from cold to hot conditions is expected due to the increased thermal conductivity of hydrogen in the packed column at the higher temperatures. 
WSRC-TR-99-00348, Rev. 2

\subsection{Effect of Different Column Wall Materials}

Keeping the cost and commercial availability in mind, the column wall tubing is modeled as either copper or 316 stainless steel. Even with the advent of such new alloys as Inconel, Monel, and Titanium etc., copper and aluminum remain the predominant materials for fabrication of heat exchanger equipment. Aluminum is not considered here due to its relatively low yield strength, low resistance to thermal shock, and fabrication concerns. The thin wall tubing in the heat exchanger is exposed to 150 psia nitrogen pressure while being cycled with the hot and cold nitrogen. This concern combined with the welding requirements for special fittings and fabrication eliminates aluminum as a candidate for column wall material. The existing 1.25 inch column is fabricated from 316 stainless steel, has performed satisfactorily since its installation, and is considered for use again.

The column wall material impacts the cooling or heating time by affecting the heat capacitance and the thermal resistance through the column wall. Higher heat capacitance increases the amount of energy stored in the material, resulting in a longer heating or cooling time. Since copper or stainless steel (S.S.) tubing would have the same dimensions, mass would depend on density, with copper being slightly higher. However, the copper has a lower specific heat, offsetting the increased mass and resulting in a lower heat capacitance than S.S. For the 2 inch column, the capacitance for the copper wall is found to be $5.4 \mathrm{Btu} /{ }^{\circ} \mathrm{F}$, while the S.S. is $6.2 \mathrm{Btu} /{ }^{\circ} \mathrm{F}$. Therefore, the copper column wall is the most attractive for this application. 
Though usually neglected, the thermal resistance through the column wall and its impact upon the overall heat transfer coefficient through the column wall from $\mathrm{Pd} / \mathrm{k}$ to nitrogen is calculated here for completeness.' The overall heat transfer coefficients calculated from equation (3.22) for Cases 2 and 3 are shown in Figures 5.7 and 5.8 and summarized in Table 5.3.

Table 5.3. Overall Heat Transfer Coefficients for Different Column Wall Materials.

\begin{tabular}{|c|c|c|c|c|}
\hline Case No. & $\begin{array}{c}\text { Column Outside } \\
\text { Diameter (inch) }\end{array}$ & $\begin{array}{c}\text { Column Wall } \\
\text { Material }\end{array}$ & $\begin{array}{c}\text { Cold Cycle } \\
\left(\mathrm{Btu} / \mathrm{hr} \cdot \mathrm{ft}^{2} \cdot{ }^{\circ} \mathrm{F}\right)\end{array}$ & $\begin{array}{c}\text { Hot Cycle } \\
\left(\mathrm{Btu} / \mathrm{hr} \cdot \mathrm{ft}^{2} \cdot{ }^{\circ} \mathrm{F}\right)\end{array}$ \\
\hline 2 & 2 & Copper & 2.63 & 3.14 \\
\hline 3 & 2 & 316 S.S. & 2.63 & 3.14 \\
\hline
\end{tabular}

Note the overall heat transfer coefficient is only calculated for comparison purposes and is not used in the methodology for the transient heat transfer calculations. The absence of a significant difference between these overall coefficients for varying wall material demonstrates the negligible effect of wall resistance. Though the thermal effects of column wall material are not prevalent here in the cases without metal foam, contact resistance between the foam and the column wall is dependent upon material and must be considered when including foam in the packed column.

\subsection{Effect of Adding Different Metal Foams}

With the goal of increasing the heat transfer coefficient within the new 2 inch diameter packed column to match the cooling and heating times of the existing 1.25 inch column and increasing the throughput by a factor of 2.8 (See Section 2.2) per thermal cycle, metal foam is inserted into the $\mathrm{Pd} / \mathrm{k}$ packed columns. The Aluminum 6101 foam is manufactured by ERG of Oakland California, however, commercially pure copper foam 
is currently being developed. By employing the aluminum or copper foam, both with high thermal conductivities, the objective is to increase the effective thermal conductivity within the packed column by providing extended surfaces for heat transfer from the $\mathrm{Pd} / \mathrm{k}$ hydrogen to the column wall. The effective thermal conductivity within the packed bed is first calculated by equations (3.13) and (3.14) and the metal foam with $93.2 \%$ porosity and properties as discussed in Section 3.3 is inserted into the $\mathrm{Pd} / \mathrm{k}$ packed column and modeled by equations provided by Roshenow [1985] for effective thermal conductivity of a cubical array with spherical inclusions. See equations (3.18) - (3.19).

For the cold nitrogen cycle, the effective thermal conductivity is increased from $0.25 \mathrm{Btu} / \mathrm{hr} \cdot \mathrm{ft} \cdot{ }^{\circ} \mathrm{F}$ without foam to $1.31 \mathrm{Btu} / \mathrm{hr} \cdot \mathrm{ft} \cdot{ }^{\circ} \mathrm{F}$ for aluminum foam and 2.55 $\dot{\mathrm{B} t u} / \mathrm{hr} \cdot \mathrm{ft} \cdot{ }^{\circ} \mathrm{F}$ for copper. For the hot nitrogen cycle, the effective thermal conductivity is increased from $0.30 \mathrm{Btu} / \mathrm{hr} \cdot \mathrm{ft} .^{\circ} \mathrm{F}$ without foam to $1.21 \mathrm{Btu} / \mathrm{hr} \cdot \mathrm{ft} \cdot{ }^{\circ} \mathrm{F}$ for aluminum foam and $2.46 \mathrm{Btu} / \mathrm{hr} \cdot \mathrm{ft} \cdot{ }^{\circ} \mathrm{F}$ for copper. This is an increase of almost $400-500 \%$.

With the addition of the metal foam into the packed bed, a contact resistance must be considered between the foam and the column wall. Even though it is assumed the foam will be machined to a very tight tolerance to the inner diameter of the 2 inch column wall and pressed into place, a contact resistance will still exist, even at a microscopic level. This contact resistance is discussed in Section 3.5 and is included in the calculation of the effective heat transfer coefficient for the $\mathrm{Pd} / \mathrm{k}$ packed column in equation (3.21).

The effective heat transfer coefficients within the $P d / k$ packed columns with foam calculated from Equations (3.13) - (3.21) are shown in Figures 5.5 and 5.6 and summarized in Table 5.4. 
WSRC-TR-99-00348, Rev. 2

Table 5.4. Effective Heat Transfer Coefficients for Different Foams \& Wall Materials.

\begin{tabular}{|c|c|c|c|c|c|}
\hline Case No. & $\begin{array}{c}\text { Column Outside } \\
\text { Diameter (inch) }\end{array}$ & $\begin{array}{c}\text { Column Wall } \\
\text { Material }\end{array}$ & $\begin{array}{c}\text { Foam } \\
\text { Material }\end{array}$ & $\begin{array}{c}\text { Cold Cycle } \\
\left(\mathrm{Btu} / \mathrm{hr}^{2} \mathrm{ft}^{\circ} \cdot{ }^{\circ} \mathrm{F}\right)\end{array}$ & $\begin{array}{c}\text { Hot Cycle } \\
\left(\mathrm{Btu} / \mathrm{hr}_{\mathrm{ft}}{ }^{2} \cdot{ }^{\circ} \mathrm{F}\right)\end{array}$ \\
\hline 4 & 2 & Copper & Aluminum & 15.6 & 14.4 \\
\hline 5 & 2 & 316 S.S. & Aluminum & 15.6 & 14.4 \\
\hline 6 & 2 & Copper & Copper & 30.3 & 29.2 \\
\hline 7 & 2 & 316 S.S. & Copper & 30.3 & 29.2 \\
\hline
\end{tabular}

As mentioned earlier, no difference in heat transfer coefficient within the packed bed is expected for different column wall materials, only for foam material, and its associated contact resistance with the wall.

Though usually neglected, the thermal resistance through the column wall and its impact upon the overall heat transfer coefficient through the column wall from $\mathrm{Pd} / \mathrm{k}$ with foam to nitrogen is calculated for completeness. The overall heat transfer coefficients for columns with foam calculated from Equation (3.23) are shown in Figures 5.7 and 5.8 and summarized in Table 5.5.

Table 5.5. Overall Heat Transfer Coefficients for Different Foams \& Wall Materials.

\begin{tabular}{|c|c|c|c|c|c|}
\hline Case No. & $\begin{array}{c}\text { Column Outside } \\
\text { Diameter (inch) }\end{array}$ & $\begin{array}{c}\text { Column Wall } \\
\text { Material }\end{array}$ & $\begin{array}{c}\text { Foam } \\
\text { Material }\end{array}$ & $\begin{array}{c}\text { Cold Cycle } \\
\left(\mathrm{Btu} / \mathrm{hr} \cdot \mathrm{ft}^{2} \cdot{ }^{\circ} \mathrm{F}\right)\end{array}$ & $\begin{array}{c}\text { Hot Cycle } \\
\left(\mathrm{Btu} / \mathrm{hr} \cdot \mathrm{ft}^{2} \cdot{ }^{\circ} \mathrm{F}\right)\end{array}$ \\
\hline 4 & 2 & Copper & Aluminum & 9.41 & 9.37 \\
\hline 5 & 2 & 316 S.S. & Aluminum & 9.35 & 9.31 \\
\hline 6 & 2 & Copper & Copper & 13.33 & 14.02 \\
\hline 7 & 2 & 316 S.S. & Copper & 13.21 & 13.89 \\
\hline
\end{tabular}

Note the overall heat transfer coefficient is only calculated for comparison purposes and is not used in the methodology for the transient heat transfer calculations. The copper foam provides the greatest advantage for increasing the rate of heat transfer. 
WSRC-TR-99-00348, Rev. 2

\subsection{Cycle Times with Varied Parameters}

The parameters described in Sections 5.3 through 5.6 are combined and the heating and cooling cycle times calculated by the transient equations provided in Section

3.8. With the new nitrogen supply set at $7000 \mathrm{lbs} / \mathrm{hr}$ for Cases 2 through 7 , and 3800 $\mathrm{lbs} / \mathrm{hr}$ for Case 1, each of the seven cases identified in Section 5.2 are shown in Figures 5.9 and 5.10 and are summarized in Table 5.6.

Table 5.6. Cycle Times with Varied Parameters

\begin{tabular}{|c|c|c|c|c|c|c|}
\hline $\begin{array}{c}\text { Case } \\
\text { No. }\end{array}$ & $\begin{array}{c}\text { Column } \\
\text { Outside } \\
\text { Diameter } \\
\text { (inch) }\end{array}$ & $\begin{array}{c}\text { Column } \\
\text { Wall } \\
\text { Material }\end{array}$ & $\begin{array}{c}\text { Foam } \\
\text { Material }\end{array}$ & $\begin{array}{c}\text { Nitrogen } \\
\text { Flow Rate } \\
(\mathrm{lbs} / \mathrm{hr})\end{array}$ & $\begin{array}{c}\text { Cooling Cycle, } \\
\text { Time to Reach } \\
-13^{\circ} \mathrm{F} \\
(\text { Minutes) }\end{array}$ & $\begin{array}{c}\text { Heating Cycle, } \\
\text { Time to Reach } \\
329^{\circ} \mathrm{F} \\
\text { (Minutes) }\end{array}$ \\
\hline 1 & 1.25 & 316 S.S. & None & 3800 & 8.1 & 8.8 \\
\hline 2 & 2 & Copper & None & 7000 & 23.5 & 23.4 \\
\hline 3 & 2 & 316 S.S. & None & 7000 & 23.6 & 23.5 \\
\hline 4 & 2 & Copper & Aluminum & 7000 & 9.4 & 10.4 \\
\hline 5 & 2 & 316 S.S. & Aluminum & 7000 & 9.7 & 10.6 \\
\hline 6 & 2 & Copper & Copper & 7000 & 7.9 & 8.3 \\
\hline 7 & 2 & 316 S.S. & Copper & 7000 & 8.2 & 8.5 \\
\hline
\end{tabular}

From examination of the cooling cycle in Figure 5.9 and Table 5.6, three major groupings of the 7 different cases occur. Cases 1,6 , and 7 reach the cooling cycle goal temperature of $-13^{\circ} \mathrm{F}$ within the same approximate cycle time of 8 minutes. The second major grouping consists of Cases 4 and 5 , which reaches the target temperature in approximately 9.5 minutes. And the third grouping, Cases 2 and 3, reaches the desired temperature in approximately 24 minutes. The addition of copper foam to the 2 inch column provides for cooling as quickly as the existing 1.25 inch column with the added advantage of absorbing 2.8 times as much hydrogen. Although the copper foam increases the heat transfer coefficient in the packed column by a factor of 10 (See Section 
5.6), and the aluminum increases it by a factor of 5 , the same magnitude of increase is not realized in the cooling of the entire heat exchanger. The aluminum foam cases are found to lag by only 1.5 minutes. However, the cooling times for the 2 inch columns without any foam are significantly greater, on the order of 2 to 3 times as long as the existing 1.25 inch column. For each of the three major groupings of cases, no significant difference is noticed in the cooling profiles of the varying column wall materials.

Similar observations can be made regarding the heating cycle. From examination of Figure 5.10 and Table 5.6, three major groupings of the 7 different cases occur. Cases 1,6 , and 7 reach the heating cycle goal temperature of $329^{\circ} \mathrm{F}$ within the same approximate cycle time of 8.5 minutes. The second major grouping consists of Cases 4 and 5, which reaches the target temperature in approximately 10.5 minutes. And the third grouping, Cases 2 and 3, reaches the desired temperature in approximately 23.5 minutes. The addition of copper foam to the 2 inch column provides for heating as quickly as the existing 1.25 inch column with the added advantage of desorbing 2.8 times as much hydrogen. Although the copper foam increases the heat transfer coefficient in the packed column by a factor of 8 (See Section 5.6), and the aluminum increases it by a factor of 4 , the same magnitude of increase is not realized in heating of the entire heat exchanger. The aluminum foam cases are found to lag by only 2 minutes. However, the heating times for the 2 inch columns without any foam are seen to be significantly greater, on the order of 2 to 3 times as long as the existing 1.25 inch column. For each of the three major groupings of cases, no significant difference is noticed in the heating profiles of the varying column wall materials. 
WSRC-TR-99-00348, Rev. 2

\subsection{Effect of Varying Time Interval}

In the application of the conservation of energy equation (3.24), the approach is to find the energy change within the control volume (section of heat exchanger) over a specified time interval. The transient heat transfer approach is based upon the use of an adequately small time interval. In order to ensure convergence of the solution, the calculations are performed at $\Delta t$ of 0.1 minutes ( 6 seconds) and then varied to 0.01 minutes ( 0.6 seconds). With this reduction of time interval to 0.01 minutes, the cooling and heating times vary by only about 0.1 to 0.2 minutes. This confirms that the interval used is sufficiently small for this calculation.

\subsection{Comparison of Results}

From Steimke's and Fowley's experimental results presented in Chapter 4, a comparison can be made for the applicability of the model developed in this work. The experiment involved the use of three coils: \#1 with 2 inch diameter S.S. with kieselguhr in helium; \#2 with 2 inch diameter S.S. with kieselguhr with copper foam in helium; and \#3 with 1.25 inch diameter S.S. with kieselguhr in helium, each at one atmosphere. Additional tests were run to allow correlation between $\mathrm{Pd} / \mathrm{k}$ and kieselguhr.

The tests showed that the 2 inch coil with copper foam heated approximately 2.5 times as fast as the 2 inch coil without copper foam. The tests also showed the heat up rate of the 2 inch coil with copper foam to equal that of the 1.25 inch without foam. This is consistent with the analytical results presented in Section 5.7 and shown in Figures 5.9 and 5.10. The relative differences between cycle times for the analytical model and 
experimental tests compare well. But if the effective thermal conductivities of the columns with and without foam are compared, some differences are noted.

Although the coil tests were run with kieselguhr, further tests were run to make a correlation from the kieselguhr to the $\mathrm{Pd} / \mathrm{k}$ - which is the actual case. The temperature response was 1.4 times greater with $\mathrm{Pd} / \mathrm{k}$, implying that a factor of 1.4 could be applied to the effective thermal conductivity calculated for kieselguhr in helium. The effective thermal conductivity of the kieselguhr in helium was found to be $0.13 \mathrm{Btu} / \mathrm{hr} \cdot \mathrm{ft} \cdot{ }^{\circ} \mathrm{F}$ without foam and $0.43 \mathrm{Btu} / \mathrm{hr} \cdot \mathrm{ft} .^{\circ} \mathrm{F}$ with copper foam. After applying the factor for $\mathrm{Pd} / \mathrm{k}$ in helium, the tests indicated an effective thermal conductivity of the $\mathrm{Pd} / \mathrm{k}$ in helium to be $0.17 \mathrm{Btu} / \mathrm{hr} \cdot \mathrm{ft} \cdot{ }^{\circ} \mathrm{F}$ without foam and $0.60 \mathrm{Btu} / \mathrm{hr} \cdot \mathrm{ft} \cdot{ }^{\circ} \mathrm{F}$ with copper foam. The thermal conductivity of hydrogen is approximately $20 \%$ greater than helium at a given temperature. To determine whether this $20 \%$ difference is valid in the methods shown here, the thermal conductivity of helium is used in the Ofuchi and Kunii [1964] method discussed in Section 3.5, which results in a $20 \%$ lower effective thermal conductivity for the $\mathrm{Pd} / \mathrm{k}$ packed column with helium than with hydrogen. If this factor is applied to the above thermal conductivity for $\mathrm{Pd} / \mathrm{k}$ in helium, the tests could be extrapolated to show the effective thermal conductivity of the $\mathrm{Pd} / \mathrm{k}$ in hydrogen is $0.2 \mathrm{Btu} / \mathrm{hr} \cdot \mathrm{ft} \cdot{ }^{\circ} \mathrm{F}$ without foam and $0.72 \mathrm{Btu} / \mathrm{hr} \cdot \mathrm{ft} \cdot{ }^{\circ} \mathrm{F}$ with copper foam.

When the analytical result for effective thermal conductivity in the $\mathrm{Pd} / \mathrm{k}$ packed column is compared with that of the experimental result, the analytical model provides a value $25 \%$ greater $(0.25$ versus 0.2$)$. Although the difference is not large, another literature search was performed to find a more accurate correlation for effective thermal conductivities of stagnant packed beds. Schumann and Voss [1934] provided a 
correlation by plotting the ratio of conductivity of the bed to the gas (hydrogen) versus the ratio of conductivity of the solid $(\mathrm{Pd} / \mathrm{k})$ to the gas (hydrogen) for various void fractions. With a void fraction of 0.34 and solid to gas conductivity ratio of approximately 7 , the graph indicates a bed to gas conductivity ratio of 2.9 -resulting in an effective thermal conductivity of $0.26 \mathrm{Btu} / \mathrm{hr} \cdot \mathrm{ft} \cdot{ }^{\circ} \mathrm{F}$. Roshenow [1998] provides a graphical comparison of six different correlations for effective thermal conductivity from different investigators at a void fraction of 0.38 . With adjustment for the difference in void fraction ( 0.34 vs. 0.38$)$, this graph also indicates a bed to gas conductivity ratio of 2.9. These seven different correlations agree well with the analytical model.

If the analytical result for the improvement of the effective thermal conductivity by adding copper foam is compared to the experimental value, the analytical model provides a factor of 10 improvement ( 2.55 vs 0.25$)$, while the experimental tests provided a factor of 3.6 improvement. There is a large disparity between the analytical and experimental results. However, from the Hydrogen Bus Project at the Savannah River Site, Heung [1997b] reported that the effective heat transfer coefficient in a metal hydride hydrogen storage bed increased by a factor of 5 when aluminum foam was added to the packed bed. This information directly correlates with the factor of 5 improvement in effective heat transfer coefficient found by the analytical model in Section 5.7 when using aluminum foam. Copper has a thermal conductivity which is two times that of aluminum. Therefore, a greater benefit from copper foam (a factor of 10) would be expected over that of aluminum.

According to Heung [1999], the copper foam used in the tested coil is from a manufacturer other than ERG. The ERG copper foam was not available at the time of 
testing. The ERG foam has higher thermal conductivity as a result of the ligaments formed during manufacturing. The ligaments in the tested copper foam are coarse and poorly connected. In addition, Heung [1999] also states that the copper foam in the tests were not tightly in contact with the inner wall of the column. Given these issues, the copper foam was unable to serve as a matrix of extended surfaces from the $P d / k$ to the column wall, thus impeding the heat transfer and lowering the effective heat transfer coefficient within the packed bed. 


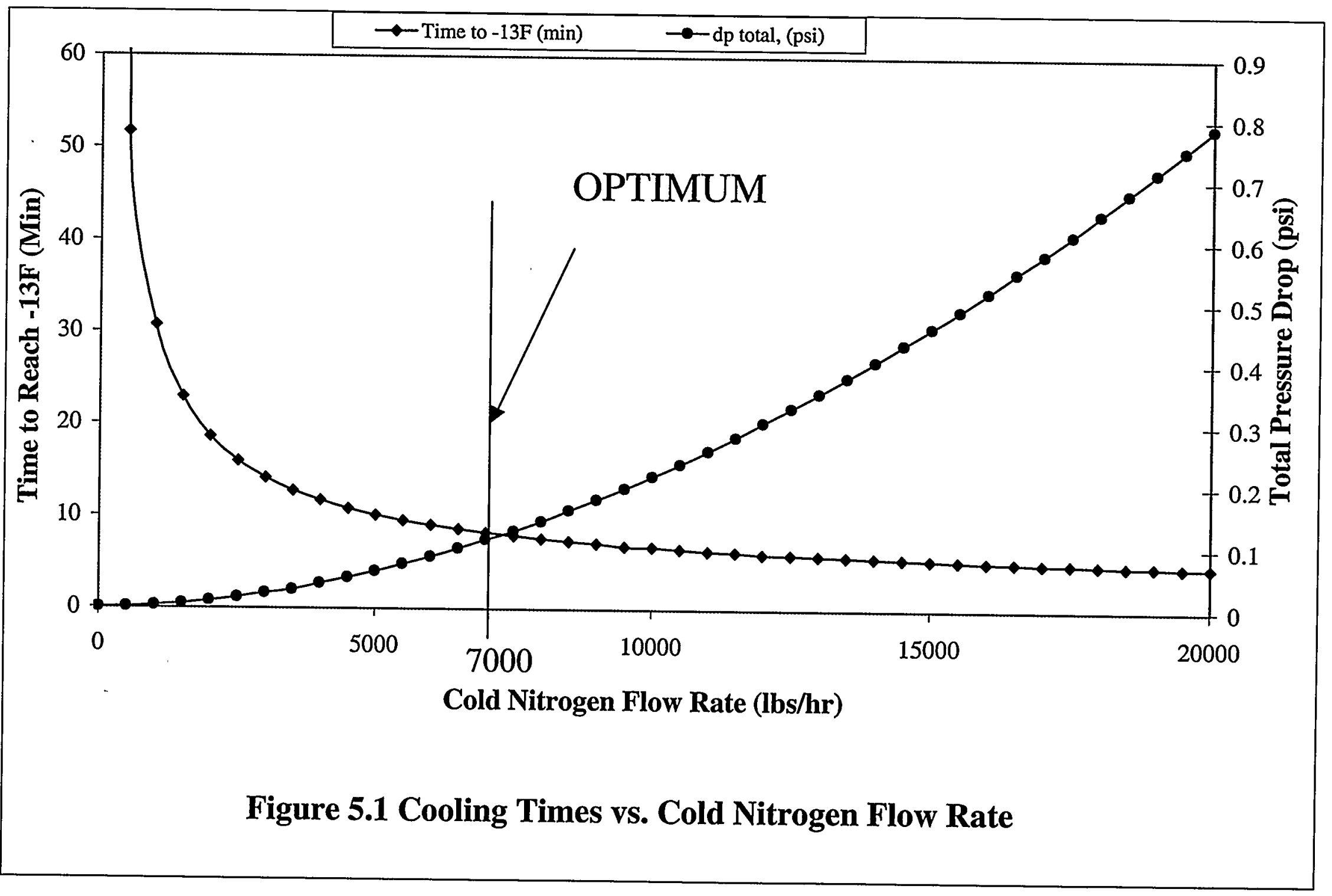




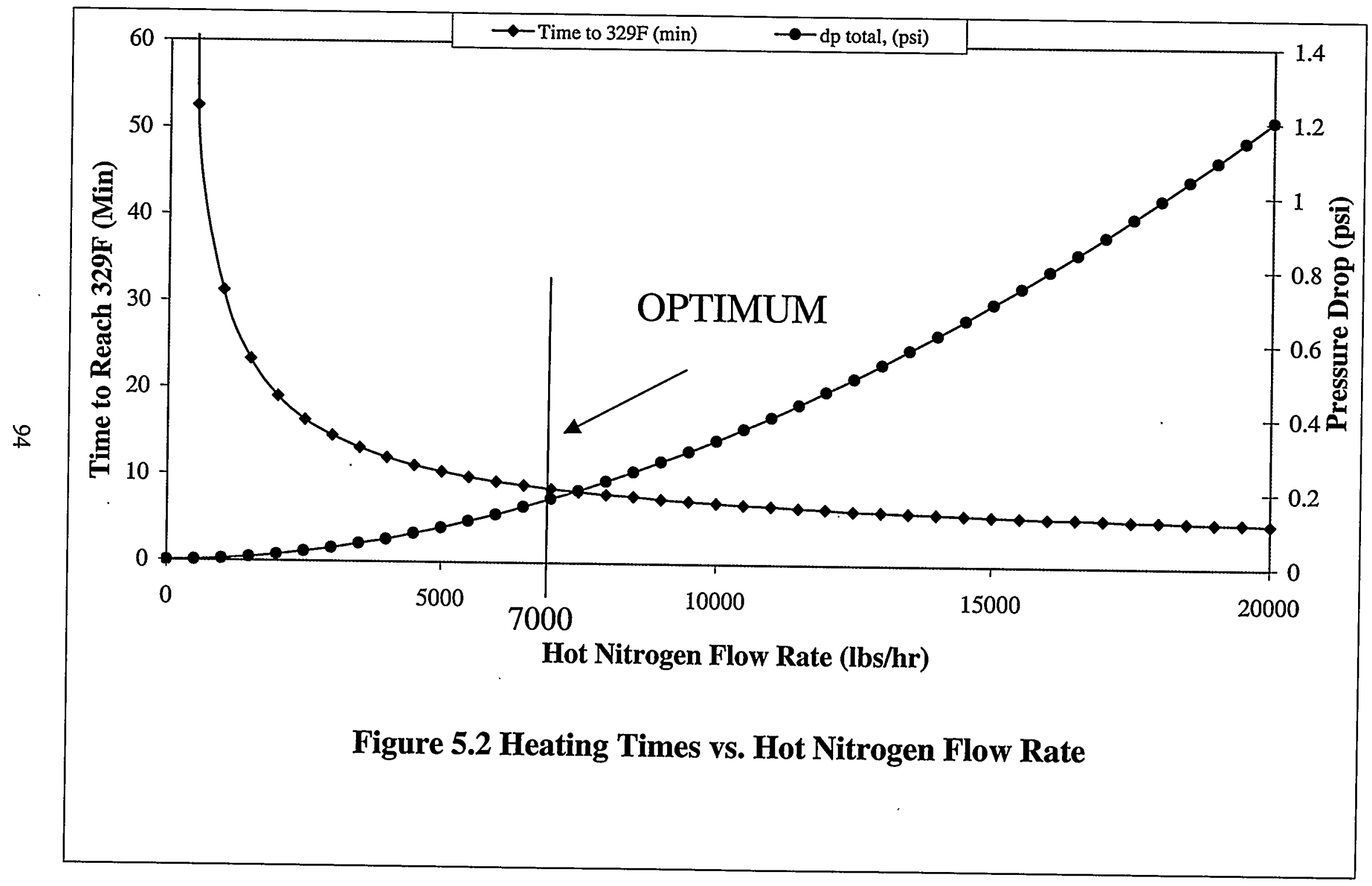




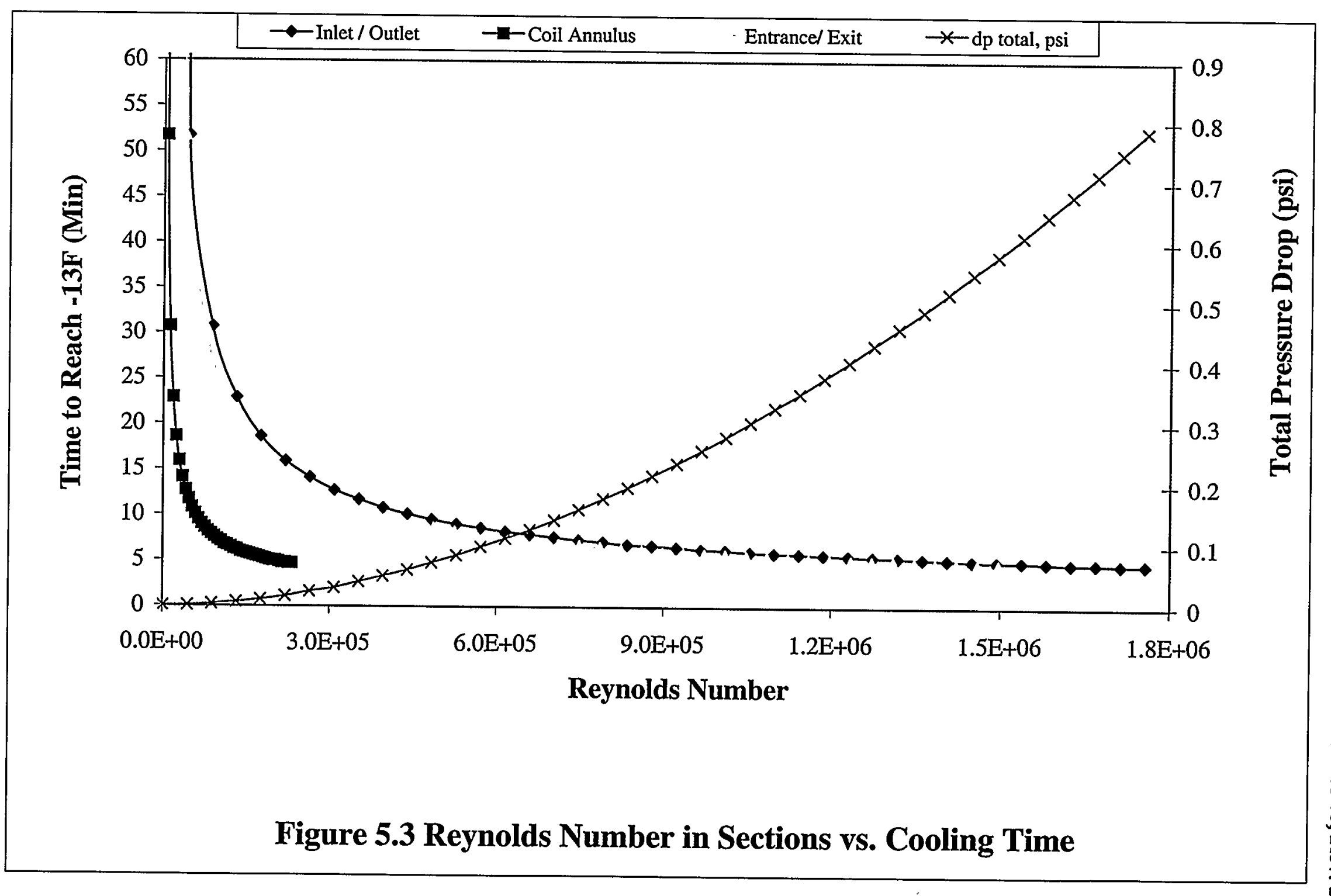




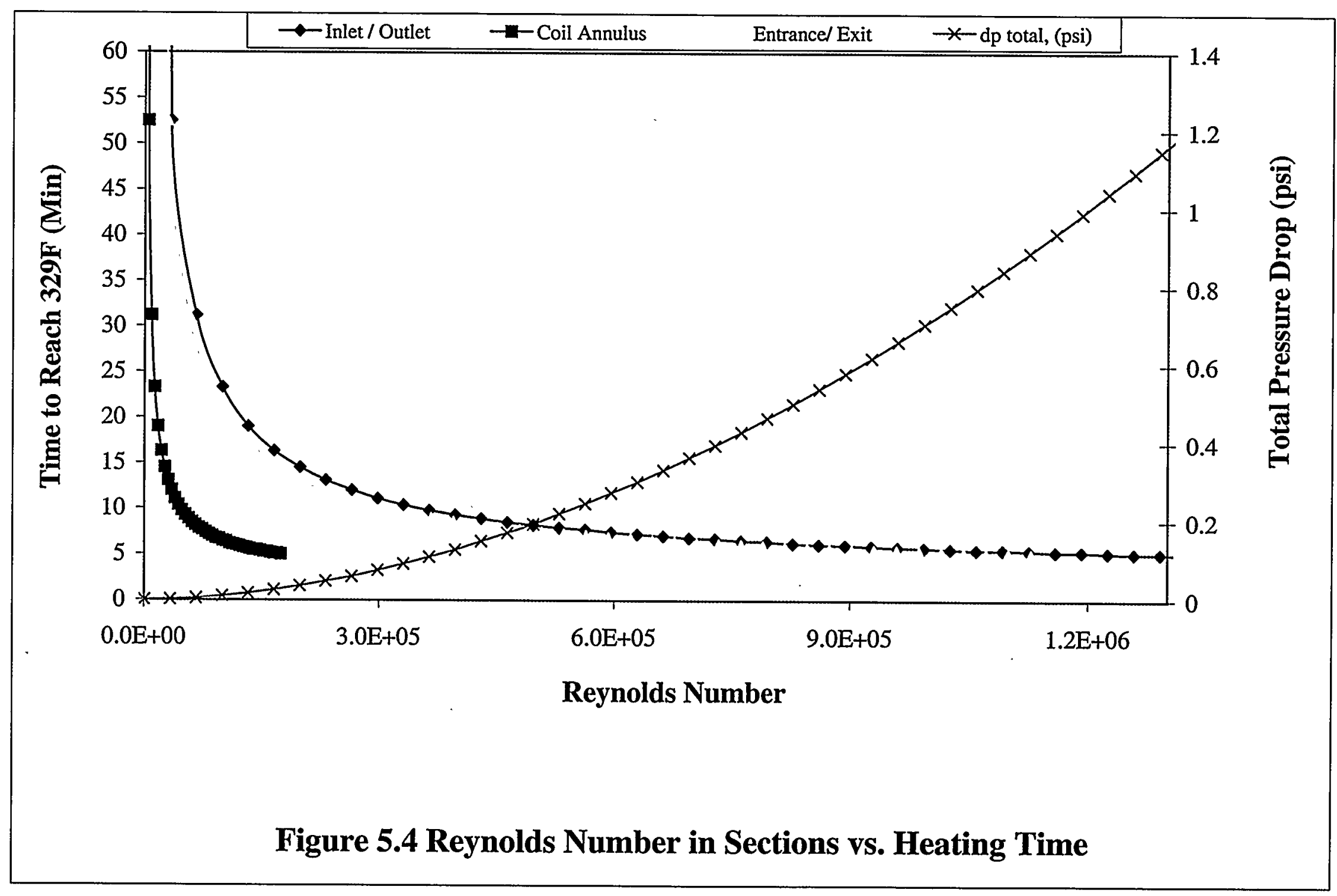

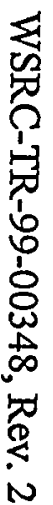


WSRC-TR-99-00348, Rev. 2

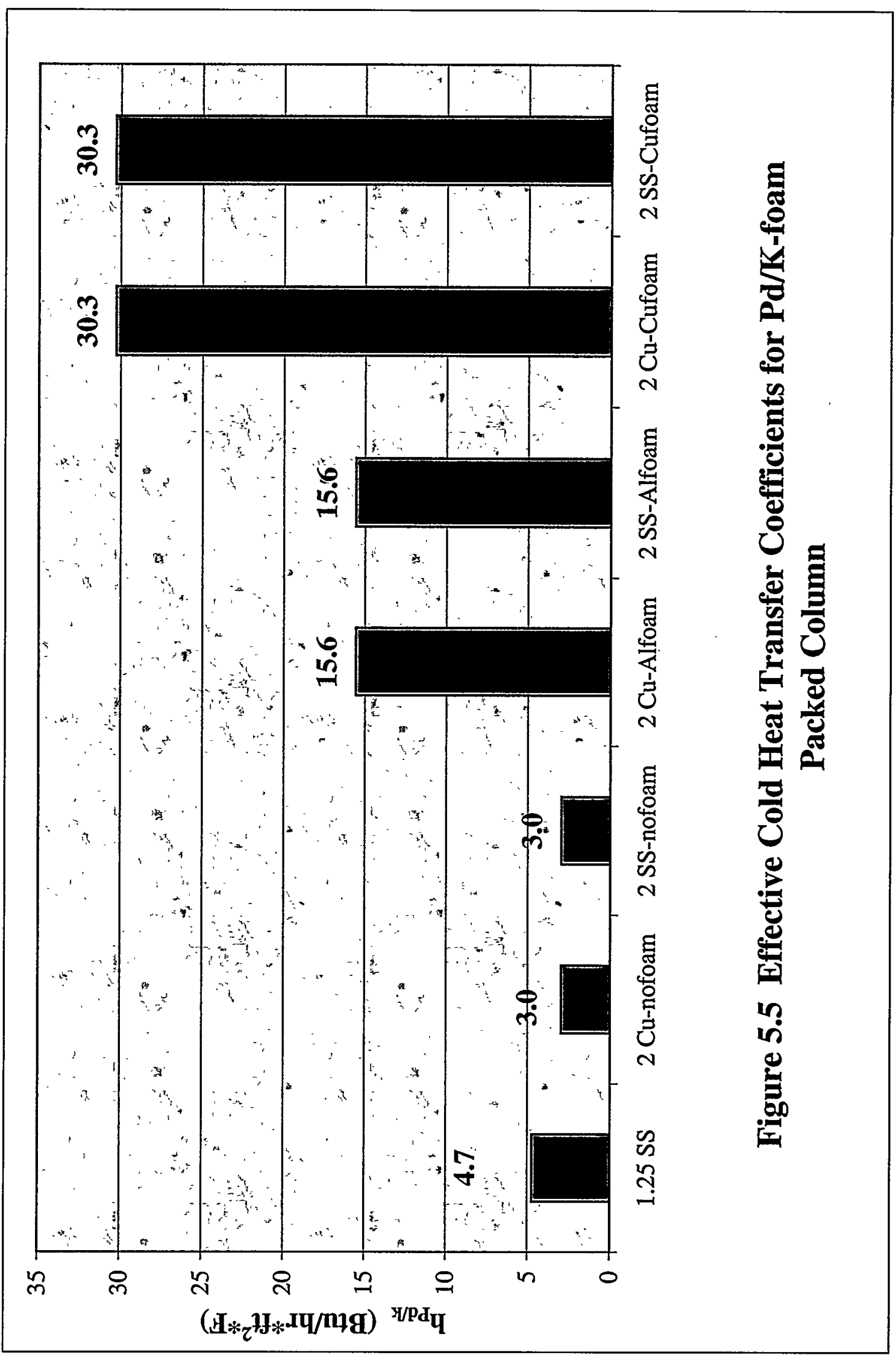


WSRC-TR-99-00348, Rev. 2

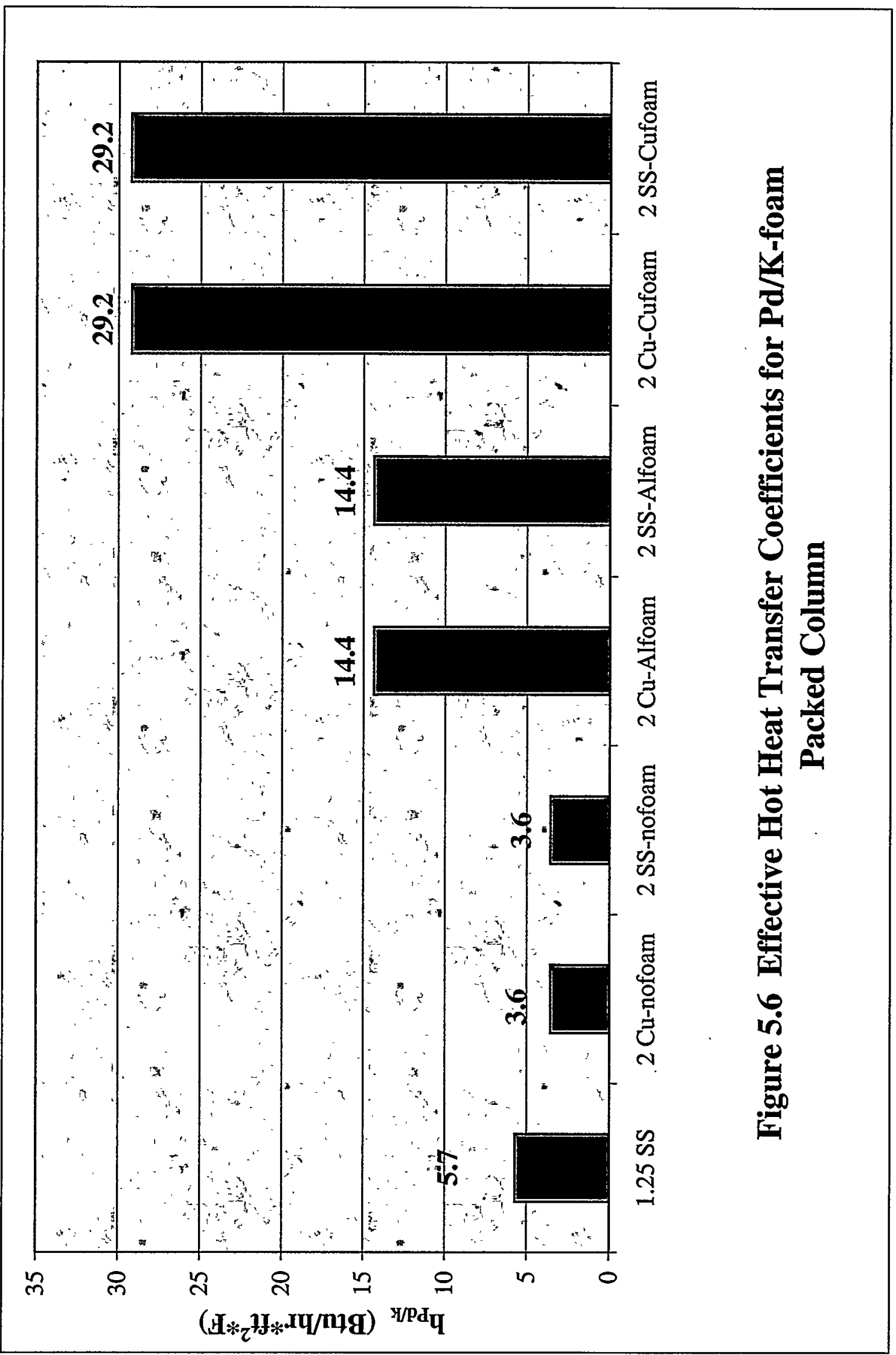




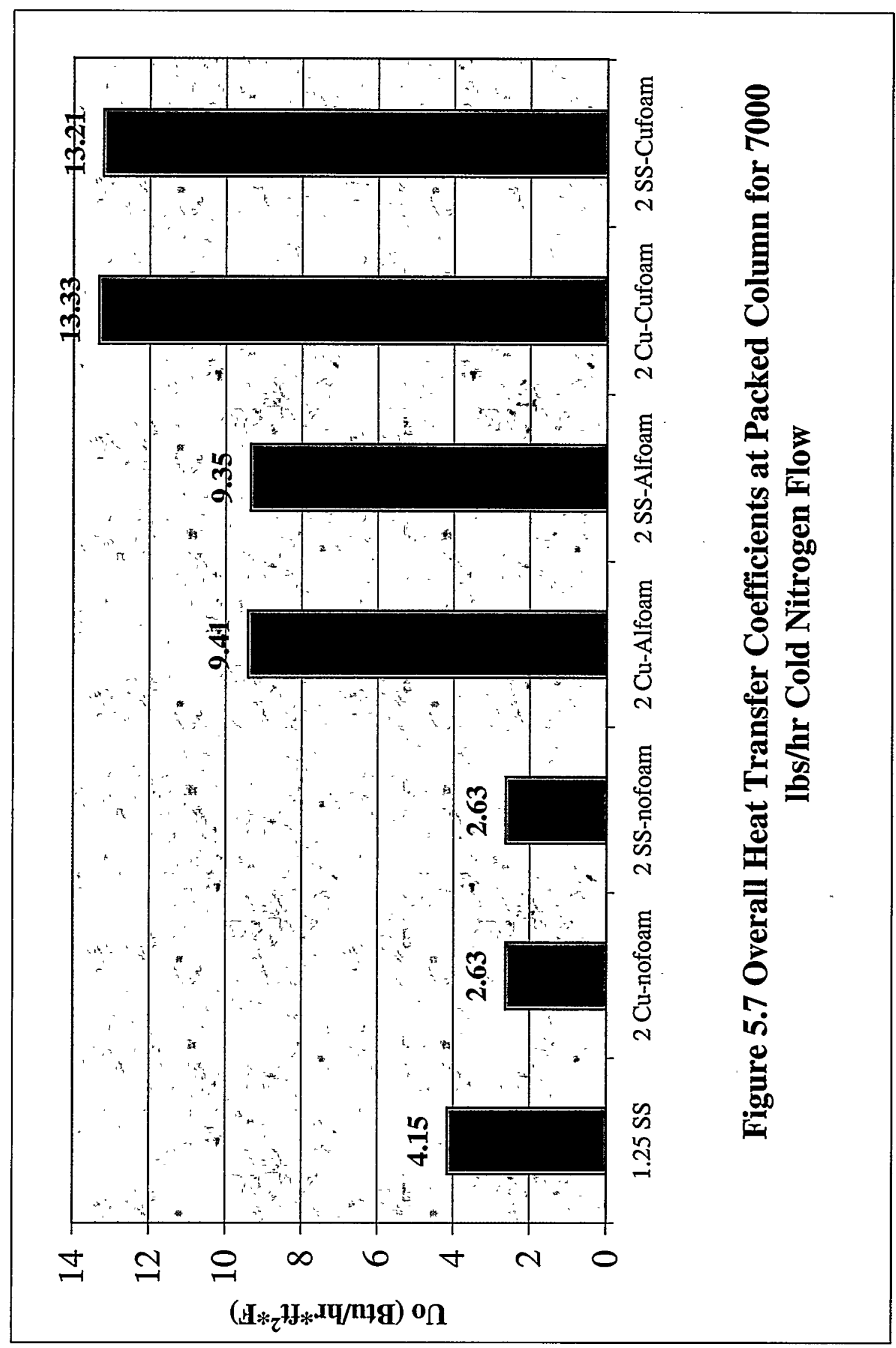


WSRC-TR-99-00348, Rev. 2

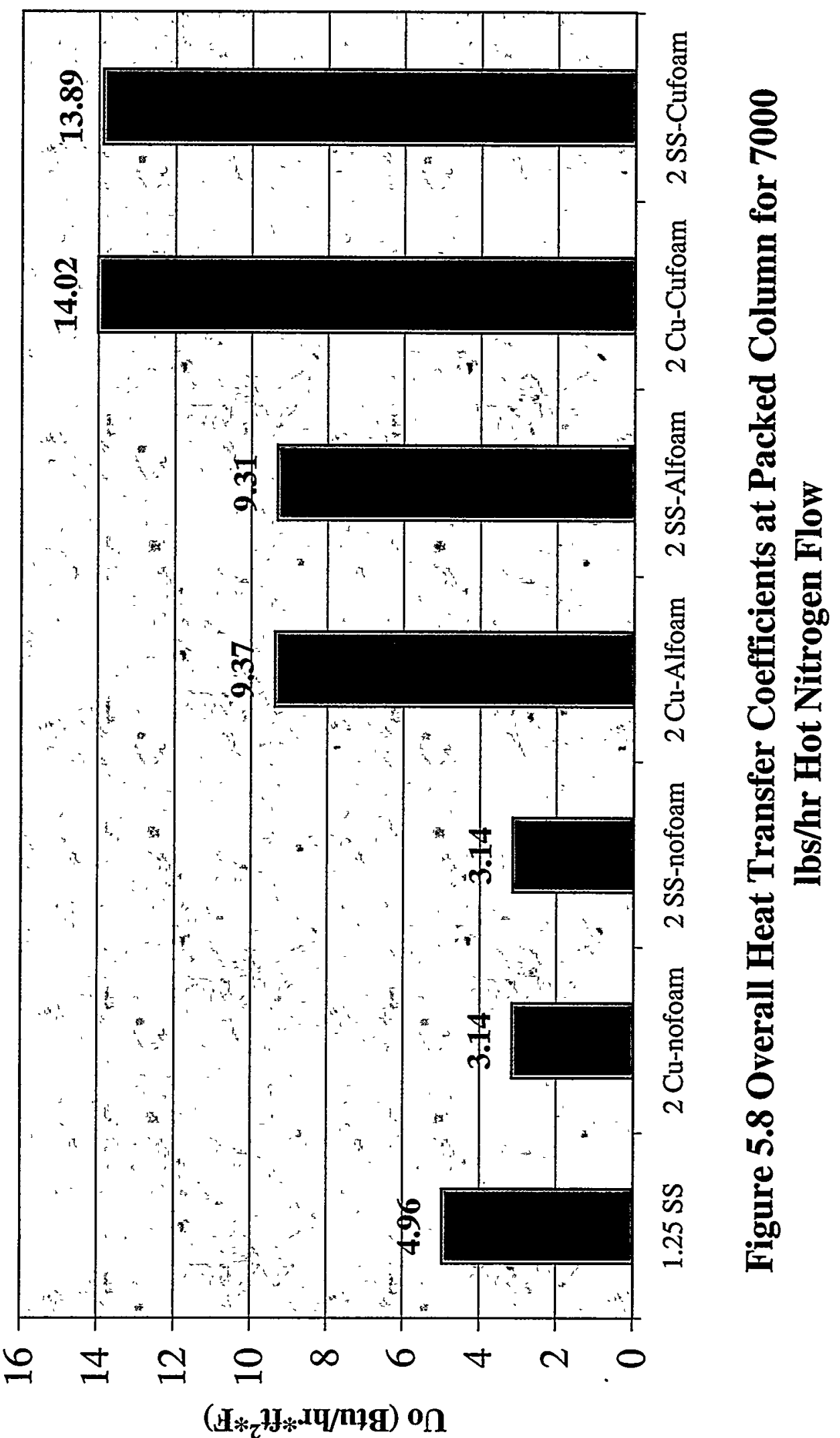




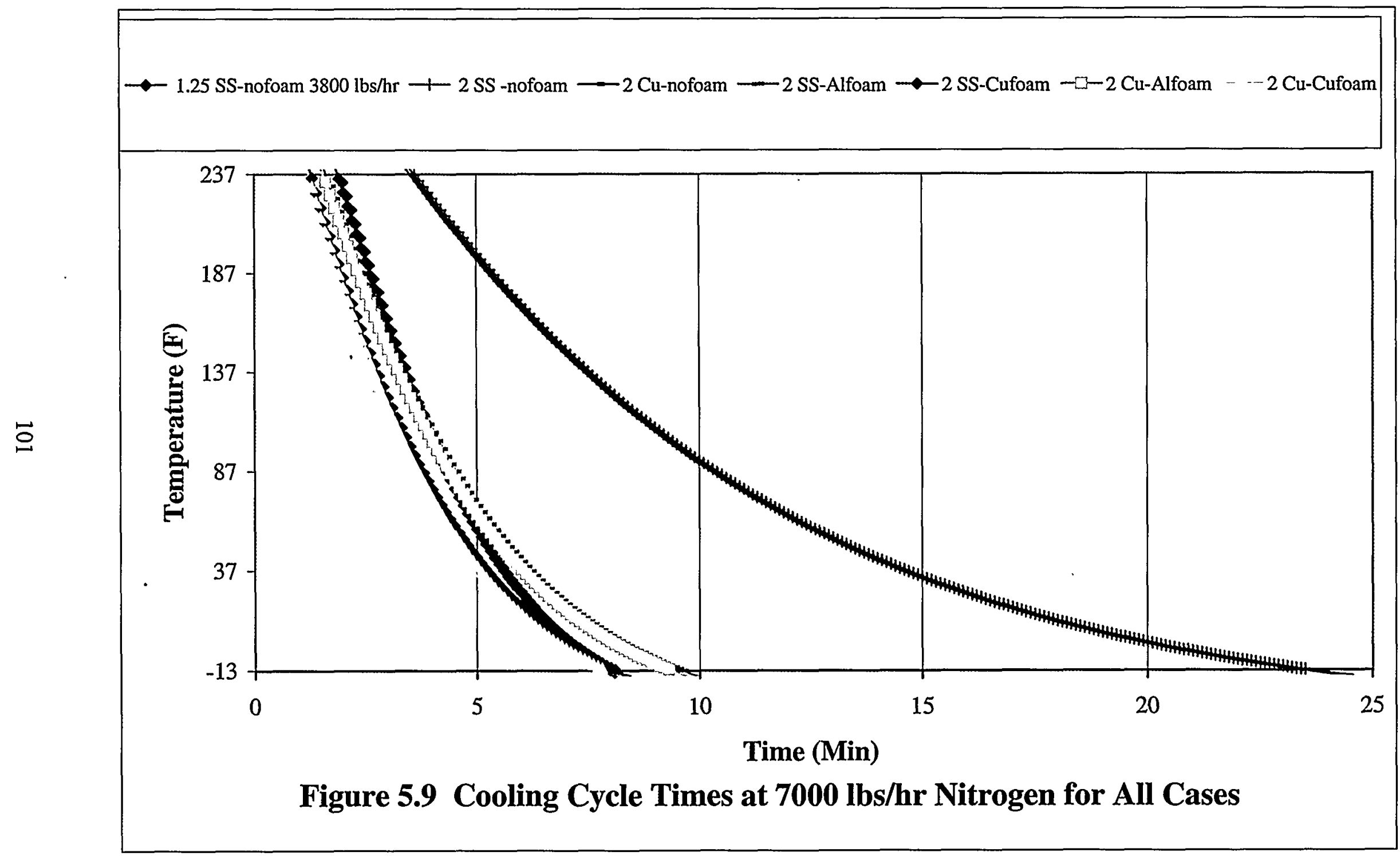

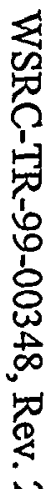




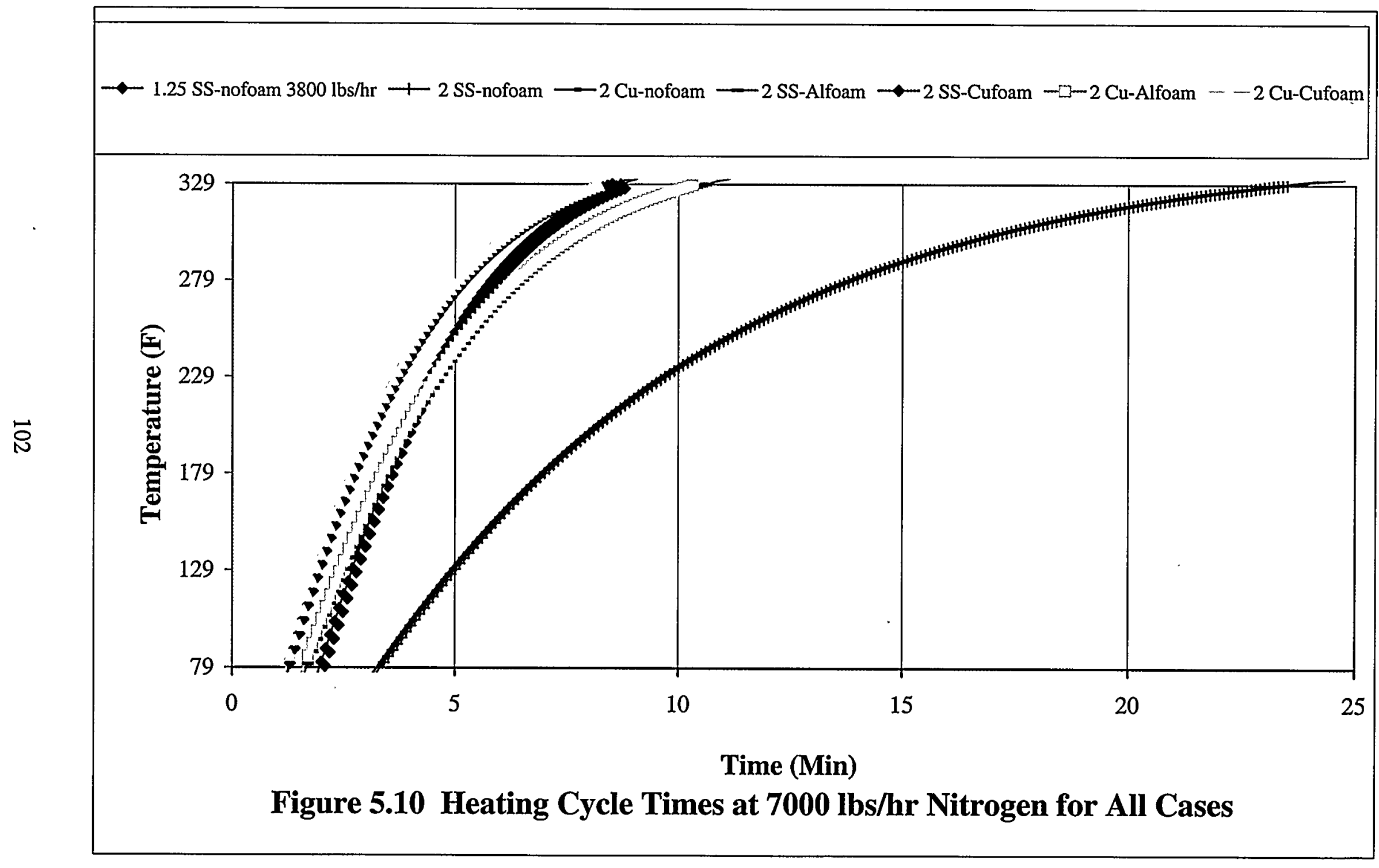


WSRC-TR-99-00348, Rev. 2

\section{Chapter 6}

\section{Conclusions and Recommendations}

\subsection{Conclusions}

In this thesis, an analytical model is developed to understand and calculate the heat transfer in a metal hydride based hydrogen separation process. The purpose of this work is to establish a means for increasing the heat transfer in a $\mathrm{Pd} / \mathrm{k}$ packed column using geometric, material, and analytical variables, as well as to examine possibilities for increasing the outside nitrogen heat transfer coefficient.

Considering pressure drop and thermal cycle duration, an optimum nitrogen flow rate is selected. An increase in flow rate beyond this optimum point adds no real benefit to cooling or heating cycling times and increases the energy load for the supporting equipment. With the geometry and nitrogen supply temperatures and flows fixed, no further increase in the nitrogen heat transfer coefficient is obtained. Although the helical column has a slight pitch out of the normal flow direction, the swirl flow following the length of the column is negligible

Increasing the column diameter has no impact on the effective thermal conductivity within the bed, but does decrease the effective heat transfer coefficient in the packed bed. This decrease in heat transfer coefficient is directly proportional to the increase in diameter. Using a column wall material of either 316 stainless steel or copper, has essentially no effect on the cooling or heating times of the Pd/k material. 
The calculated effective thermal conductivity in the $\mathrm{Pd} / \mathrm{k}$ - hydrogen packed column is $25 \%$ higher than that found from extrapolated laboratory testing using corrections to the kieselguhr and helium tests. Despite these tested results, results from several investigators compare well with the calculated value (within 5\%). Conducting lab tests based upon kieselguhr and helium to provide comparison to actual operation with $\mathrm{Pd} / \mathrm{k}$ and hydrogen seems to have uncertainty. Therefore, the model predicts accurate results for the cases without foam.

Adding aluminum and copper foams to the packed column, increases the effective heat transfer coefficient by factors of 5 and 10 respectively. The laboratory tests with the addition of copper foam provided a factor of only 2.2 above that without foam. However, the copper foam used in the tests was of a poor quality and was not properly machined and fit into the column. Actual applications have shown a factor of 5 increase with addition of the ERG aluminum foam in a packed metal hydride. If quality copper foam can be produced equivalent to that of the aluminum, a factor of 10 increase in effective heat transfer coefficient is expected for addition of copper foam to the $\mathrm{Pd} / \mathrm{k}$ packed column.

The cycle times for the 2 inch columns with copper foam are equivalent to the 1.25 inch column without foam, and about 2.5 times shorter than the 2 inch without copper foam. These trends for the copper foam are consistent with the laboratory tests. The cycle times for the 2 inch columns with aluminum foam are approximately $25 \%$ longer than those with copper foam. Convergence of the transient model requires time intervals of 0.1 minutes. 
The analysis in this thesis provides an accurate model of the metal hydride based hydrogen separation process, TCAP heat exchanger. The general trends provided in the laboratory tests and technology application are reinforced by published results. The new larger TCAP heat exchanger with copper foam will be able to separate an additional $180 \%$ of hydrogen in the available gas stream within the same cycle time as the existing column.

\subsection{Recommendations}

The throughput from the metal hydride based hydrogen separation process is increased by any one or combination of the following: 1).increasing the heat transfer coefficient inside of the $\mathrm{Pd} / \mathrm{k}$ packed column; 2) increasing the heat transfer coefficient outside of the column in the annulus; and 3) increasing the temperature difference between the $\mathrm{Pd} / \mathrm{k}$ and the supply hot or cold nitrogen.

Increase of the heat transfer coefficient inside the $\mathrm{Pd} / \mathrm{k}$ packed column is accomplished by the addition of either copper or aluminum foam with varying effects. The addition of aluminum foam increases the effective heat transfer inside of the Pd/k packed column by a factor of 5 . This has been demonstrated in the Savannah River Site hydrogen bus project, where aluminum foam was added to a metal hydride packed bed and increased the internal heat transfer coefficient by a factor of 5 [Heung, 1997]. Due to the two-fold increase in heat transfer expected from the ERG copper foam, further laboratory testing should be conducted using equivalent porosity and quality to the aluminum foam. The development of the copper foam should be completed and used in the new 2 inch diameter packed column. If the integrity of the copper foam is not as 
predicted and thermal properties are compromised, then it is recommended that aluminum be used. Aluminum foam modeled cooling and heating times are approximately two minutes longer than that of the 2 inch columns with the copper foam. Also, increasing the hydrogen pressure to the threshold of the palladium in the packed column would not only increase the effective thermal conductivity of the column, but would allow for more hydrogen to be separated per cycle.

Since fabrication and thermal expansion restraints limit the minimum gap clearance in the annulus between the column and inner/outer shells, consideration should be given to the use of intermittent baffles between column helical turns to provide increased mixing, and therefore more efficient heat transfer at the outer column wall surface. Fins cannot be placed on the outer wall of the packed column due to its fabrication sequence. The uncoiled columin is filled with $\mathrm{Pd} / \mathrm{k}$ and foam, and then rolled to a diameter of 20 inches. The fins can not be affixed prior to rolling, and the heat of welding on the thin walled column will damage the packing foam and Pd/k. Due to the negligible increase in cooling and heating times with copper column walls over that of stainless steel, a 316 stainless steel wall is recommended for use.

There are other opportunities for improvement. Increase the temperature gradient between the goal temperature of the $\mathrm{Pd} / \mathrm{k}$ for both heating and cooling cycles. Consider using different compression equipment to achieve a greater temperature difference in the cold nitrogen supply. Alternatives to multi-stage compressors could include a blended halocarbon refrigerant with a more efficient compressor impeller design. Employ energy recovery equipment for the hot nitrogen system to utilize the heat released from refrigeration equipment and compression equipment to boost the hot nitrogen gas 
temperature. Investigate the use of different types of metal hydrides for the packed column. Solid metal hydride powders possess significantly higher thermal conductivities (and capacitance) than palladium deposited on a diatomite (kieselguhr). Another option for investigation may include obtaining smaller diameter kieselguhr on which the palladium is deposited, providing increased surface area for hydrogen absorption and desorption, and a lower void fraction in the column. The model provided in this thesis would be applicable to these alternative studies. 
WSRC-TR-99-00348, Rev. 2

\section{Bibliography}

Beek, J. (1962) "Design of Packed Catalytic Reactors," Advanced Chemical Engineering, Vol. 3, pp. 203-271.

Carslaw, H.S., Jaeger, J.C. (1959) Heat Conduction in Solids, 2nd Ed., pg. 200, Figure 24, Oxford Press, London.

Cengel, Y.A. (1998) Heat Transfer: A Practical Approach, pp. 142-143, McGraw-Hill, New York.

Chen, J.C., Churchill S.W. (1963) "Radiant Heat Transfer in Packed Beds," AIChE Journal, Vol. 9, No. 1, pp. 35-41.

Cohen, R.L., Wernick, J.H. (1981) Science, Vol. 214, pg. 1081.

Colburn, A.P. (1993) “Transactions of AIChE”, Vol 29, pp. 174-210.

Dittus, F.W., Boelter, L.M.K. (1930) University of California on Engineering, Vol. 2, p443, Berkeley.

Grimison, E.D. (1937, 1938) "Transactions of ASME," Vol. 59, pp. 583-594, Vol. 60, pp. 381-392.

Haagen-Smit, A.J. (1952) "Chemistry and Physiology of Los Angeles Smog”, Ind. Eng. Chem., Vol. 44, pg. 1342.

Fdi $\mathrm{GR}$ (1986) and Mass Transfer, Vol. 29, No. 6, pp. 909-920.

Heung, L.K. (1997a) "WSRC-TR-97-00412, Rev. 0: Conceptual Design of the Flow Through Bed", Westinghouse Savannah River Company Technical Report, Unclassified.

Heung, L.K. (1997b) "Hydrogen Power: Theoretical and Engineering Solutions", Proceedings of the Hypothesis II Symposium held in Grimstad, Norway, August 18-22, 1997. 
Heung, L.K. (1999) "WSRC-TR-99-00071, Rev. 1: TFM\&C Heat Transfer (U)", Westinghouse Savannah River Company Technical Report, Unclassified.

Heywood, J.B. (1988) Internal Combustion Engine Fundamentals, pp 5-7, McGraw-Hill, New York.

Incropera, F.P., DeWitt, D.P. (1990) Fundamentals of Heat and Mass Transfer, $3^{\text {rd }}$ Ed., pg 504, Appendix A, John Wiley \& Sons, New York.

International Critical Tables (1928), Vol.2, McGraw-Hill.

Jaguaribe, E.F., Beasley, D.E. (1984) "Modeling of the Effective Thermal Conductivity and Diffusivity of a Packed Bed with Stagnant Fluid," Int. J. of Heat and Mass Transfer, Vol. 27, No. 3, pp. 399-407.

Kays, W.M., Lo, R.K. (1952) Stanford University Technical Report No. 15.

Kays, W.M., London, A.L. (1964) Compact Heat Exchangers, $2^{\text {nd }}$ Ed., McGraw-Hill, New York.

Klein, J.E. (editor) et. al. (1997). "WSRC-TR-97-00340TL: Conceptual Design For Consolidation TCAP", Westinghouse Savannah River Company Technical Report, Unclassified and Released.

Knight, J.R. (1999) "SRT-CHT-98-2015TL: TCAP Design Basis and Fabrication Concerns", Westinghouse Savannah River Company Interoffice Memorandum, Unclassified.

Kreith, F., Bohn, M.S. (1993) Principles of Heat Transfer, $5^{\text {th }}$ Ed., Appendix 2. West Publishing, St. Paul, MN.

Kunii, D., Smith, J.M. (1960) "Heat Transfer Characteristics of Porous Rocks", AIChE Journal, Vol. 6, No.1, pp. 71-78.

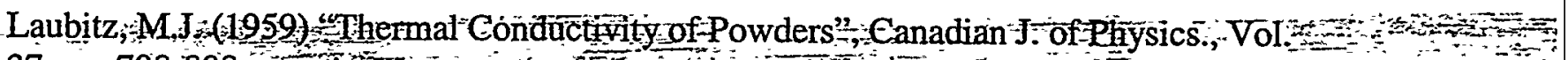
37 , pp. $798-808$.

Legawiec, B., Ziolkowski, D. (1997) "Axial Thermal Effective Conductivity in PackedBed Catalytic Tubular Reactors," Chemical Engineering Science, Vol. 52, No. 12, pp. $1875-1882$.

Lide, D.R. Editor in Chief (1995) CRC Handbook of Chemistry and Physics, $76^{\text {th }}$ Ed., CRC Press, Boca Raton.

Lin, T., Watson, J.S., Fisher, P.W. (1985) "Thermal Conductivity of Iron-Titanium Powders," J. of Chemical Engineering Data, Vol. 30, pp 369-372. 
Obert, E.F. (1973), Internal Combustion Engines and Air Pollution, $3^{\text {rd }}$ Ed., pp 342-382, Harper and Row, New York.

Ofuchi, K., Kunii, D. (1964) "Heat Transfer Characteristics of Packed Beds with Stagnant Fluids", Int. J. of Heat and Mass Transfer, Vol. 8, pp. 749-757:

Perry, J.H. (1963) Chemical Engineer's Handbook, $4^{\text {th }}$ Ed., p 5-24, McGraw-Hill, New York.

Rayleigh, Lord (1892), Phil. Magazine, Vol. 34, p 481.

Reynolds, O. (1901) "Scientific Papers of Osborne Reynolds", Vol. I, pp. 81-85, Cambridge, London.

Roshenow, W.M., Hartnett, J.P., Ganic, E.N. (1985) Handbook of Heat Transfer Fundamentals, $2^{\text {nd }}$ Ed., pp. 4-163 - 4-167, pg 4-57, McGraw-Hill, New York.

Roshenow, W.M., Hartnett, J.P., Cho, Y.I. (1998) Handbook of Heat Transfer Fundamentals, 3rd Ed., pg 9-7, Figure 9-4, McGraw-Hill, New York.

Russell, H.W., (1935) J. of American Ceramic Society., Vol. 18, p 1.

Sandrock, G.D., Huston, E.L. (1981) Chemtech, Vol. 11, pp. 754.

Scogin, J.H., Poore, A.S. (1995) "Fusion Technology: Startup and Operation of a Metal Hydride Based Isotope Separation Process", Proceedings of the Fifth Topical Meeting on Tritium Technology in Fission, Fusion, and Isotopic Applications held in Belgirate, Italy, May 28-June 3.

Schumann, T.E.W., Voss, V. (1934) Fuel, Vol. 13, pg. 239.

Shanmuganathan, N, Fleming Jr., W.H. (1999) "M-CLC-H-01697, Rev. B: Calculate the Times Required for Heating and Cooling the Pd/K in the HT-TCAP Coil (U)",

Snape, E., Lynch, F.E. (1980) Chemtech, Vol. 10, pp. 578.

Steimke, J.L., Fowley, M.D. (1999) "WSRC-TR-98-00431: Transient Heat Transfer in TCAP Coils (U)", Westinghouse Savannah River Company Technical Report, Unclassified and Released.

Suissa, E., Jacob, I., Hadari, Z. (1984) "Experimental Measurements and General Conclusions on the Effective Thermal Conductivity of Powdered Metal Hydrides", J. of Less Common Metals, Vol. 104, pp 27-295. 
Upadyhay, S.N., Agarwal, B.K.D., Singh, D.R. ( 1975) “'On the Low Reynolds Number Mass Transfer in Packed Beds," J. of Chemical Engineering, Japan., Vol. 8, pp. 413-415.

U.S. Department of Energy Office of Declassification (1999) "RDD-5: Drawing Back the Curtain on Secrecy - Restricted Data Declassification Decisions 1946 to Present, January 1, 1999", pg II-15, Item 20.

Wakao, N., Vortmeyer, D. (1971) "Pressure Dependency of Effective Thermal Conductivity of Packed Beds," Chemical Engineering Science, Vol. 26, pp. 17531765.

Whitaker, S. (1972) "Forced Convection Heat Transfer Correlation for Flow in Pipes, Past Flat Plates, Single Cylinders, Single Spheres and for Flow in Packed Beds and Tube Bundles," AIChE J., Vol. 18, pp. 361-371.

Yagi, S., Kunii, D. (1960) "Studies on Heat Transfer Near Wall in Packed Beds," AIChE Journal, Vol. 6, p. 97.

Yagi, S., Kunii, D. (1960) "Studies on Heat Transfer in Packed Beds," Int. Development in Heat Transfer, Part IV, p. 750.

Yovanovich, M.M. (1967) "Thermal Contact Resistance Across Elastically Deformed Spheres," J. of Spacecraft and Rockets, Vol. 4, pp. 119-122.

Zukauskas, A. (1972) "Heat Transfer from Tubes in Cross Flow," in J.P. Hartnett and T.F. Irvine, Jr. Eds., Advances in Heat Transfer, Vol, 8, Academic Press, New York. 